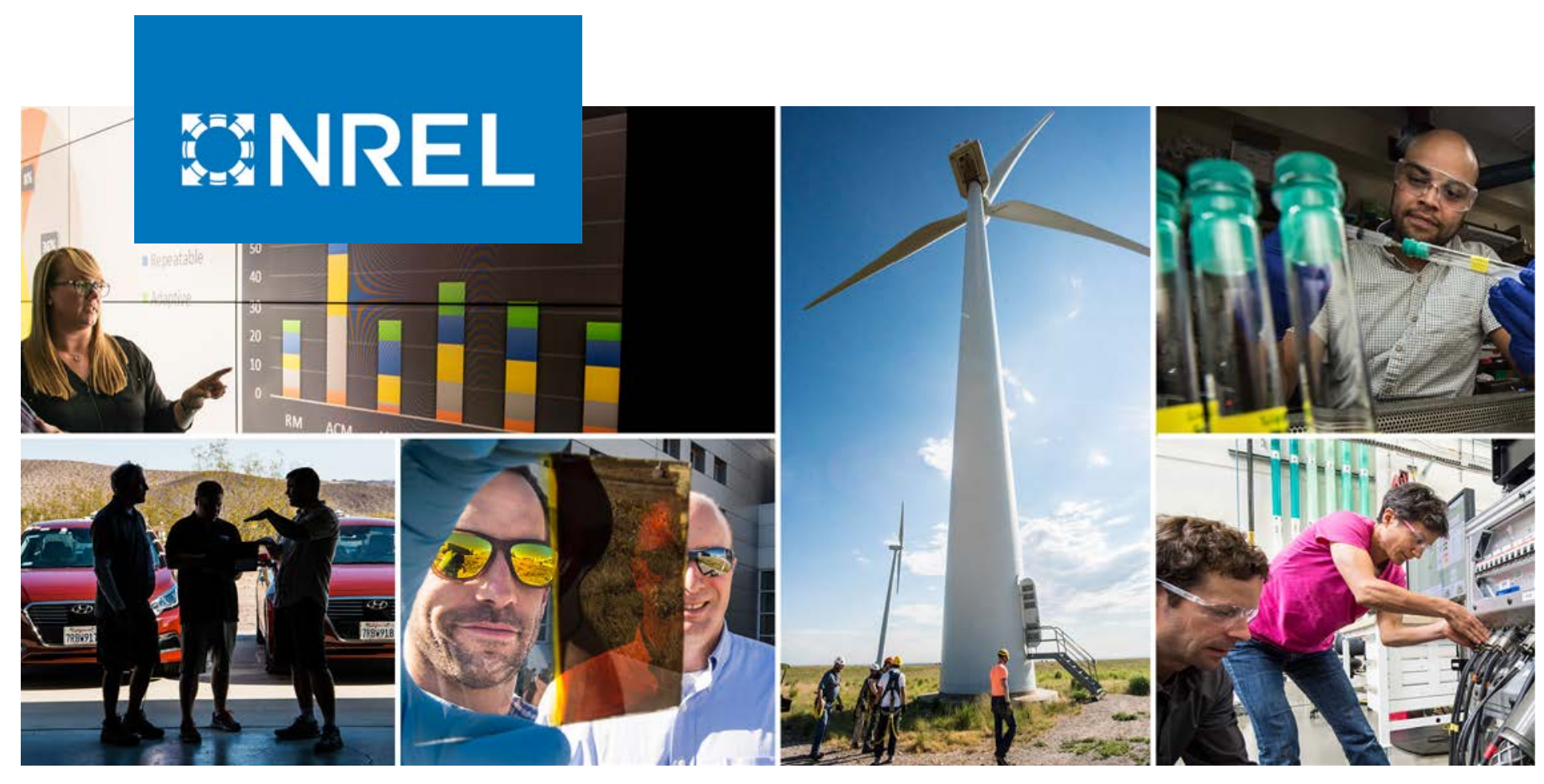

\title{
Cambium Documentation: Version 2021
}

Pieter Gagnon, Will Frazier, Wesley Cole, and Elaine Hale

National Renewable Energy Laboratory

NREL is a national laboratory of the U.S. Department of Energy

Office of Energy Efficiency \& Renewable Energy

Operated by the Alliance for Sustainable Energy, LLC

This report is available at no cost from the National Renewable Energy Laboratory (NREL) at www.nrel.gov/publications.

\section{Technical Report}

NREL/TP-6A40-81611

December 2021 


\section{GHREL}

\section{Cambium Documentation: Version 2021}

Pieter Gagnon, Will Frazier, Wesley Cole, and Elaine Hale

National Renewable Energy Laboratory

\section{Suggested Citation}

Gagnon, Pieter, Will Frazier, Wesley Cole, and Elaine Hale. 2021.

Cambium Documentation: Version 2021. Golden, CO: National Renewable Energy

Laboratory. NREL/TP-6A40-81611. https://www.nrel.gov/docs/fy22osti/81611.pdf

NREL is a national laboratory of the U.S. Department of Energy Office of Energy Efficiency \& Renewable Energy Operated by the Alliance for Sustainable Energy, LLC

This report is available at no cost from the National Renewable Energy Laboratory (NREL) at www.nrel.gov/publications.

Contract No. DE-AC36-08GO28308
Technical Report

NREL/TP-6A40-81611

December 2021

National Renewable Energy Laboratory 15013 Denver West Parkway Golden, CO 80401

303-275-3000 • www.nrel.gov 


\section{NOTICE}

This work was authored by the National Renewable Energy Laboratory, operated by Alliance for Sustainable Energy, LLC, for the U.S. Department of Energy (DOE) under Contract No. DE-AC36-08G028308. Funding provided by the U.S. Department of Energy Office of Energy Efficiency and Renewable Energy Strategic Programs Office. The views expressed herein do not necessarily represent the views of the DOE or the U.S. Government.

This report is available at no cost from the National Renewable Energy Laboratory (NREL) at www.nrel.gov/publications.

U.S. Department of Energy (DOE) reports produced after 1991 and a growing number of pre-1991 documents are available free via www.OSTI.gov.

Cover Photos by Dennis Schroeder: (clockwise, left to right) NREL 51934, NREL 45897, NREL 42160, NREL 45891, NREL 48097, NREL 46526.

NREL prints on paper that contains recycled content. 


\section{Acknowledgments}

This report was funded by the DOE Office of Energy Efficiency and Renewable Energy under contract number DE-AC36-08GO28308. Any errors or omissions are the sole responsibility of the authors. 


\section{List of Abbreviations and Acronyms}

$\begin{array}{ll}\text { AC } & \text { alternating current } \\ \text { BA } & \text { balancing area } \\ \text { CES } & \text { clean energy standard(s) } \\ \mathrm{CO}_{2} \text { e } & \text { carbon dioxide equivalent } \\ \text { CSP } & \text { concentrating solar power } \\ \text { DAC } & \text { direct air capture } \\ \text { GEA } & \text { generation and emissions assessment } \\ \text { IPCC } & \text { Intergovernmental Panel on Climate Change } \\ \text { LRMER } & \text { long-run marginal emission rate } \\ \text { NGCT } & \text { natural gas combustion turbine } \\ \text { NREL } & \text { National Renewable Energy Laboratory } \\ \text { PRM } & \text { planning reserve margin } \\ \text { PV } & \text { photovoltaics } \\ \text { RAZ } & \text { reliability assessment zone(s) } \\ \text { REC } & \text { renewable energy credit } \\ \text { RPS } & \text { renewable portfolio standard(s) } \\ \text { RTE } & \text { round-trip efficiency } \\ \text { SRMC } & \text { short-run marginal costs } \\ \text { SRMER } & \text { short-run marginal emission rate }\end{array}$




\section{Table of Contents}

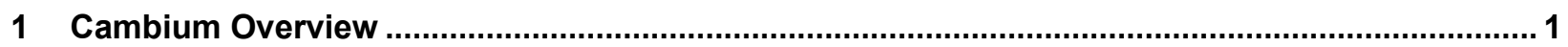

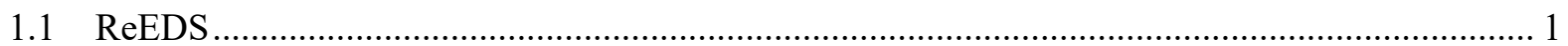

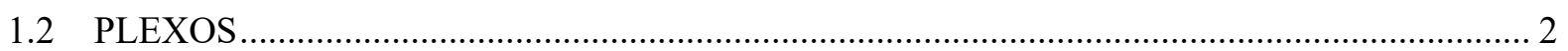

2 User Guidance, Caveats, and Limitations of Cambium Databases............................................ 4

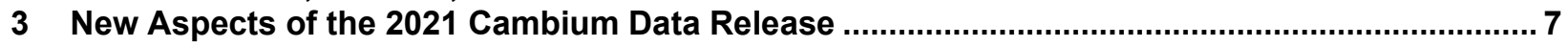

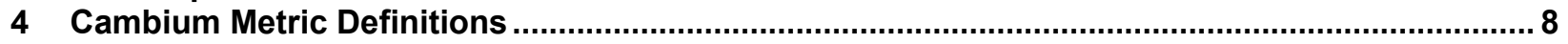

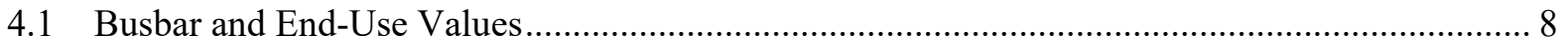

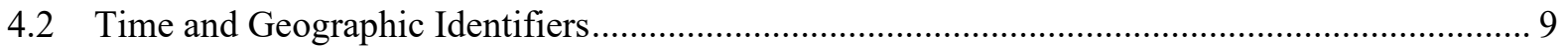

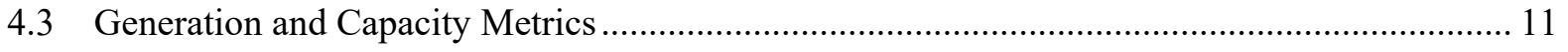

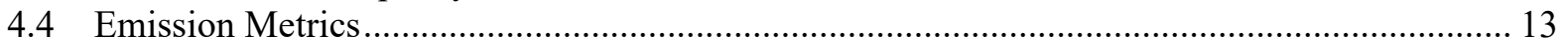

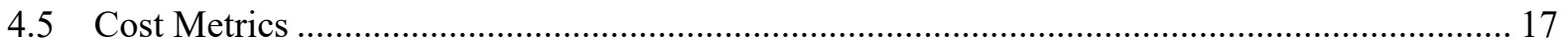

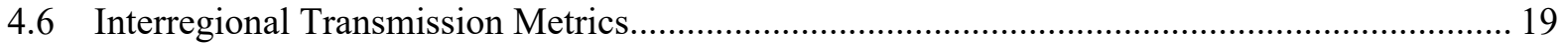

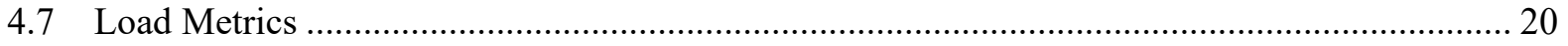

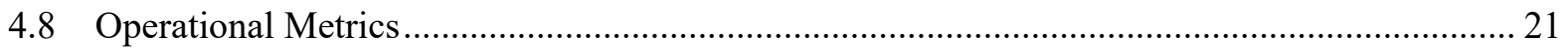

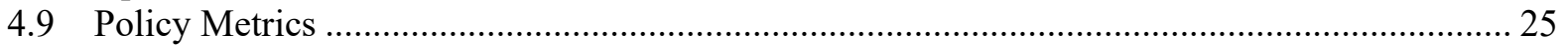

4.10 Short-run Marginal Generators and Marginal Energy Sources ............................................... 26

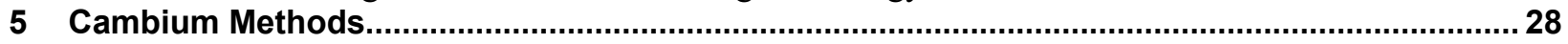

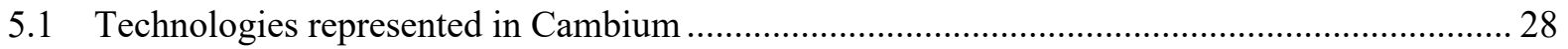

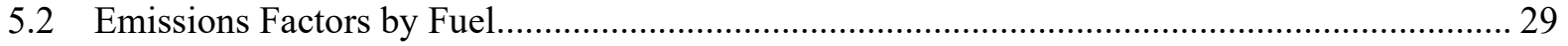

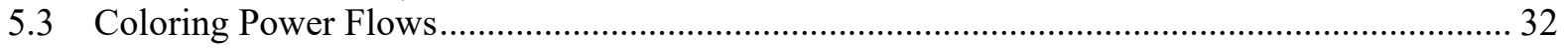

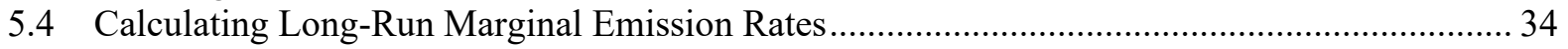

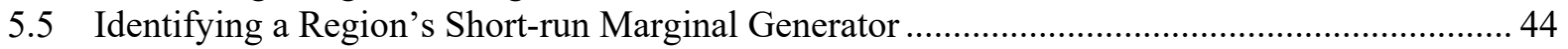

5.6 Identifying the Energy Source When an Energy-Constrained Generator is on the Short-run

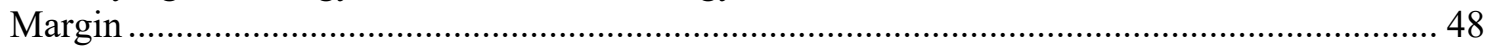

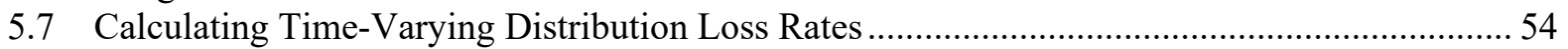

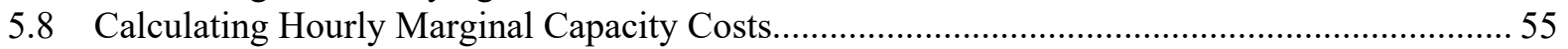

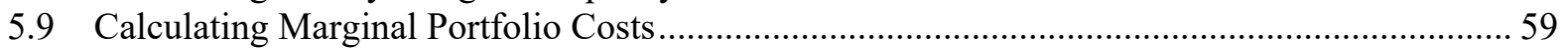

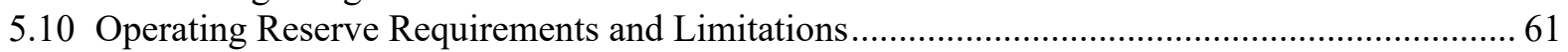

5.11 Creation of Generation and Emission Assessment (GEA) Regions ........................................... 63

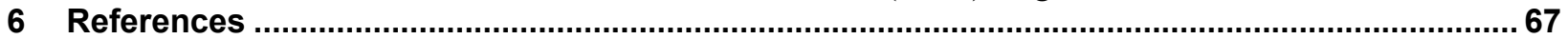




\section{List of Figures}

Figure 1. Balancing areas and reliability assessment zones used in Cambium, ReEDS, and PLEXOS

Figure 2: Cambium's Generation and Emission Assessment (GEA) Regions

Figure 3. Simple network for illustrating power flow coloring ....................................................... 32

Figure 4. Charge and discharge patterns of an electrical battery..................................................... 50

Figure 5. Example of an "opportunity window" for an electric battery ........................................... 51

Figure 6. Cambium's Generation and Emission Assessment (GEA) Regions (repeat of Figure 2)..... 65

\section{List of Tables}

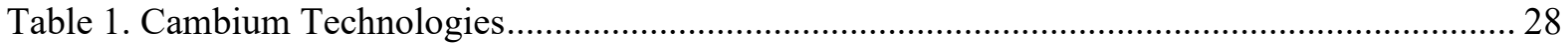

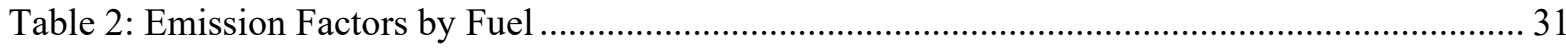

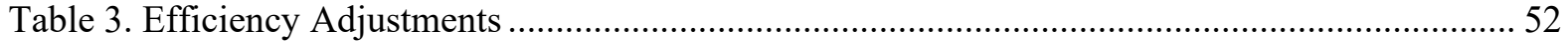

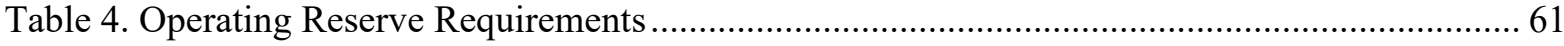

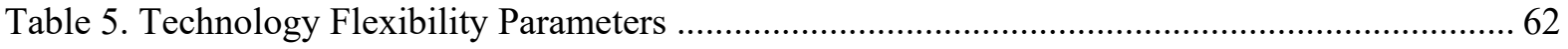

Table 6: Mapping between GEA regions and ReEDS balancing areas .............................................. 66 


\section{Cambium Overview}

Cambium is a tool that assembles structured data sets of simulated hourly emission, cost, and operational data for modeled futures of the U.S. electric sector with metrics designed to be useful for long-term decision-making. It was built to expand the metrics reported in the National Renewable Energy Laboratory's (NREL's) Standard Scenarios - an annually released set of projections of how the U.S. electric sector could evolve across a suite of different potential futures, looking forward through 2050 (Cole et al. 2021) Information about Cambium and related publications can be found at https://nrel.gov/analysis/cambium.html, and the Cambium data sets for the Standard Scenarios can be viewed and downloaded at https://cambium.nrel.gov/.

In this documentation, we define the metrics reported in Cambium databases (Section 4) and document the Cambium-specific methods for calculating those metrics (Section 5). As this document is intended to cover multiple Cambium data releases, we do not document specific scenarios here - for individual data releases, readers should look for an accompanying report that describes the assumptions and data that underlie that specific release. For Cambium databases that are built on NREL's Standard Scenarios, for example, reports describing the scenarios can be found on the Standard Scenarios web site (https://www.nrel.gov/analysis/standardscenarios.html).

Cambium draws primarily from the outputs of two models: ${ }^{1}$

- The Regional Energy Deployment System (ReEDS) model, which uses a least-cost framework to project structural changes in the U.S. electric sector under different possible futures (Ho et al. 2021).

- PLEXOS, which is a commercial production cost model that we use to simulate the hourly operation of the future electric systems projected by ReEDS (Energy Exemplar 2019).

Cambium transforms the outputs produced by these models into a structured data set that conveys future electric grid operations and value streams.

\subsection{ReEDS}

The first of two models that Cambium draws from is ReEDS (Ho et al. 2021). ${ }^{2}$ ReEDS is an NREL-developed, publicly available mathematical programming model of the electric power sector. Given a set of input assumptions such as fuel costs, technology costs, and policies, ReEDS models the evolution of generation and transmission assets, solving a linear program to make investment and operational decisions to minimize the overall cost of the electric system. The model has been used to explore how the evolution of the electric sector is impacted by a range of technology and policy scenarios.

\footnotetext{
${ }^{1}$ We briefly summarize ReEDS and PLEXOS in this section, and we refer readers to the literature cited in each of those sections for documentation of how each model functions.

${ }^{2}$ (Ho et al. 2021) documents the 2020 version of ReEDS. More information about ReEDS, including the most up-todate documentation, open-source access, and other publications can be found at https://www.nrel.gov/analysis/reeds/.
} 
The conterminous United States (i.e., the lower 48 states and the District of Columbia) is represented in ReEDS as 134 model balancing areas (BAs), which are connected by a representation of the transmission network. The network starts with existing transmission capacity and can be expanded as part of ReEDS' decision-space. Likewise, the model starts with representations of all existing generation capacity and announced future builds for each BA, and it can choose to build new capacity or retire old capacity to meet demand at the lowest cost. Historical patterns are used as a starting point for assumptions about end-use electricity demands, and assumptions about the evolution of that demand vary by scenario.

The linear program for balancing supply and demand within ReEDS includes a representative set of time-slices that are meant to capture seasonal and diurnal trends. A submodule, Augur, is used to calculate key parameters from hourly data, where the time-slice representation is too coarse. The ability of variable generators (e.g., wind and solar) and storage to contribute firm capacity, curtailment of variable generators, and the energy arbitrage value of storage generators are examples of parameters derived in Augur.

The linear program that forms the core of ReEDS makes investment and retirement decisions for bulk power system assets. For behind-the-meter solar photovoltaics (PV), the model imports projections from NREL's Distributed Generation Market Demand Model (dGen, [Sigrin et al. 2016]). ${ }^{3}$

\subsection{PLEXOS}

The ReEDS reduced-form dispatch, aided by Augur's parameterization, aims to capture enough operational detail for realistic bulk power system investment and retirement decisions, but it does not have the temporal resolution that is desired for Cambium databases. To obtain more-detailed simulations of the electric systems projected by ReEDS, NREL developed utilities to represent a ReEDS capacity expansion solution in the second of the two models that Cambium draws from: PLEXOS (Energy Exemplar 2019). ${ }^{4}$

PLEXOS is a commercial production cost model that can simulate least-cost hourly dispatch of a set of generators with a network of nodes and transmission lines. It incorporates representations of unit-commitment decisions, detailed operating constraints (e.g., maximum ramp rates and minimum generation levels), and operating reserves; and it can be run with nested receding horizon planning periods (e.g., day-ahead and real-time) to simulate realistic electric system operations. $^{5}$

For representing a ReEDS solution as a PLEXOS model, the spatial resolution from ReEDS is retained: the 134 BAs in ReEDS are represented as transmission nodes in PLEXOS, and the connections between them are modeled using the line capacities and loss rates in the ReEDS

\footnotetext{
${ }^{3}$ (Sigrin et al. 2016) is the most recent documentation of the dGen model. More information about dGen, such as the most up-to-date documentation, open-source access, and other publications can be found at https://www.nrel.gov/analysis/dgen.

${ }^{4}$ The ability to represent a ReEDS-modeled solution in PLEXOS has also been used to study ReEDS-built systems for other NREL analyses (Frew et al. 2019; Cole et al. 2020; Cole et al. 2019).

${ }^{5}$ Separately from ReEDS, PLEXOS has been used extensively by NREL for analyses of the electric sector, such as the Western Wind and Solar Integration Study (Lew et al. 2013) and the Eastern Renewable Grid Integration Study (Bloom et al. 2016).
} 
aggregated transmission representation. Generation capacity at each node is, however, converted from aggregate ReEDS capacity to individual generators using a characteristic unit size for each technology. For consistency, ReEDS cost and performance parameters are used when possible and reasonable, but values derived from previous NREL studies (e.g., Lew et al. [2013]) are used when parameters are unavailable from ReEDS or are available but unreasonable because of structural differences between the models.

Once the ReEDS solution is converted to a PLEXOS database, the hourly dispatch of the grid can be simulated for a full year. For Cambium databases, we run PLEXOS as a mixed integer program, with day-ahead unit commitment and dispatch (without any real-time adjustments for subhourly dispatch or forecast error). For each modeled year, generators have constant heat rates and maximum generator output. Generator short-run marginal costs (SRMC) are generally constant across the year, except for natural gas powered generators, whose SRMC changes with monthly variations in natural gas prices. Supply and demand are balanced at the busbar level, and distribution losses are captured in data pre- and post-processing, as described in Section 5.7. Inter-BA transmission is represented as pipe flow with constant loss rates, with no intra-BA transmission losses. Generator outages are represented by de-rating installed capacity to an effective capacity based on annual average outage rates that vary by technology. Three operating reserves are represented - regulation, flexibility, and spinning reserves - as detailed in Section 5.10 .

We draw from these simulated results - from both ReEDS and PLEXOS - to calculate the metrics reported within Cambium databases, with varying degrees of post-processing, as described in the remainder of this document. 


\section{User Guidance, Caveats, and Limitations of Cambium Databases}

When projecting the expansion and operation of the U.S. electric system in coming decades, it is necessary to make various simplifications. Here, we list some important limitations and caveats that result from these simplifications:

- The Metrics in Cambium Databases Have Not Been Validated for Every Possible Application: The models used by Cambium are necessarily simplifications of reality. The metrics produced by those models, therefore, deviate from reality to some degree. Given the breadth of possible uses, it is not feasible to validate and summarize each metric's accuracy for every conceivable application. We encourage users to critically evaluate the suitability of Cambium metrics for new analyses by reviewing existing literature and comparing Cambium data against empirical data where possible.

- Cambium's Metrics are Derived from System-Wide, Cost-Minimizing Optimization Models: The models that Cambium draws from take system-wide, cost-minimizing perspectives that do not necessarily reflect the decision-making of individual actors, whose actions may not align with system-wide cost-minimization because of differing incentives or information deficits.

- The Spatial and Temporal Resolution of the Underlying Models is Coarse: Though the models that Cambium draws from have high spatial and temporal resolution for models of their scope, they do require simplifications and aggregations along those dimensions. ${ }^{6}$ Perhaps most critically, the United States is represented as 134 "copperplate" balancing areas (BA). This lack of transmission losses and constraints within BAs tends to produce lower marginal costs than what is observed in practice.

- Cambium Reports Marginal Costs, Which Can Differ from Market Prices:

Cambium databases contain estimates of various marginal costs (i.e., how much the costs of building and operating the power sector increases with an increase in demand). Importantly, market prices in practice can deviate from marginal costs due to market design, contract structures, cost recovery for non-variable costs, and bidding strategies. We strongly encourage users to read the descriptions of each marginal cost metric reported in Cambium (Section 4.5) for an understanding of the limitations of each metric.

- Cambium's Marginal Costs are Not Estimates of Retail Rates: The marginal costs in Cambium should not be directly used as estimates of retail electricity prices because (1) retail rates typically include cost recovery for administrative, distribution infrastructure, and other expenses that are not represented in Cambium databases and (2) retail rates are often set through a ratemaking process that, while sometimes reflecting temporal patterns in the marginal costs of electricity, are generally not priced directly at marginal costs but rather seek to balance cost-recovery, equity, and cost-causation.

- The Full Range of Uncertainty is Not Captured: The models that Cambium draws from compute deterministic least-cost solutions for a particular set of assumptions - each

\footnotetext{
${ }^{6}$ See (Cole et al. 2017) for a multi-model analysis that, in part, explores the impact of spatial and temporal resolution in long-term planning models.
} 
scenario, therefore, does not fully reflect the uncertainties in the underlying assumptions and data. Cambium, through the Standard Scenarios, tries to address this by providing a suite of possible futures, although the full range of possible outcomes can never be fully captured; for example, no scenario includes a severe economic depression as one of many possible futures that are not modeled.

- Cambium is Not Designed to Assess Grid Reliability or Resource Adequacy: Although the models that Cambium draws from can recognize dropped load when insufficient capacity is available to meet demand, these runs should not be considered as assessing grid reliability or resource adequacy, because, among other reasons, (1) only a specific set of conditions (weather, load, and renewable resource quality) is simulated, (2) important temperature effects on generator efficiencies and transmission losses are not represented, (3) transmission line outages are not represented, and (4) intra-BA transmission line constraints are not captured.

- ReEDS' Capacity Expansion Decisions Have Limited Foresight: Except when it runs with intertemporal optimization, ReEDS has limited long-term foresight and therefore model decision-making in a particular modeled year does not account for anticipated changes to markets or policies in future years. For example, when running without intertemporal optimization, ReEDS would not anticipate or react to the upcoming expiration of an incentive program. Unless otherwise specified, scenarios in Cambium databases are not run with intertemporal optimization.

- PLEXOS' Production Cost Modeling Does Not Have Forecast Error: Although PLEXOS is capable of representing load and variable generator forecast error, we do not deploy this feature in the runs that Cambium draws from.

- Cambium Databases Do Not Contain Elasticity Data: There are no estimates of the elasticity of the metrics reported in Cambium databases (i.e., how much a metric's value would change if load or generation changed). Though many metrics may change little across a wide range of intervention sizes, some metrics may be highly elastic, particularly at certain points in time. Hours with a marginal energy cost of zero, for example, could become nonzero with small increases in demand. In general, the larger an intervention being analyzed, the more likely it is that the Cambium values are not accurate for that specific intervention.

- Flexible Loads are Not Currently Represented in Cambium: Although the models that Cambium draws from have the ability to represent flexible load, this capability is not currently used for Cambium. Grid-responsive buildings and intelligent charging of electrical vehicles are two of many potential examples of electric loads that may play a meaningful role in operation of the grid in the future-for example, by absorbing otherwise-curtailed energy or shifting load away from high-demand periods.

- The Project Pipeline and Retirements Data is Likely Incomplete: Although ReEDS incorporates data of planned or under-construction projects, these data are unlikely to include all projects in progress, and it is possible that some planned projects included in ReEDS will not be finished. Similarly, scheduled near-term retirements are represented, but may be incomplete or reversed. 
- Only the U.S. Electric Sector is Represented in Cambium: The models that Cambium draws from only represent the electric sector of the coterminous United States, not adjacent sectors nor the global energy economy. For example, competing uses of natural gas or financial capital across sectors and countries are not dynamically represented.

- A Single Year of Weather Data is Used for Most Cambium Metrics: The PLEXOS runs that Cambium draws from use weather data from a single year, 2012. Therefore, most metrics in Cambium databases (e.g., the marginal cost and variable generator patterns) are not "expected values," although they do capture realistic weather-induced hourly variations.

To help users better understand some of these limitations, we have provided modeled data for 2018 in the Mid-case of the 2020 Standard Scenarios data release so that users can compare observed historical market and operational data with the data provided in Cambium databases.

We also point interested users to a review of Cambium's 2020 marginal cost patterns performed by Lawrence Berkley National Laboratory (Seel and Mills 2021). The report describes the 2020 Cambium data release, and there were various incremental improvements made to the 2021 Cambium data release, but the general findings and recommendations of the LBNL report still hold. 


\section{New Aspects of the 2021 Cambium Data Release}

This section highlights the major differences between the 2020 and 2021 Cambium data releases:

- Other greenhouse gas emissions added: The 2020 release only had carbon dioxide emissions from direct combustion. Methane and nitrous oxide emissions have been added in the 2021 release.

- Precombustion emissions added: The 2020 release only had emissions from direct combustion. In the 2021 release emissions from precombustion processes (fuel extraction, processing, and transportation, including fugitive emissions) have been added.

- Decarbonization scenarios added: The 2021 Cambium release includes two new scenarios that see $95 \%$ decarbonization nation-wide by 2035 and 2050 respectively.

- New technologies added: Bioenergy with carbon capture and storage, direct air capture, small modular reactors for nuclear, hybrid PV and battery generators, and renewable combustion turbines were all added to the models in the Cambium workflow.

- Improvements to the long-run marginal emission rate methodology: Various incremental improvements were made to the methodology used to derive the long-run marginal emission rates, such as incorporating accounting transfers for state policies and performing a second set of runs designed to decrease noise.

- New geographic aggregation: A new type of region, the Generation and Emission Assessment (GEA) region, has been added to the database. GEA regions are based off of the US EPA's eGRID regions, although they are not identical due to the structure of the models in the Cambium workflow.

- New temporal aggregations: In addition to the hourly and annual data previously available for download, the 2021 data release also contains month-hour and time-of-day (i.e., a 24-hour vector) aggregations of the data. 


\section{Cambium Metric Definitions}

In this section, we briefly define all the metrics in Cambium databases. The outputs from ReEDS and PLEXOS are the starting point for Cambium's processing; some of the metrics are direct reports from those models, but others involve extensive post-processing. We describe the Cambium-specific post-processing methods in Section 5.

\subsection{Busbar and End-Use Values}

Metrics in Cambium databases are reported at either the busbar or end-use level, depending on their most common usage (and indicated in the "Units" header information throughout this section, for each family of metrics). Busbar refers to the point where bulk generating stations connect to the grid, whereas end use refers to the point of consumption. Analyses of bulk generators would typically use busbar values, whereas analyses of electricity consumers would typically use end-use values. In Cambium databases, busbar and end-use values differ by the distribution loss rates between the two points.

An analyst may wish to transform a Cambium busbar metric into its end-use value, or vice versa, using the following equations. For example, marginal emission rates are given in end-use terms as they are most commonly used to assess the change in emissions associated with a change in end-use electric demand. However, if an analyst wishes to use a marginal emission rate to estimate the change in emissions from a change in load or generation at the busbar level, they could apply the following equation to change the marginal emission rate into its busbar equivalent value).

For a generic "average" metric $X$ (e.g., the average $\mathrm{CO}_{2}$ rate of in-region generation), the two values are related by the average distribution loss rate $\alpha$. For a generic "marginal" metric $Y$ (e.g., the marginal energy cost), the two values are related by the marginal distribution loss rate $\mu$.

$$
\begin{aligned}
& \text { Averages: } X_{\text {end-use }}=\frac{X_{\text {busbar }}}{(1-\alpha)} \\
& \text { Marginals: } Y_{\text {end-use }}=\frac{Y_{\text {busbar }}}{(1-\mu)}
\end{aligned}
$$

Hourly $\alpha$ and $\mu$ values are given in Cambium databases as distloss_rate_avg and distloss_rate_marg respectively. See Section 5.7 for our approach and assumptions for calculating these metrics. 


\subsection{Time and Geographic Identifiers}

Metric Family: timestamp

Metric Names: timestamp and timestamp_local

The timestamp metric is the time in Eastern Standard Time. The timestamp_local variable is the time in the local Standard Time. If no timestamp_local variable is in a file, the data are in Eastern Standard Time (and therefore indicated with the timestamp variable).

Both timestamp variables are hour-beginning, meaning a 1:00 timestamp indicates data for 1:002:00. Neither timestamp variable includes the effects of Daylight Savings Time. Every year in a Cambium data set has 8,760 hours; leap days are omitted in the timestamps during leap years, although the 7-day weekday/weekend pattern is preserved. ${ }^{7}$

Every time series - and the underlying data - in a Cambium data set starts on a Sunday, regardless of the actual day of the week for January 1 of that year. ${ }^{8}$ This keeps the weekend/weekday patterns and hour positions consistent between years in the data, which facilitates analysis that spans across multiple years.

Metric Family: time zone Metric Name: $t z$

The $t z$ variable in the metadata indicates the time zone used for the timestamp_local variable. For regions that contain multiple time zones, the data are reported using the time zone where the majority of the load is located.

Metric Family: ReEDS model balancing area (BA) Metric Names: $r$

The balancing area $(r)$ is the finest geographic unit for which Cambium data are reported (Figure 1). There are $134 \mathrm{BAs}$, which are used as the nodes for balancing supply and demand in both the ReEDS and PLEXOS models that Cambium draws from.

\footnotetext{
${ }^{7}$ If users wish to represent the additional 24 hours in leap years, we recommend they copy the data from the third day from each year (a Tuesday in Cambium) and add it to the end of the year's time series and then rename the datetimes to incorporate February 29. If, instead, 24 hours of data are added between February 28 and March 1, the weekday/weekend pattern of the time series would be disrupted.

${ }^{8}$ Cambium data starts on a Sunday because the underlying weather and load data are from 2012, which also start on a Sunday.
} 


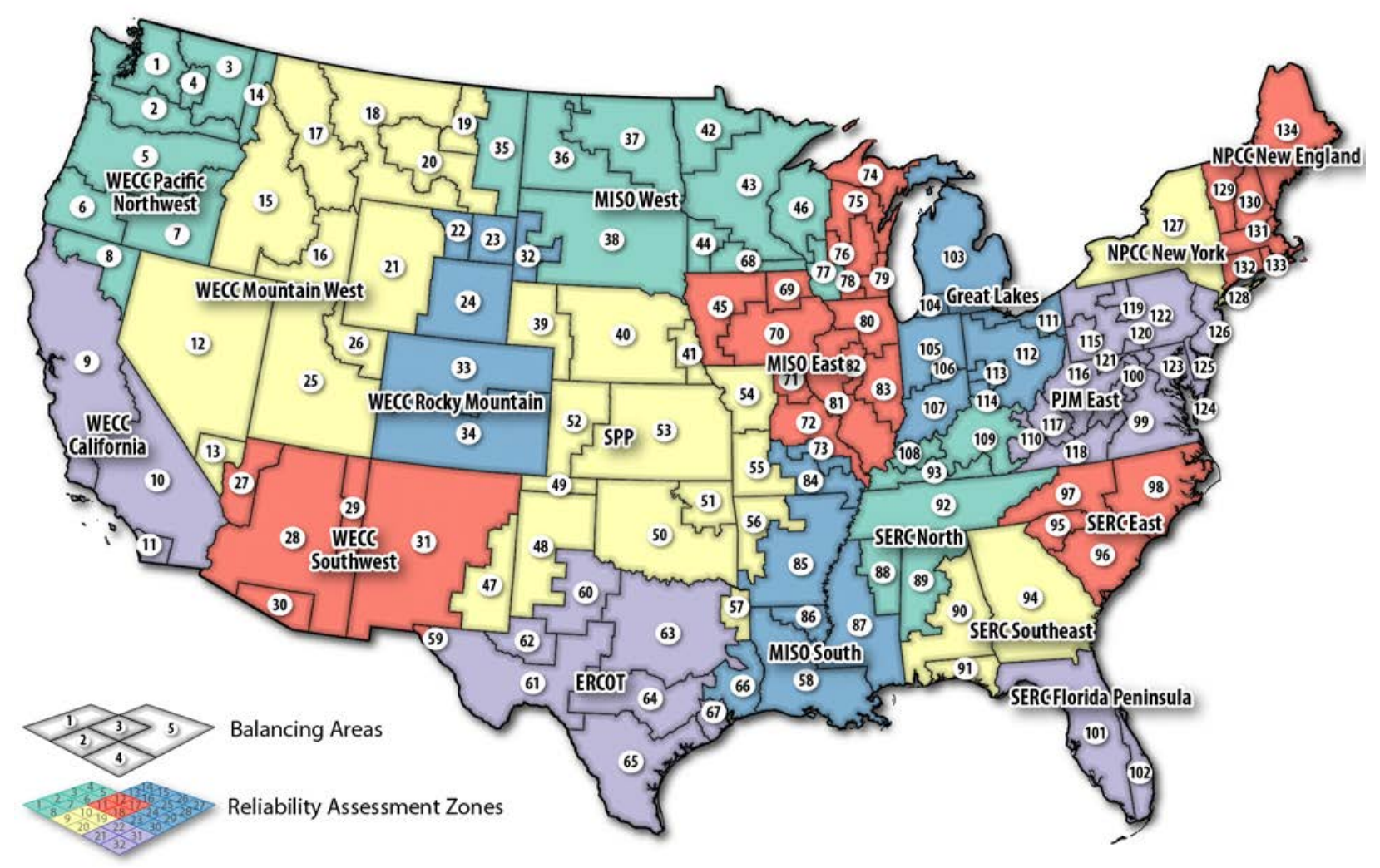

Figure 1. Balancing areas and reliability assessment zones used in Cambium, ReEDS, and PLEXOS

MISO: Midcontinent Independent System Operator; NPCC: Northeast Power Coordinating Council; SERC: SERC Reliability Corporation; SPP: Southwest Power Pool; WECC: Western Electricity Coordinating Council

Metric Family: reliability assessment zone Metric Name: $r a z$

The reliability assessment zones (RAZ) are 18 regions that ReEDS uses for various calculations, such as determining the capacity credit of variable generators. They are also used for enforcing operating reserve requirements in PLEXOS. They are shown in Figure 1.

Metric Family: Cambium Generation and Emission Assessment region (GEA) Metric Names: gea

Cambium's GEA regions are 20 regions covering the contiguous United States. They are based off of the US EPA's eGRID regions (https://www.epa.gov/egrid), but are not identical to them due to the geographic structure of the models in the Cambium workflow. The GEA regions are shown in Figure 2, a table giving their mapping to ReEDS regions is given in Table 6, and their derivation is discussed in Section 5.11. 


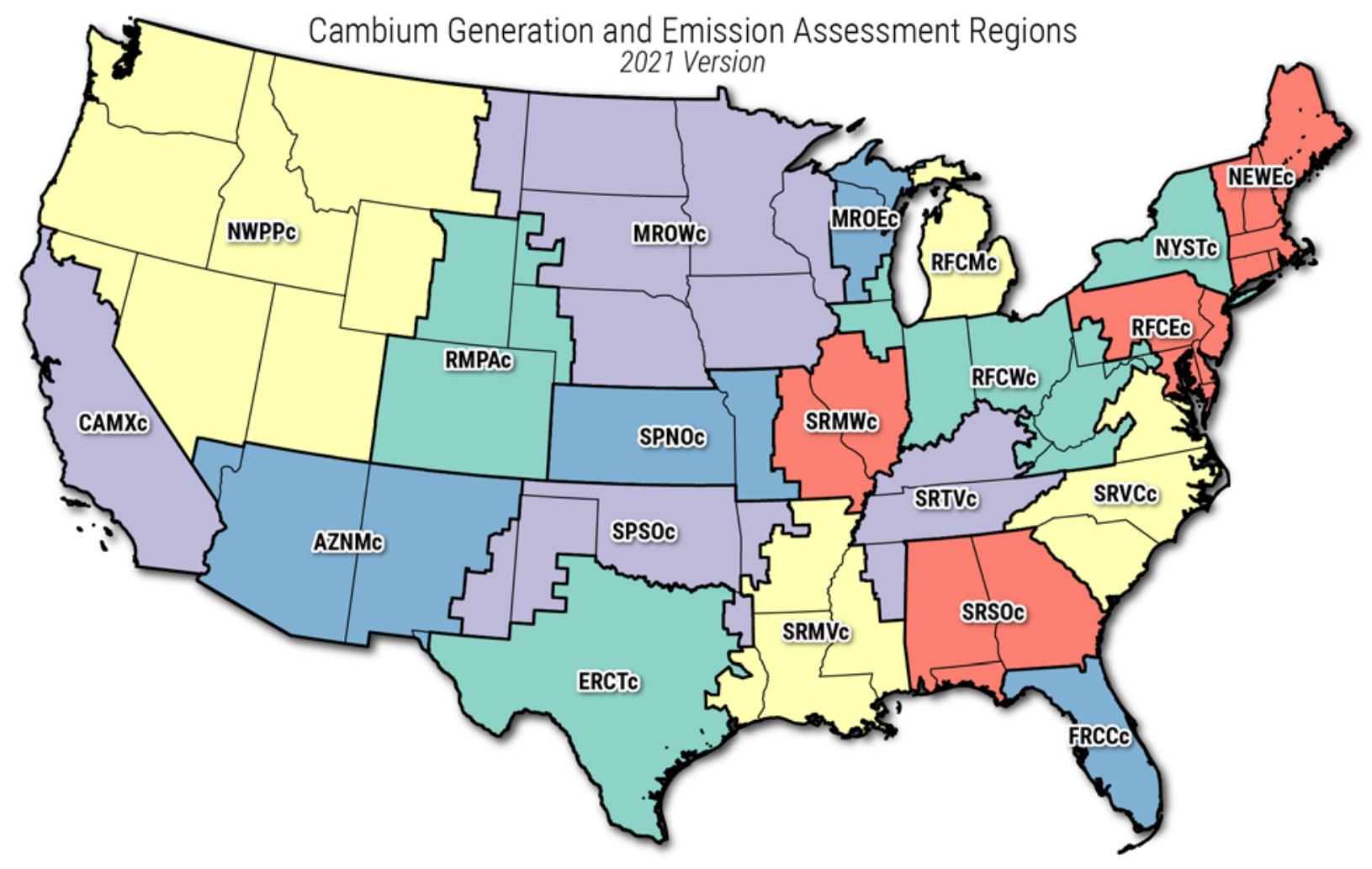

Figure 2: Cambium's Generation and Emission Assessment (GEA) Regions

\subsection{Generation and Capacity Metrics}

Metric Family: total generation

Metric name: generation

Units: MWhbusbar

The generation metric reports the total generation from all generators within a region. It includes generation from storage (e.g., batteries or pumped hydro storage). It does not include curtailed energy. If there are net imports or exports from a region, generation will not match load.

Behind-the-meter PV generation is included in the generation metric and is reported as the equivalent amount of busbar generation (i.e., it is increased to reflect the assumption that it does not incur distribution losses).

Metric Family: variable generation

Metric Name: variable_generation

Units: MWhbusbar

The variable generation metric reports the total generation from all variable generators within a region, which includes PV, concentrating solar power (CSP) without storage, and wind. It does 
not include curtailed energy. Behind-the-meter PV generation is included, and as with generation, is reported as the equivalent amount of busbar generation.

Metric Family: generation by technology

Metric Name: technology_MWh

Units: MWhbusbar

These metrics report the total generation within a region from each of the 19 technologies listed in Table 1 (page 28). These generation values do not include curtailed energy. Generation from behind-the-meter PV, which is assumed to occur at the point of end use, is reported as an equivalent amount of busbar generation. The McIntosh compressed air energy storage plant in McIntosh, Alabama, has its generation reported as one-third natural-gas combined cycle generation, and two-thirds battery generation.

These generation metrics should not be confused with the battery_energy_cap_MWh, phs_energy_cap_MWh, and csp_energy_cap_MWh, which report energy storage capacity, not generation.

Metric Family: nameplate capacity by technology

Metric Name: technology_MW Units: MW

These metrics report the total nameplate capacity within a region from each of the technologies listed in Table 1 (page 28) (except for Canadian imports). Behind-the-meter PV is reported as the AC inverter capacity - it is not adjusted to a busbar equivalent capacity, unlike generation from the same technology. The capacities of wind and solar generation are reported at their original nameplate capacities when they were installed (i.e., their reported capacity is not reduced over time by degradation). Outages are represented by derating the installed capacity to an effective capacity - these technology_MWh metrics report the original installed capacities, not the derated capacities. The McIntosh compressed air energy storage plant in McIntosh, Alabama, has its capacity reported as one-third natural-gas combined cycle capacity and two-thirds battery capacity.

The nameplate capacity of Direct Air Capture (DAC) devices are reported as dac_MW. It should be noted that DAC consumes electricity, it does not generate it.

Metric Family: nameplate energy storage capacity by technology

Metric Name: technology_energy_cap_MWh

Units: MWh

These metrics report the total nameplate energy storage capacity within a region for batteries, pumped hydro storage, and concentrating solar power. 


\subsection{Emission Metrics}

Emissions are reported for three gasses: carbon dioxide $\left(\mathrm{CO}_{2}\right)$, methane $\left(\mathrm{CH}_{4}\right)$, and nitrous oxides $\left(\mathrm{N}_{2} \mathrm{O}\right)$. $\mathrm{CO}_{2}$ equivalent $\left(\mathrm{CO}_{2} \mathrm{e}\right)$ values are also given that combine the three emissions using 100-year global warming potential (GWP) values from the IPCC fifth assessment report. $\mathrm{CH}_{4}$ and $\mathrm{N}_{2} \mathrm{O}$ rate metrics are reported in $\mathrm{g} / \mathrm{MWh}$, whereas $\mathrm{CO}_{2}$ and $\mathrm{CO}_{2} \mathrm{e}$ rate metrics are reported in $\mathrm{kg} / \mathrm{MWh}$.

Additionally, emissions are reported for direct combustion (indicated with “_c" in the metric name) and precombustion processes (indicated with " $p$ " in the metric name). Precombustion processes include fuel extraction, processing, and transport (including fugitive emissions).

Emission metrics with "_co2e" and no "_c" or " $p$ " report the combined $\mathrm{CO}_{2} \mathrm{e}$ value from both combustion and precombustion.

For the fuel-specific emissions factors used in all emissions calculations, see section 5.2.

Metric Family: average emission rates of in-region generation

Metric Name: aer_gen_co2_c, aer_gen_ch4_c,aer_gen_n2o_c,aer_gen_co2_p, aer_gen_ch4_p,aer_gen_n2o_p,aer_gen_co2e_c,aer_gen_co2e_p,aer_gen_co2e

Units: $\mathrm{kg} / \mathrm{MWh}$ generation for $\mathrm{CO}_{2}$ and $\mathrm{CO}_{2} \mathrm{e}, \mathrm{g} / \mathrm{MWh}$ generation for $\mathrm{CH}_{4}$ and $\mathrm{N}_{2} \mathrm{O}$

The aer_gen family of metrics is the average emission rate of all generation within a region for the specified duration of time, in either kilograms $(\mathrm{kg})$ or grams $(\mathrm{g})$ of emissions per megawatt-hour (MWh) of busbar generation. No adjustment is made for imported or exported electricity. Start-up and shut-down emissions are not included.

The $\mathrm{CH}_{4}$ and $\mathrm{N}_{2} \mathrm{O}$ metrics are reported in $\mathrm{g} / \mathrm{MWh}$, whereas $\mathrm{CO}_{2}$ and $\mathrm{CO}_{2}$ rate metrics are reported in $\mathrm{kg} / \mathrm{MWh}$. " $c$ " indicates emissions from direct combustion, whereas " $p$ " indicates emissions from precombustion processes. aer_gen_co2e reports combined combustion and precombustion rates.

Metric Family: average emission rates of generation induced by a region's load Metric Name: aer_load_co2_c,aer_load_ch4_c, aer_load_n2o_c, aer_load_co2_p, aer_load_ch4_p,aer_load_n2o_p,aer_load_co2e_c, aer_load_co2e_p, aer_load_co2e

Units: $\mathrm{kg} / \mathrm{MWh}$ nduse for $\mathrm{CO}_{2}$ and $\mathrm{CO}_{2} \mathrm{e}, \mathrm{g} / \mathrm{MWh}$ enduse for $\mathrm{CH}_{4}$ and $\mathrm{N}_{2} \mathrm{O}$

The aer_load family of metrics is the average emission rate of the generation that is allocated to a region's end-use load, in either kilograms or grams of emissions per megawatt-hour of end-use load. Unlike the average emission rate of in-region generation, this metric includes the effects of imported and exported power. For example, if the power for a region's load is being supplied in equal parts from in-region generation with a $\mathrm{CO}_{2}$ emission rate of $400 \mathrm{~kg} / \mathrm{MWh}$ and out-ofregion generation with a $\mathrm{CO}_{2}$ emission rate of $1,000 \mathrm{~kg} / \mathrm{MWh}$, the average $\mathrm{CO}_{2}$ rate for generation supplying the power for that load would be $700 \mathrm{~kg} / \mathrm{MWh}$. If distribution losses were $5 \%$, this metric would report the average $\mathrm{CO}_{2}$ rate as $737 \mathrm{~kg} / \mathrm{MWh}$ of end-use load. 
Cambium allocates generation, and therefore the emissions from generation, by assuming perfect mixing through nodes. For a description of the method employed in Cambium for power flow accounting, and its limitations, see Section 5.3.

The PLEXOS runs that Cambium draws from do not restrict which generators can provide power to which locations. In practice, some states have restrictions on the types of out-of-state power that can be imported, such as California's limits on long-term contracts for out-of-state coal power. Additionally, utilities often contract with specific suppliers that may justify them claiming power mixtures that are different from the estimates produced by the perfect-mixing approach implemented in Cambium. Cambium does not currently capture these state or utility accounting effects; it just assumes perfect mixing through all nodes. This assumption, and therefore this metric, may not be appropriate for some analyses.

Similarly, this metric does not include the effects of any type of energy attribute accounting, such as unbundled renewable energy credit (REC) purchases. End users could claim that the emission rate induced by their load is different from this metric if they retired RECs to cover some or all of their demand.

The $\mathrm{CH}_{4}$ and $\mathrm{N}_{2} \mathrm{O}$ metrics are reported in $\mathrm{g} / \mathrm{MWh}$, whereas $\mathrm{CO}_{2}$ and $\mathrm{CO}_{2} \mathrm{e}$ rate metrics are reported in $\mathrm{kg} / \mathrm{MWh}$. " $c$ " indicates emissions from direct combustion, whereas " $p$ " indicates emissions from precombustion processes. aer_load_co2e reports combined combustion and precombustion rates.

Metric Family: short-run marginal emission rates for a region's load Metric Name: srmer_co2_c, srmer_ch4_c, srmer_n2o_c, srmer_co2_p, srmer_ch4_p, srmer_n2o_p, srmer_co2e_c, srmer_co2e_p, srmer_co2e

Units: $\mathrm{kg} / \overline{\mathrm{MWh}}_{\text {enduse }}$ for $\overline{\mathrm{CO}}_{2}$ and $\mathrm{CO}_{2} \mathrm{e}, \mathrm{g} / \mathrm{MWh}_{\text {enduse }}$ for $\mathrm{CH}_{4}$ and $\mathrm{N}_{2} \mathrm{O}$

These metrics are the short-run marginal emission rates (SRMER) for end-use load, which is the rate of emissions that would be induced by a marginal increase in a region's load at a specific point in time. The value is the emission rate of whichever generator would have served the marginal increase in load, modified by any relevant transmission, distribution, and efficiency losses. ${ }^{9}$ For an overview of the method that Cambium uses to interpret PLEXOS results and estimate which generator was on the margin at every point in time, see Section 5.5.

These metrics are reported as rates per MWh of end-use load. If a user wishes to obtain the SRMER at the busbar level (if they are estimating the emissions avoided by an alternative generation source injected at the busbar level, for example), they should adjust by the marginal distribution loss rate, as described in Section 4.1.

SRMER does not capture the structural changes to the electric sector that may be induced by increased demand, and it is therefore typically unsuitable for assessing the emissions impact of

\footnotetext{
${ }^{9}$ If the marginal generator is not the initial source of energy (e.g., when the marginal generator is a battery), the marginal emission rate is derived from the emission rate of the actual marginal source of energy and is further modified by the efficiency of the energy-storing generator. For a discussion of how Cambium determines what the marginal energy source is in these circumstances, see Section 5.5.
} 
a change in demand that is expected to persist for several years or longer. Instead, the long-run marginal emission rate (LRMER) is a more suitable metric for persistent changes in demand.

For every balancing area and every hour, the Cambium method identifies a single marginal generator, although multiple regions can have the same marginal generator if they are connected by a partially utilized transmission line. In practice, which generator is on the margin can (and typically does) switch much more frequently than the 1-hour resolution of the Cambium data sets.

SRMER depends on proper identification of the marginal generator (and energy source). As we discuss in Section 5.5, identification of marginal generators and energy sources is an ongoing area of research. We encourage any researcher working with this metric to approach it with a critical eye.

Cambium's modeled SRMER values are not appropriate for real-time operational decisionmaking. The primary intended use of this metric is to inform research questions that depend on anticipating the patterns of SRMER in potential futures (e.g., what the patterns of SRMER might look like in a future with high variable generator deployment).

The $\mathrm{CH}_{4}$ and $\mathrm{N}_{2} \mathrm{O}$ metrics are reported in $\mathrm{g} / \mathrm{MWh}$, whereas $\mathrm{CO}_{2}$ and $\mathrm{CO}_{2} \mathrm{e}$ rate metrics are reported in $\mathrm{kg} / \mathrm{MWh}$. " $c$ " indicates emissions from direct combustion, whereas " $p$ " indicates emissions from precombustion processes. srmer_co2e reports combined combustion and precombustion rates.

Metric Family: long-run marginal emission rates for a region's load Metric Name: lrmer_co2_c, lrmer_ch4_c,lrmer_n2o_c, lrmer_co2 $p$, lrmer_ch4_p, lrmer_n2o_p, lrmer_co2e_c,lrmer_co2e_p,lrmer_co2e

Units: $\mathrm{kg} / \mathrm{MWh}$ enduse for $\mathrm{CO}_{2}$ and $\overline{\mathrm{CO}}_{2} \mathrm{e}, \mathrm{g} / \mathrm{MWh}$ enduse for $\mathrm{CH}_{4}$ and $\mathrm{N}_{2} \mathrm{O}$

The long-run marginal emission rate (LRMER) is the emission rate of the mixture of generation that would be either induced or avoided by a long-term (i.e., more than several years) change in end-use demand. It incorporates both the operational and structural (i.e., the building and retiring of capital assets, such as generators and transmission lines) consequences of the change in demand. Is it therefore distinct from the short-run marginal emission rate, which treats the grid assets as fixed. The units are kilograms or grams of emission per megawatt-hour of end-use load. For a description of the methodology used to calculate LRMER, see Section 5.4.

LRMER is designed to inform decisions that would result in a persistent change in load. The "long-run" in LRMER does not refer to a specific length of time, but instead refers to the equilibrium least-cost solution when the option for structural changes to the grid are taken into account. Therefore, we recommend LRMER be used for analyzing changes in load that are expected to persist for several years or more, although the actual length of time it takes for an intervention to influence the structure of a grid depends on the particularities of the local planning processes.

These metrics are reported as rates per MWh of end-use load. If a user wishes to obtain the LRMER at the busbar level (if they are estimating the emissions avoided by an alternative 
generation source injected at the busbar level, for example), they should adjust by the marginal distribution loss rate, as described in Section 4.1.

As with all marginal values in Cambium databases, LRMER can be applied to either load increases or decreases. Load increases could be estimating the electric-sector emissions that would be induced by increased electric vehicle charging or replacing a natural gas furnace with a heat pump. Load decreases might be estimating the emissions avoided by installing a more efficient cooling technology.

The $\mathrm{CH}_{4}$ and $\mathrm{N}_{2} \mathrm{O}$ metrics are reported in $\mathrm{g} / \mathrm{MWh}$, whereas $\mathrm{CO}_{2}$ and $\mathrm{CO}_{2} \mathrm{e}$ rate metrics are reported in $\mathrm{kg} / \mathrm{MWh}$. " $c$ " indicates emissions from direct combustion, whereas " $p$ " indicates emissions from precombustion processes. lrmer_co2e reports combined combustion and precombustion rates.

Metric Family: total emissions by region

Metric Name: total_gen_co2_c,total_gen_ch4_c,total_gen_n2o_c, total_gen_co2_p, total_gen_ch4_p,total_gen_n2o_p,total_gen_co2e_c,total_gen_co2e_p,total_gen_co2e Units: metric tons

The total_gen family of metrics reports the total emissions from all generation within a region, in metric tons. No adjustment is made for imported or exported electricity. Start-up and shut-down emissions are not included. No adjustments are made to reflect absorption by Direct Air Capture technologies, although the capture from CCS technologies is included.

The $\mathrm{CH}_{4}$ and $\mathrm{N}_{2} \mathrm{O}$ metrics are reported in $\mathrm{g} / \mathrm{MWh}$, whereas $\mathrm{CO}_{2}$ and $\mathrm{CO}_{2} \mathrm{e}$ rate metrics are reported in $\mathrm{kg} / \mathrm{MWh}$. " $c$ " indicates emissions from direct combustion, whereas " $p$ " indicates emissions from precombustion processes. aer_gen_co2e reports combined combustion and precombustion rates.

Metric Family: total emissions by region, net of direct air capture

Metric Name: total_net_co2_c, total_net_co2, total_net_co2e

Units: metric tons

These metrics report total emissions from all generation within a region, less any Direct Air Capture of $\mathrm{CO}_{2}$ occurring within that region during that timestep. No adjustment is made for imported or exported electricity. Start-up and shut-down emissions are not included.

total_net_co2_c reports the total $\mathrm{CO}_{2}$ from direct combustion less DAC. total_net_co2 reports the total $\mathrm{CO}_{2}$ from both combustion and precombustion less DAC. total_net_co2e reports the total $\mathrm{CO}_{2} \mathrm{e}$ from $\mathrm{CO}_{2}, \mathrm{CH}_{4}$, and $\mathrm{N}_{2} \mathrm{O}$ from both combustion and precombustion, less DAC.

Metric Family: carbon capture

Metric Name: co2_captured_dac, co2_captured_ccs

Units: metric tons

These metrics report the $\mathrm{CO}_{2}$ captured by Direct Air Capture (DAC) and Carbon Capture and Sequestration generation technologies (CCS), within a given region during a given timestep, in metric tons. 


\subsection{Cost Metrics}

The metrics in this section are estimates of the marginal costs induced by an increase in demand (or avoided costs from a decrease in demand). In some instances, it may be appropriate to use these values as approximations of market prices for corresponding electric services, but it is important for users to understand the limitations of using marginal costs from least-cost optimization models as estimates of market prices. We strongly recommend users read Section 2, as well as the methods sections that discuss each cost metric in more detail than do the brief summaries given in this section.

All dollar values are in real terms for a constant dollar year. For the Standard Scenarios data sets, the dollar year is the year preceding the release (e.g., the 2021 Standard Scenarios dollar values are in 2020 dollars).

Metric Family: marginal energy costs

Metric Names: energy_cost_busbar and energy_cost_enduse

Units: $\$ / M W h_{\text {busbar and }} \$ / M W h$ end-use

The energy_cost_busbar and energy_cost_enduse metrics report the short-run marginal costs of providing the energy for a marginal increase in load, in dollars per megawatt-hour of either busbar or end-use load. These metrics are derived using the shadow price off of an energy constraint in the PLEXOS model. They include short-run costs that vary as a function of load (fuel and variable costs), but they do not reflect other operational costs that are fixed or vary as "steps," such as start-up costs or fixed operation and maintenance costs.

These metrics are conceptually similar to a day-ahead locational marginal price, given the limitations discussed in Section 2. Specifically, the coarse geographic resolution, lack of temperature effects on generator heat rates and transmission losses, and fact that these are derived from the shadow prices out of a system-wide least-cost optimization model all contribute to these marginal costs tending to be less variable than observed prices in energy markets.

These marginal costs include the effects of generator short-run marginal costs, inter-BA transmission losses, and inter-BA transmission congestion. In the case of energy_cost_enduse, distribution loss effects are also included. Cost-recovery for start-up costs are not reflected in these values, as these are marginal costs and start-up costs are step changes. Debt service and fixed operations and maintenance costs are likewise not reflected in these marginal costs.

As a least-cost optimization model, PLEXOS can sometimes find solutions that result in exceptionally high marginal costs. For example, PLEXOS will sometimes drop a small amount of a reserve product and incur the associated penalty rather than incur the costs of starting up a generator that could have provided those reserves. This results in the marginal energy cost being set by the $\$ / M W h$ penalty for dropping the reserve product in that hour. Though this is a technically correct description of the least-cost solution, we feel these marginal cost spikes are not useful descriptions of the situation and are not generally helpful for the types of analyses for which Cambium data are used. Therefore, for each BA and each time-step, we cap the marginal energy costs at the short-run marginal cost (plus an adder for start-up cost recovery) of the least- 
expensive natural-gas combustion turbine (NGCT) that has available capacity in that BA. When there is not a NGCT in the BA with remaining capacity, the SRMC plus start-up adder of the most expensive NGCT in the conterminous United States is used as a cap. As stated in Section 2, the models that Cambium draws from are not set up to assess resource adequacy or reliability, and the implementation of these price caps reflects that limitation.

For scenarios that include national carbon constraints (the Mid-case $95 \%$ decarbonization by 2050 and Mid-case 95\% decarbonization by 2035 scenarios in the 2021 Cambium release), the shadow price on the carbon constraint for the corresponding year in the underlying ReEDS model run is added to the operating costs of emitting generators for the corresponding PLEXOS run. This tends to meaningfully increase the marginal energy costs in the decarbonization scenarios.

Metric Family: marginal capacity costs

Metric Names: capacity_cost_busbar and capacity_cost_enduse Units: $\$ / M W h$ busbar and $\$ / \bar{M} W h_{\text {end-use }}$

The capacity_cost_busbar and capacity_cost_enduse metrics report the long-run cost of additional capital investment necessary to maintain a target planning reserve margin when demand is increased. An annual marginal capacity cost is derived from the shadow price off of the capacity constraint in the ReEDS model, which is set by the least-cost option for obtaining a marginal increase in firm capacity within each BA. The increase in firm capacity can be achieved by building new generation capacity, by holding on to existing generation capacity that would otherwise have been retired, or by building new inter-BA transmission capacity, whichever is the least-cost solution.

The annual shadow price is then increased by the planning reserve margin and allocated to the highest net-load hours within the year. The use of net-load is a heuristic for identifying the hours with the highest loss of load probability, and therefore the hours in which increased demand would induce a need for more firm capacity. For a detailed discussion of these methods and their limitations see Section 5.8.

A region can have a marginal capacity cost of zero for a year if the capacity constraint was not binding for that year (i.e., the available firm capacity exceeded what was required by the region's planning reserve margin and peak load).

The annual planning reserve margin and shadow price on the capacity constraint are also provided in Cambium databases as the metrics prm and capacity_shadow_price respectively. The quantity of firm capacity set by the planning reserve margin is reported as planning_capacity_MW.

Metric Family: marginal costs of renewable and clean energy portfolio standards

Metric Names: portfolio_cost_busbar and portfolio_cost_enduse

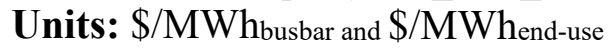

The portfolio_cost_busbar and portfolio_cost_enduse metrics report the marginal cost of staying in compliance with a state's portfolio standard policies - both renewable portfolio standards (RPS) and clean energy standards (CES) - when end use demand is increased. For Cambium databases, unless otherwise noted in a scenario, enacted state-level RPS and CES are included. 
For example, if a noncompliant technology (e.g., a natural gas generator for an RPS) is on the margin during a particular hour, additional consumption during that hour would require an increase in compliant generation at another point in the year for the standard to still be met. This cost reflects the cost of obtaining the required generation or credits through either operations or purchase.

In contrast, if a compliant technology is on the margin (e.g., a curtailing solar photovoltaic generator under most portfolio standards), there would be a value (i.e., negative cost) to additional consumption during that hour, as additional consumption would create credits from the otherwise-curtailed-generator, decreasing the need to acquire them through other means.

These costs are zero if either there are no portfolio standard policies or the policies that exist are not binding at that point in time.

For a discussion of how these metrics are calculated for Cambium databases, see Section 5.9. For a discussion of which policies are represented, and how they are represented in ReEDS, see (Ho et al. 2021).

Cambium databases also include the annual shadow prices on the policy constraints (see rps shadow_price and ces_shadow_price), as well as the fraction of end-use load covered by each policy (see rps $f$ and $c e s \_$).

Metric Family: total marginal cost

Metric Names: total_cost_busbar and total_cost_enduse

Units: $\$ / M W h_{\text {busbar and }} \$ / \mathrm{MWh}_{\text {end-use }}$

The total_cost_busbar and total_cost_enduse metrics are the sum of energy, capacity, and portfolio costs. These are only the costs that are currently included in Cambium databases, and they do not include costs for distribution capacity, transmission capacity, administrative and general expenses, and other electric sector expenses. Therefore, this metric does not capture all the costs of building and operating the electric system. If the intervention being analyzed would influence costs beyond the ones currently included in the Cambium database, those additional costs may need to be estimated through other methods for a complete analysis.

Additionally, we emphasize that these costs are estimates of the costs incurred by the bulk power system by marginal consumption, and they are not estimates of retail electricity prices. Retail prices typically include cost recovery for other expenses and are often set by ratemaking methods designed to collect target revenue amounts from various customer classes, instead of adhering strictly to marginal cost pricing.

\subsection{Interregional Transmission Metrics}

These transmission metrics include only transmission between BAs, not within BAs. They also do not include Canadian imports and exports, which are represented as generation and end-use loads in the respective border regions. 
Metric Family: total imports and total exports

Metric Names: imports and exports

Units: MWhbusbar

The imports and exports metrics capture the total imports and exports into and out of a region through interregional transmission lines, in megawatt-hours of energy at the busbar level.

This value is the energy sent along the transmission lines, and it is not netted by transmission losses. Transmission losses (reported in Cambium databases as additional load in the trans_losses metric) are allocated equally between the sending and receiving regions. For example, if $100 \mathrm{MWh}$ of energy is transmitted between two regions while incurring $5 \mathrm{MWh}$ of losses, the load in both the sending and receiving regions would increase by $2.5 \mathrm{MWh}$. In effect, the receiving region would receive a net of $97.5 \mathrm{MWh}$ of energy while the burden on the sending region would be higher by $102.5 \mathrm{MWh}$. This would be reported as $100 \mathrm{MWh}$ of imports in the receiving region, $100 \mathrm{MWh}$ of exports in the sending region, and $2.5 \mathrm{MWh}$ of trans losses in both the sending and receiving regions.

\subsection{Load Metrics}

Metric Family: total load at the busbar

Metric Name: busbar_load

Units: MWhbusbar

The busbar_load metric reports the total electric load in a region, in megawatt-hours of busbar load. It includes the load from end uses (including the busbar equivalent of end-use load that is served by behind-the-meter PV), load incurred through transmission losses, and load from storage generators charging.

Metric Family: end-use load

Metric Names: enduse_load and busbar_load_for_enduse

Units: MWhenduse and MWhbusbar

The enduse_load metric reports the amount of electricity consumed at the point of end use within a region, including end-use load that is served by behind-the-meter PV. End-use load includes load consumed by Direct Air Capture technologies. The metric busbar_load_for_enduse reports the quantity of load consumed at the busbar level to meet that end-use load. Therefore, busbar_load_for_enduse is larger because it is prior to incurring distribution losses whereas enduse_load is smaller because it is after incurring distribution losses.

Neither of these metrics includes transmission losses or storage load, which are both loads induced at the busbar.

In border regions, Canadian exports are included in the end-use load metric. 
Metric Family: DAC load

Metric Names: dac_load

Units: MWhbusbar

The dac_load metric reports the amount of electricity consumed at the busbar, in order to serve Direct Air Capture of $\mathrm{CO}_{2}$.

Metric Family: load from transmission losses

Metric Name: trans_losses

Units: MWhbusbar

The trans_losses metric reports the amount of energy that is lost due to inter-BA transmission losses. The losses are represented as an additional load at the busbar level, split equally between the sending and receiving BA.

Metric Family: load from storage generators that are charging

Metric Names: battery_charging, phs_charging, and storage_charging

Units: MWhbusbar

The metrics battery_charging and phs_charging report the busbar load caused by the charging of electric battery storage and pumped hydro storage, respectively. The battery_charging metric includes charging from the McIntosh compressed air energy storage plant in McIntosh, Alabama. storage_charging is the sum of the other two metrics.

Metric Family: net load

Metric Name: net_load_busbar

Units: MWhbusbar

The metric net_load_busbar reports the busbar_load_for_enduse minus variable_generation.

\subsection{Operational Metrics}

Metric Family: distribution loss rates

Metric Names: distloss_rate_avg and distloss_rate_marg

Units: $\mathrm{MWh}_{\text {losses }} / \mathrm{MWh}$ busbar_load

The metric distloss_rate_avg is the average distribution loss rate (i.e., the rate of losses incurred in the distribution of electricity to end uses in a region). The metric distloss_rate_marg is the marginal distribution loss rate (i.e., the rate of losses incurred in the distribution system by a marginal increase in the end-use load in the region). Marginal loss rates, and therefore average loss rates, increase as the end-use load in a region increases.

The average loss rate $(\alpha)$ is defined as losses $(L)$ per busbar load consumed for end use $(D)$ :

$$
\alpha=\frac{L}{D}
$$


For example, if $100 \mathrm{MWh}$ of energy were consumed at the busbar for end uses, and $5 \mathrm{MWh}$ were lost in distribution, the total consumption at the end use would be $95 \mathrm{MWh}$ and the average loss rate would be $5 \%$. Similarly, the marginal loss rate $(\mu)$ is defined as the increase in losses per marginal increase in busbar load consumed for end use.

See Section 5.7 for our approach and assumptions for calculating average and marginal distribution loss rates.

Metric Family: planning reserve margin

Metric Name: $p r m$

Units: $\mathrm{MW}_{\text {firm }} / \mathrm{MW}_{\text {peak }}$

The prm metric reports the planning reserve margin (PRM) used within ReEDS. Utilities, regulators, and system operators use the PRM as a heuristic for procuring sufficient firm capacity to achieve a desired level of resource adequacy, where resource adequacy is defined as "the ability of supply- and demand-side resources to meet the aggregate electrical demand" (NERC 2020).

The PRM is defined as the fraction of firm capacity above peak demand:

$$
P R M=\frac{\text { Firm Capacity }- \text { Peak Demand }}{\text { Peak Demand }}
$$

For example, in a region with a peak demand of $100 \mathrm{MW}$ and a PRM of 0.15 , the planned capacity would be $115 \mathrm{MW}$.

The PRMs applied in ReEDS are based on reserve margin requirements for North American Electric Reliability Corporation reliability subregions (NERC 2010). ${ }^{10}$

Metric Family: planning capacity

Metric Name: planning_capacity_MW

Units: $M W_{\text {firm }}$

The planning_capacity_MW metric reports how much firm capacity is called for in each region to meet the planning reserve margin, where firm capacity is defined as capacity that can reliably contribute to meeting the region's peak demand. For documentation of how ReEDS assesses the ability of different generators to contribute firm capacity, see (Ho et al. 2021).

The sum of the BA-level planning capacities will exceed the maximum amount of firm capacity available in the conterminous United States, because peak demand periods are noncoincident across the country, and therefore capacity trading can reduce the total capacity needed to below the sum of the BA's requirements.

\footnotetext{
10 The PRM is constant year-over-year for all regions except ERCOT. Because ERCOT was below its NERCrecommended level in 2018, the ERCOT PRM is set to the observed level of $10.9 \%$, and the 2019 value is set at the 2019 projected level of $8.5 \%$. The 2020 value is set at the average of $8.5 \%$ and the NERC-reference level of $13.75 \%$, and years from 2021 onward are set at $13.75 \%$.
} 
Metric Family: shadow price on the capacity constraint

Metric Name: capacity_shadow_price

Units: $\$ / \mathrm{MW}_{\text {firm }}$

The capacity_shadow_price, which is an annual value from the ReEDS model, is the marginal cost of procuring another megawatt of firm generation capacity. It is used in the calculation of the marginal capacity cost.

The shadow price off of this constraint is the $\$ / \mathrm{MW}$-year marginal cost for obtaining additional firm capacity. The model will find the least-cost option through three possible decision variables within the model:

- New Generation Capacity: Referred to as net cost of new entry (net CONE), the shadow price of the capacity constraint may be set by the annualized revenue needed to recover the costs of the generator that can provide firm capacity at the lowest cost, minus any revenue that the generator could obtain by providing other services (e.g., energy or operating reserves). This is often a natural gas combustion turbine plant or a battery, although in many regions in the 2020's and 2030's it can also be variable resources like wind and solar, if their generation is well-aligned with peak demand. ${ }^{11}$

- New Transmission Capacity: If a neighboring BA has excess generation capacity, the shadow price of the capacity constraint may be set by the annualized cost of building additional transmission capacity, minus the revenue the line would obtain from transmitting energy or operating reserve products.

- Delayed Retirement: ReEDS will choose to retire generation capacity if the capacity is not providing sufficient value to the system to cover its fixed costs (amplified by a multiplier to represent the "stickiness" of retirement). When this is happening, the shadow price of the capacity constraint can be set by the revenue that would have been required to keep that capacity online, minus the revenue it would have received for any other services.

Because of the prevalence of retiring generators, and the ability of wind and solar to contribute firm capacity, Cambium results for the 2020s often show capacity shadow prices that are substantially lower than what they would be if the shadow price were only being set by the net CONE of a natural gas combustion turbine. For some analyses, it may be appropriate for an analyst to substitute Cambium's shadow price with a different estimate of the marginal cost of capacity (e.g., annualized cost of a new combustion turbine) if there is reason to believe such an estimate describes the behavior of the region being analyzed better than the solution found by Cambium.

\footnotetext{
${ }^{11}$ ReEDS assesses the ability of variable generators (wind and solar) to provide firm capacity through a net load duration curve approach. Doing so tends to result in variable generators being able to provide firm capacity in the nearer term, which eventually goes to zero as net load peaks shift away from times of peak variable generation. See (Ho et al. 2021) and the forthcoming documentation of the 2021 version of ReEDS for a more detailed discussion of this approach.
} 
Metric Family: technology of the marginal generator and marginal energy source Metric Names: marg_gen_tech and marg_es_tech

The marg_gen_tech and marg_es_tech are the technologies of the short-run marginal generator and the short-run marginal energy source for a given location and time. These metrics only refer to the short-run marginal generator. In the long run, a marginal increase in demand is typically served by a mixture of generators.

The marginal generator is the generator that would provide the power to cover an increase in load, precisely when the load is increased. However, we differentiate between the marginal generator and the marginal energy source because some generators are energy-constrained and would therefore be unable to create new electrical energy if they were the marginal generator. We call these generators energy-constrained generators, and they include both generators that never have the ability to create new energy (e.g., batteries) and generators that have a limited budget of energy that they would dispatch entirely under expected conditions (e.g., dispatchable hydropower).

If an energy-constrained generator provides power, a different generator-one that can create new electric energy - must increase its generation at a different time. The generator that would ultimately increase its generation in response to the energy-constrained generator providing power as a marginal generator is the generator we consider to be the marginal energy source.

Each balancing area can only have a single marginal generator and marginal energy source during each time-step, although multiple balancing areas can share the same generators through transmission.

For a discussion of how the marginal generators and marginal energy sources are identified for Cambium databases, see Sections 5.5 and 5.6.

Metric Family: operating reserve requirements

Metric Names: spin_MW,flex_MW, and reg_MW Units: MW

The spin_MW,flex_MW, and reg_MW metrics are the requirements in megawatts for three types of operating reserves: spinning reserves, flexibility reserves, and regulation reserves.

Generators that are turned on but not dedicating their full capacity to energy generation can provide these reserves. Generators can provide both spinning and flexibility reserves from the same capacity if they meet the relevant requirements. Nuclear, PV, CSP without storage, and wind are not eligible to provide these reserves. Electric batteries and pumped hydro storage can provide these reserves if the generators have enough stored energy that they could discharge at full capacity for at least one hour.

For a discussion of these reserves, which generators can provide them, and the limitations of our representation, see Section 5.10. 
Metric Family: shadow price on operating reserve constraints

Metric Names: spin_shadow_price,flex_shadow_price, and reg_shadow_price Units: \$/MW

The spin_shadow_price, flex_shadow_price, and reg_shadow_price metrics are the shadow prices on each of the operating reserve constraints from PLEXOS. They represent the marginal cost of procuring another megawatt of each reserve.

Importantly, these shadow prices are often zero in Cambium because of (1) the assumption that there are no direct operating costs for generators to provide these reserves and (2) the step changes in available capacity that result from the commitment of a generator. As a result, there are only nonzero shadow prices for these reserves when there is an opportunity cost associated with the capacity that would provide a marginal increase in the reserve product. Because most hours tend to have at least some online capacity not already dedicated to energy generation and reserve provision, these shadow prices are often zero.

In practice, market prices for operating reserves are typical non-zero. Though we provide these values as indications of how our models view the marginal costs of holding these reserves, we recommend against using these costs as estimates for the market prices for similar services.

For a discussion of these reserves, which generators can provide them, and the limitations of our representation, see Section 5.10.

\subsection{Policy Metrics}

Metric Family: shadow price on portfolio standard constraints

Metric Names: rps_shadow_price and ces_shadow_price

Units: \$/MWh

These metrics are the shadow prices on portfolio standard constraints from the ReEDS model. Unless otherwise specified in a scenario's description, the ReEDS runs that Cambium draws from represents both renewable portfolio standards and clean energy standards.

These metrics are annual values, and they represent the marginal cost of procuring another megawatt-hour of generation (or an unbundled credit from eligible generation, where allowed) that is eligible to satisfy the requirements of the policy.

Although these metrics are conceptually similar to the price of policy credits (e.g., RECs), important limitations to our representation mean these values are unlikely to be good estimates of the market price of these credits in practice. These limitations include the lack of inter-year credit banking, imperfect representations of policies, no representation of other consumers of policy credits, and the fact that these are long-run not short-run values (i.e., the shadow price reflects the option of building additional capacity to generate more credits).

For a discussion about how these values are used in calculating the marginal portfolio costs, see Section 5.9. For documentation of how these policies are represented in ReEDS, see (Ho et al. 2021). 
Metric Family: portfolio standard fractions

Metric Names: $r p s \_f$ and $c e s \_f$

Units: $\mathrm{MWh}_{\text {credit }} / \mathrm{MWh}$ end-use

These metrics are the requirements of state-level portfolio standard constraints from the ReEDS model. Unless otherwise specified in a scenario's description, the ReEDS runs that Cambium draws from represent both renewable portfolio standards and clean energy standards.

All policies are represented as requiring a certain amount of eligible generation (or unbundled credit from eligible generation, where allowed) as a fraction of end-use load. Most renewable portfolio standards follow this same convention in practice, where the required credits are determined as a function of retail sales.

These fractions are the average requirement for the end-use load within the region covered by the policy. Defined in this way, these fractions are frequently lower than the nominal top-line number of the policy they represent, as many policies exclude certain types of load from being covered. For example, many states exempt utilities below a certain size from their policies. Such exemptions would result in a fraction that is lower than the nominal RPS goal.

For a discussion about how these values are used in calculating the marginal portfolio costs, see Section 5.9. For documentation of how these policies are represented in ReEDS, see (Ho et al. 2021).

Metric Family: shadow price on $\mathrm{CO}_{2}$ constraint

Metric Names: co2_shadow_price

Units: $\$ /$ metric ton

This metric reports the shadow price on the $\mathrm{CO}_{2}$ constraint, if such a constraint is present for a particular scenario. As the shadow price is derived in the ReEDS model, it is a long-run value, not a short-run value (i.e., the shadow price reflects the option of building additional capacity).

\subsection{Short-run Marginal Generators and Marginal Energy Sources}

In Cambium databases, we differentiate between short-run marginal generators (the generator that would provide the power to cover an increase in load at the moment when the load is increased) and marginal energy sources. The distinction is needed because some generators, such as electric batteries, cannot create new electrical energy. We call these generators energyconstrained generators, and they include both generators that never have the ability to create new energy (e.g., batteries) and generators that have a limited budget of energy that they would dispatch entirely under expected conditions (e.g., dispatchable hydropower).

If an energy-constrained generator provides power, a different generator-one that can create new electric energy - must increase its generation at a different time. The generator that would ultimately increase its generation in response to the energy-constrained generator providing power as a marginal generator is the generator that we consider to be the marginal energy source.

Energy-constrained generators are conceptually equivalent to transmission lines, except they connect marginal energy sources to load over time instead of over space. In the same way that 
it can be insufficient to say a transmission line is providing the marginal unit of power at some moment in time, it also can be insufficient to say that an energy-constrained generator is providing the marginal unit of power.

Identifying the marginal energy source is relevant for some metrics in a Cambium database because the characteristics of the marginal energy source determines the impacts of increasing demand. The short-run marginal emission rate, for example, is driven by the emission rate of the marginal energy source, and modified by relevant transmission and efficiency losses, if the marginal generator is an energy-constrained generator.

We describe how we identify marginal generators in Section 5.5 and how we identify marginal energy sources in Section 5.6. 


\section{Cambium Methods}

Cambium draws from the outputs of ReEDS and PLEXOS when creating its output database. This section documents the methods that Cambium implements to process the outputs from ReEDS and PLEXOS into the final Cambium database.

\subsection{Technologies represented in Cambium}

Data are reported for 18 technology groups in Cambium (Table 1). The actual number of discrete technologies in both the ReEDS and PLEXOS runs is greater, but the data are grouped to reduce the size of the database. The ReEDS and PLEXOS technologies that are within each of Cambium's technology groups is given in Table 1. Within each ReEDS and PLEXOS technology, there can be generators with varying performance characteristics (e.g., heat rates), based on improvement over time, but we do not consider those as distinct technologies. For a detailed discussion of how each technology is represented, see (Ho et al. 2021).

Unless otherwise specified in a project or scenario description, Cambium databases are based on the NREL's Standard Scenarios (https://www.nrel.gov/analysis/standard-scenarios.html). See the corresponding Standard Scenario report (i.e., the 2021 Cambium data release draws from the 2021 Standard Scenarios) for a description of the technology cost and performance assumptions for each scenario, most of which draw from NREL's Annual Technology Baseline (https://atb.nrel.gov/).

The McIntosh compressed air energy storage plant in McIntosh, Alabama, has both its generation and capacity reported as one-third natural gas combined cycle and two-thirds battery to align with its representation in the PLEXOS model runs.

A "renewable combustion turbine" (i.e., a combustion turbine fueled by a generic net-zeroemissions fuel with a cost of $\$ 20$ per MMBtu of fuel) was represented as an investment option in all the ReEDS runs underlying the 2021 release of Cambium, but was never selected for investment, and therefore not included in the generation and capacity outputs.

Hybrid PV and battery generators are available for investment in the ReEDS runs underlying the 2021 Cambium data release. When invested in, however, they are represented as discrete PV and battery generators in the PLEXOS runs used for Cambium, due to insufficient time to develop satisfactory hybrid representation in PLEXOS. Therefore, the PV and battery generation and capacity metrics in Cambium databases include both stand-alone and hybrid generators.

Table 1. Cambium Technologies

\begin{tabular}{|l|l|l|}
\hline Technology in Cambium & $\begin{array}{l}\text { Technology Name in } \\
\text { Cambium Database }\end{array}$ & Technologies in ReEDS and PLEXOS \\
\hline Behind-the-meter PV & distpv & Behind-the-meter PV \\
\hline $\begin{array}{l}\text { Bioenergy with carbon } \\
\text { capture and storage }\end{array}$ & beccs & $\begin{array}{l}\text { Bioenergy with carbon capture and } \\
\text { storage }\end{array}$ \\
\hline Biomass & biomass & Biopower and landfill gas \\
\hline Canadian imports & canada & Canadian imports \\
\hline
\end{tabular}




\begin{tabular}{|c|c|c|}
\hline Technology in Cambium & $\begin{array}{l}\text { Technology Name in } \\
\text { Cambium Database }\end{array}$ & Technologies in ReEDS and PLEXOS \\
\hline Coal & coal & $\begin{array}{l}\text { Coal (scrubbed and unscrubbed, } \\
\text { integrated gasification combined cycle, } \\
\text { and biomass cofired technologies) }\end{array}$ \\
\hline $\begin{array}{l}\text { Coal with carbon capture } \\
\text { and storage }\end{array}$ & coal-ccs & Coal with carbon capture and storage \\
\hline Concentrating solar power & $\operatorname{csp}$ & $\begin{array}{l}\text { Concentrating solar power (with and } \\
\text { without thermal energy storage) }\end{array}$ \\
\hline Electric batteries & battery & $\begin{array}{l}\text { Electric batteries, two-thirds of Mclntosh } \\
\text { compressed-air energy storage plant }\end{array}$ \\
\hline Geothermal & geothermal & $\begin{array}{l}\text { Geothermal (hydrothermal, near-field } \\
\text { enhanced geothermal, and deep } \\
\text { enhanced geothermal systems) }\end{array}$ \\
\hline Hydropower & hydro & $\begin{array}{l}\text { Hydropower (existing and undiscovered, } \\
\text { dispatchable and nondispatchable) }\end{array}$ \\
\hline Natural gas combined cycle & gas-cc & $\begin{array}{l}\text { Natural gas combined cycle, one-third of } \\
\text { Mclntosh compressed-air energy } \\
\text { storage plant }\end{array}$ \\
\hline $\begin{array}{l}\text { Natural gas combined cycle } \\
\text { with carbon capture and } \\
\text { storage }\end{array}$ & gas-cc-ccs & $\begin{array}{l}\text { Natural gas combined cycle with } \\
\text { carbon capture and storage }\end{array}$ \\
\hline $\begin{array}{l}\text { Natural gas combustion } \\
\text { turbine }\end{array}$ & gas-ct & Natural gas combustion turbine \\
\hline Nuclear & nuclear & $\begin{array}{l}\text { Nuclear (both conventional and small } \\
\text { modular reactors) }\end{array}$ \\
\hline Offshore wind & wind-ofs & Offshore wind \\
\hline Oil-gas-steam & o-g-s & Oil-gas-steam \\
\hline Onshore wind & wind-ons & Onshore wind \\
\hline Pumped hydro storage & phs & Pumped hydro storage \\
\hline Utility-scale PV & upv & $\begin{array}{l}\text { Utility-scale PV and distributed-utility- } \\
\text { scale PV }\end{array}$ \\
\hline
\end{tabular}

\subsection{Emissions Factors by Fuel}

Cambium emission metrics are calculated using the fuel-specific emissions factors given in Table 2. The resulting emissions per MWh of electric generation is a function of the generator's heat rate (i.e., the rate at which fuel is converted into electricity), which can vary by generator. Heat rates for newly built generators in Cambium datasets generally follow the projections in NREL's Annual Technology Baseline, unless otherwise specified. Heat rates for existing generators draw from EIA data and are available by accessing the ReEDS repository, which is accessible upon request. 
The precombustion emission factors include fuel extraction, processing, and transport, including fugitive emissions. Because these activities occur prior to combustion, it should be noted that the precombustion emissions associated with a particular timestep are not actually occurring at that timestep.

The precombustion emissions for natural gas are drawn from (Littlefield et al__._2019). Power plants are assumed to avoid distribution losses, resulting in a fugitive methane emissions rate of $1.08 \% .^{12}$

Emissions from ongoing, non-combustion activities (e.g., the emissions induced by operations and maintenance activities) are not included in Cambium emissions metrics. Emissions from commissioning or decommissioning generators or other physical infrastructure are also not included.

Bioenergy with carbon capture and storage technologies are assumed to have a net capture rate of $79.6 \mathrm{~kg}$ of $\mathrm{CO}_{2}$ per MMBtu of fuel, following the assumption in ReEDS. That value is for $\mathrm{CO}_{2}$ from direct combustion, and the rest of the emission factors take the same values as the biomass category.

Natural gas and coal generators with carbon capture are assumed to have a $90 \%$ reduction in their $\mathrm{CO}_{2}$ from direct combustion. All other emissions factors for those generating technologies following their fuel-specific values.

Sources:

- US LCI: U.S. Life Cycle Inventory Database, (National Renewable Energy Laboratory 2021)

- EPA 2016: Greenhouse Gas Inventory Guidance: Direct Emissions from Stationary Combustion Sources, (United States Environmental Protection Agency 2016).

- ATB 2021: Annual Technology Baseline 2021, (NREL 2021).

- CARB 11-307: Assessment of the Emissions and Energy Impacts of Biomass and Biogas Use in California, (Carreras-Sospedra et al. 2015).

- NETL 2019: Life Cycle Analysis of Natural Gas Extraction and Power Generation, (Littlefield et al. 2019).

${ }^{12}$ Assuming power plants avoid distribution losses was explicitly stated in a predecessor publication (Skㅡone 2014). 
Table 2: Emission Factors by Fuel

\begin{tabular}{|c|c|c|c|c|c|}
\hline Fuel & Type & Emission & $\begin{array}{l}\text { Emission } \\
\text { Factor }\end{array}$ & Units & Source \\
\hline \multirow{6}{*}{ Coal } & \multirow{3}{*}{ Precombustion } & $\mathrm{CO}_{2}$ & 2.94 & $\mathrm{~kg} / \mathrm{MMBtu}$ & US LCI, Bituminous Coal at power plant \\
\hline & & $\mathrm{CH}_{4}$ & 208.26 & $\mathrm{~g} / \mathrm{MMBtu}$ & US LCI, Bituminous Coal at power plant \\
\hline & & $\mathrm{N}_{2} \mathrm{O}$ & 0.05 & g/MMBtu & US LCI, Bituminous Coal at power plant \\
\hline & \multirow{3}{*}{ Combustion } & $\mathrm{CO}_{2}$ & 95.52 & kg/MMBtu & $\begin{array}{l}\text { EPA 2016, Table A-3, Coal and Coke, } \\
\text { Mixed (Electric Power Sector) }\end{array}$ \\
\hline & & $\mathrm{CH}_{4}$ & 11.00 & g/MMBtu & $\begin{array}{l}\text { EPA 2016, Table A-3, Coal and Coke, } \\
\text { Mixed (Electric Power Sector) }\end{array}$ \\
\hline & & $\mathrm{N}_{2} \mathrm{O}$ & 1.60 & g/MMBtu & $\begin{array}{l}\text { EPA 2016, Table A-3, Coal and Coke, } \\
\text { Mixed (Electric Power Sector) }\end{array}$ \\
\hline \multirow{6}{*}{$\begin{array}{l}\text { Natural } \\
\text { Gas }\end{array}$} & \multirow{3}{*}{ Precombustion } & $\mathrm{CO}_{2}$ & 6.27 & $\mathrm{~kg} / \mathrm{MMBtu}$ & US LCI, Natural Gas at power plant \\
\hline & & $\mathrm{CH}_{4}$ & 277.45 & $\mathrm{~g} / \mathrm{MMBtu}$ & NETL 2019 \\
\hline & & $\mathrm{N}_{2} \mathrm{O}$ & 0.02 & $\mathrm{~g} / \mathrm{MMBtu}$ & US LCI, Natural Gas at power plant \\
\hline & \multirow{3}{*}{ Combustion } & $\mathrm{CO}_{2}$ & 53.06 & $\mathrm{~kg} / \mathrm{MMBtu}$ & EPA 2016, Table A-3, Natural Gas \\
\hline & & $\mathrm{CH}_{4}$ & 1.00 & g/MMBtu & EPA 2016, Table A-3, Natural Gas \\
\hline & & $\mathrm{N}_{2} \mathrm{O}$ & 0.10 & g/MMBtu & EPA 2016, Table A-3, Natural Gas \\
\hline \multirow{6}{*}{$\begin{array}{l}\text { Residual } \\
\text { Fuel Oil }\end{array}$} & \multirow{3}{*}{ Precombustion } & $\mathrm{CO}_{2}$ & 9.91 & $\mathrm{~kg} / \mathrm{MMBtu}$ & US LCl at power plant \\
\hline & & $\mathrm{CH}_{4}$ & 153.45 & $\mathrm{~g} / \mathrm{MMBtu}$ & US LCl at power plant \\
\hline & & $\mathrm{N}_{2} \mathrm{O}$ & 0.17 & g/MMBtu & US LCl at power plant \\
\hline & \multirow{3}{*}{ Combustion } & $\mathrm{CO}_{2}$ & 75.10 & $\mathrm{~kg} / \mathrm{MMBtu}$ & $\begin{array}{l}\text { EPA 2016, Table A-3, Petroleum } \\
\text { Products, Residual Fuel Oil No. } 6\end{array}$ \\
\hline & & $\mathrm{CH}_{4}$ & 3.00 & g/MMBtu & $\begin{array}{l}\text { EPA 2016, Table A-3, Petroleum } \\
\text { Products, Residual Fuel Oil No. } 6\end{array}$ \\
\hline & & $\mathrm{N}_{2} \mathrm{O}$ & 0.60 & g/MMBtu & $\begin{array}{l}\text { EPA 2016, Table A-3, Petroleum } \\
\text { Products, Residual Fuel Oil No. } 6\end{array}$ \\
\hline \multirow{6}{*}{ Uranium } & \multirow{3}{*}{ Precombustion } & $\mathrm{CO}_{2}$ & 0.84 & $\mathrm{~kg} / \mathrm{MMBtu}$ & US LCI, Uranium at power plant \\
\hline & & $\mathrm{CH}_{4}$ & 2.10 & g/MMBtu & US LCI, Uranium at power plant \\
\hline & & $\mathrm{N}_{2} \mathrm{O}$ & 0.02 & $\mathrm{~g} / \mathrm{MMBtu}$ & US LCI, Uranium at power plant \\
\hline & \multirow{3}{*}{ Combustion } & $\mathrm{CO}_{2}$ & 0.00 & $\mathrm{~kg} / \mathrm{MMBtu}$ & ATB 2021 \\
\hline & & $\mathrm{CH}_{4}$ & 0.00 & g/MMBtu & - \\
\hline & & $\mathrm{N}_{2} \mathrm{O}$ & 0.00 & g/MMBtu & - \\
\hline \multirow{6}{*}{ Biomass } & \multirow{3}{*}{ Precombustion } & $\mathrm{CO}_{2}$ & 2.46 & kg/MMBtu & CARB 11-307, Table 15 \\
\hline & & $\mathrm{CH}_{4}$ & 2.94 & $\mathrm{~g} / \mathrm{MMBtu}$ & CARB 11-307, Table 15 \\
\hline & & $\mathrm{N}_{2} \mathrm{O}$ & 0.01 & g/MMBtu & CARB 11-307, Table 15 \\
\hline & \multirow{3}{*}{ Combustion } & $\mathrm{CO}_{2}$ & 0.00 & kg/MMBtu & ATB 2021 \\
\hline & & $\mathrm{CH}_{4}$ & 0.00 & g/MMBtu & - \\
\hline & & $\mathrm{N}_{2} \mathrm{O}$ & 0.00 & $\mathrm{~g} / \mathrm{MMBtu}$ & - \\
\hline
\end{tabular}




\subsection{Coloring Power Flows}

When calculating the characteristics of the generation induced by load at a certain point - such as the average emission rate of the generators serving end-use consumption - the composition of the source generation must be determined, including the contribution of generators in different regions that may be sending power through transmission lines. Therefore, we need a method for allocating the generation from each generator to loads - or, from the other perspective, finding where the power for a given node's end use originally came from. To do so, we take the network of nodes and transmission flows in each PLEXOS solution that Cambium draws from, and assume each node is a "perfect mixer" (i.e., that any electricity consumed or exported from a node is a perfect mixture of the electricity being supplied to the node).

Consider the network in Figure 3:

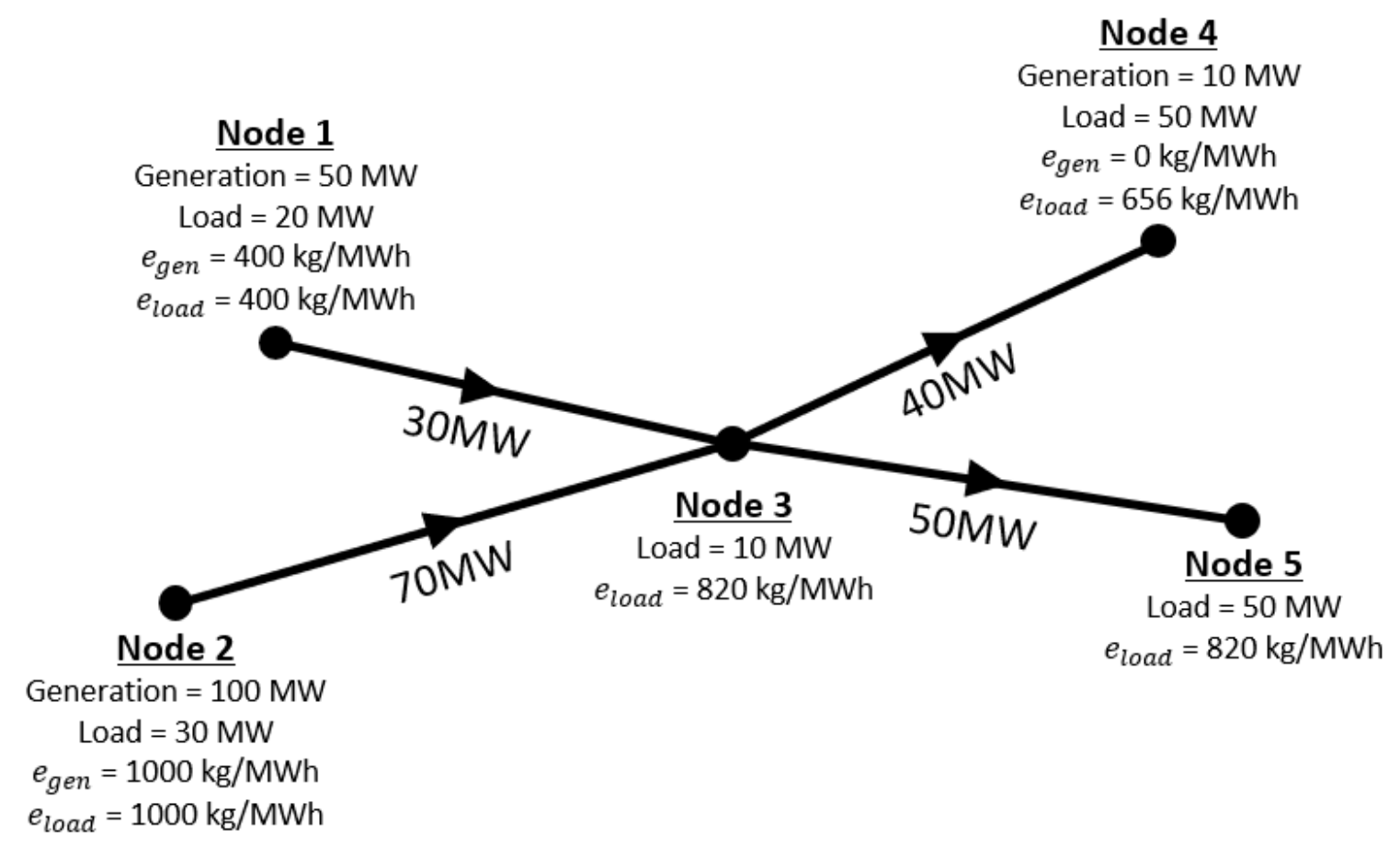

Figure 3. Simple network for illustrating power flow coloring

In this toy example shown in Figure 3, we have a system with five nodes $\left(N_{1}-N_{5}\right)$, connected by four transmission lines. Only notes $N_{1}, N_{2}$, and $N_{3}$ have generation, with emission rates for inregion generation $\left(e_{g e n}\right)$ of $400,1,000$, and $0 \mathrm{~kg} / \mathrm{MWh}$ respectively. For this example, we assume there are no transmission losses.

The question we are trying to answer is: What is the emission rate that you could ascribe to each of the five nodes' load $\left(e_{\text {load }}\right)$ ?

For $N_{1}$ and $N_{2}$, the only power flowing into the node is from their own generation (they are not importing any power), and therefore we consider the emission rates induced by their load to be the rates of their in-region generation, which are $400 \mathrm{~kg} / \mathrm{MWh}$ and $1,000 \mathrm{~kg} / \mathrm{MWh}$ respectively. 
For $N_{3}$, we see that $30 \%$ of the power it is receiving is coming from $N_{1}$, and $70 \%$ is coming from $\mathrm{N}_{2}$. The weighted average of those two sources is $820 \mathrm{~kg} / \mathrm{MWh}$, and therefore we take that as the emission rate induced by the load at $N_{3}$.

Given the assumption of perfect mixing through $N_{3}$, we assume the power that both $N_{4}$ and $N_{5}$ are receiving from $N_{3}$ must be identical, and of the same character as the power that was consumed within $N_{3}$ itself. Therefore, the transmission from $N_{3}$ to $N_{4}$ and from $N_{3}$ to $N_{5}$ is assumed to have an emission rate of $820 \mathrm{~kg} / \mathrm{MWh}$.

$N_{4}$ is receiving $40 \mathrm{MW}$ of power from $N_{3}$ at $820 \mathrm{~kg} / \mathrm{MWh}$ and $10 \mathrm{MW}$ of power from its own generation at $0 \mathrm{~kg} / \mathrm{MWh}$. The result is an emission rate of $656 \mathrm{~kg} / \mathrm{MWh}$ ascribed to the load in $N_{4}$.

$N_{5}$ is only importing power from $N_{3}$, and therefore its load is ascribed the emission rate of 820 $\mathrm{kg} / \mathrm{MWh}$.

The example above is a trivial network: to calculate the contribution of each BA's generation to each BA's loads for the 134 BAs in Cambium (which are the nodes in our models), we use the downstream-looking algorithm from Bialek (1996), which we summarize next for our application here.

For each BA and each time-step, we take the generation in the node $\left(g_{i}\right)$, total imports into the node $\left(f_{\text {in }, i}\right)$, and total exports from the node $\left(f_{\text {out }, i}\right)$, and derive the load $\left(l_{i}\right):^{13}$

$$
l_{i}=g_{i}+f_{\text {in }, i}-f_{\text {out }, i}
$$

We then calculate the nodal through-flow $P_{i}$ as the sum of the node's load and outflow.

$$
P_{i}=l_{i}+f_{\text {out }, i}
$$

We then calculate the values for the downstream distribution matrix $\left(\boldsymbol{A}_{d}\right)$, which is a square matrix whose length and width is the number of nodes. The $(i, l)$ element of $\boldsymbol{A}_{d}$ is:

$$
\left[\boldsymbol{A}_{d}\right]_{i, l}=\left\{\begin{aligned}
1, & i=l \\
-\left|f_{i-l}\right| / P_{i}, & l \in \alpha_{i}^{(d)} \\
0, & \text { otherwise }
\end{aligned}\right.
$$

Where $\alpha_{i}^{(d)}$ is the set of nodes that are directly supplied by node $i$ and $f_{i-l}$ is the total flow into node $l$ directly from node $i$.

We then take the inverse of $\boldsymbol{A}_{d}$ to obtain $\boldsymbol{A}_{d}^{-1}$. Using each $(i, l)$ element of $\boldsymbol{A}_{d}^{-1}$, we calculate the amount of generation from source BA $i$ that can be allocated to the load in destination BA $l$ $\left(g_{i-l}\right)$ :

\footnotetext{
${ }^{13}$ We derive the load, instead of using the output from PLEXOS, to avoid violations of Kirchhoff's current law that could arise from rounding errors in the outputs.
} 


$$
g_{i-l}=g_{i} * l_{l} *\left[\boldsymbol{A}_{d}^{-1}\right]_{i, l} / P_{i}
$$

Note that this can also be expressed as an allocation factor $f_{i-l}$ which can be used to allocate any quantity from node $i$ to node $l$, if it is assumed to flow proportionally with generation:

$$
f_{i-l}=l_{l} *\left[\boldsymbol{A}_{d}^{-1}\right]_{i, l} / P_{i}
$$

Lastly, we use the allocation of generation to determine the weighted average of the characteristics of the generation sources supplying each BA. For example, for generic attribute $X_{l}$ :

$$
X_{l}=\frac{\sum_{i=1}^{n} g_{i-l} * X_{i}}{l_{l}} \quad i=1,2, \ldots, n
$$

This is the general form of the method we described above for our trivial network in Figure 3.

In Cambium, we iterate through every time-step, calculating the allocation factors $g_{i-l}$ between every pair of the 134 BAs (i.e., what fraction of the generation from one BA is allocated to the load in another BA). With these allocation factors, we can calculate the characteristics of the generation that is supplying every BA, at every time-step.

\section{Caveats and Limitations}

Allocating generation based on the assumption of perfect mixing through every node is not always appropriate. If load in one BA contracted to have generation of a certain type produced in a neighboring BA and shipped to them (e.g., with a power purchase agreement), it may be appropriate to assign all that generation to the BA that contracted for that specific type of energy. Similarly, some states, like California, have restrictions on importing power from certain fuel types (e.g., coal), and these restrictions would not necessarily be respected with this perfectmixing implementation.

Relatedly, some state renewable portfolio standards allow unbundled RECs to be purchased from other regions and retired to satisfy the requirements for a utility's load. Depending on the question an analyst is trying to answer, it may be appropriate to take these unbundled REC transfers into account when reporting an emission rate associated with a particular node's load. Our approach does not currently have a representation of unbundled REC transfers; instead, it essentially assumes all credit for renewable energy is attached to the flow of the renewable power itself.

Lastly, because transmission losses are represented as load in our models, we are not accurately capturing their impact. Our current approach slightly dilutes the emission rate ascribed to enduse load, because it is not separated from the load induced by transmission losses. In future iterations of Cambium, we intend on improving this algorithm to properly reflect the effects of transmission losses, which our current implementation does not do.

\subsection{Calculating Long-Run Marginal Emission Rates}

The long-run marginal emission rate (LRMER) is the emission rate of the generation that would either be induced or avoided by a marginal change in electric load, including both the operational 
and structural (e.g., building new generation or transmission capacity) consequences of the marginal change. ${ }^{14}$ This is in contrast to the short-run marginal emission rate, which is the emission rate that would serve a marginal increase in load, but with the capital assets of the grid being fixed (i.e., the short-run marginal emission rate only reflects the immediate operational consequences of a marginal change in load).

It is worth noting explicitly that the LRMER is not simply the SRMER in the future (or averaged over a long period of time). Because the LRMER incorporates the potential for structural change into its formulation, whereas the SRMER is strictly an operational metric, they are fundamentally different metrics, not the same metric for different time periods.

We generally consider the LRMER to be more suitable than the SRMER for estimating the emissions that are induced by a marginal change in load, if the load is going to be a persistent change for more than several years. ${ }^{15}$ This is because the procurement and retirement of capital assets is an ongoing process that is influenced by the quantity and patterns of electrical demand, and therefore a persistent change in electrical demand has the potential to influence the structural evolution of the grid. ${ }^{16}$ The differences between the two metrics can be significant, with the SRMER often not fully capturing the effects of wind and solar investments induced by load increases, and therefore generally being higher than the LRMER.

For Cambium, we estimate the LRMER by solving each modeled year twice: once with the projected conditions (the "Base" solve) and again with everything the same except for a 5\% scalar increase in end-use electricity demand (the "Perturb" solve). As the perturb solve includes both operational as well as structural changes to serve the additional demand (at least cost subject to policy and operational constraints), it represents a long-run solution, not a short-run. By comparing the generation mixtures between the two solves, we can derive a long-run marginal emission rate.

At a high level, the approach is:

1. Run each solve year twice, a Base and Perturb solve.

2. Use power flow accounting to allocate any increases in generation to the regions that consume the increases, and then subtract any decreases in generation to derive a net change in consumed generation of each technology type.

3. Assign origination mixtures for energy-constrained generators.

4. Examine the resulting mixtures by state. Where the resulting mixtures would not be in compliance with a state policy, trade credits with states that have excess to reflect accounting transfers.

\footnotetext{
14 The terms "short-run" and "long-run" do not refer to specific lengths in time, but instead are just referring to whether the equilibrium solution is evaluated with fixed capital assets (short-run), or by allowing capital assets to vary as part of the solution (long-run).

${ }^{15}$ By "persistent" we do not mean "continuous throughout the year". E.g., a persistent load increase could be adding demand only during winter evening hours, as long as that load would continue to exist year-over-year.

${ }^{16}$ Published research on marginal emission rates generally focuses on short-run marginal emission rates (SilerEvans et al. 2012; Thind et al. 2017), though the literature has addressed long-run marginal emission rates (Hawkes 2014; 2010). Work by Energy+Environmental Economics has developed long-run source energy factors and emissions factors for the state of California (Energy+Environmental Economics 2020).
} 
5. Calculate a rolling average LRMER by combining the preceding, current, and following year.

6. Apply distribution losses.

We walk through our methodology in more detail below. We discuss the limitations of our current method at the end of this section.

\section{Step 1: Run Each Solve Year Twice}

The objective of the long-run marginal emission rate metric is to estimate the change in emissions that would result from a change in end-use electric demand, taking into account both operational and structural responses to the change in demand. Therefore, to calculate the LRMER, we run both our ReEDS and PLEXOS models twice for each solve year. The first run (the "Base" run) is the same run that we use for all other metrics in the database (i.e., all of the inputs take their projected values for that point in time). The second run (the "Perturb" run) is identical for every input except for one: end-use load is scaled up 5\% from the base run.

Because the only difference between the two runs is the end-use electrical demand, we can then examine the differences between the two runs and ascribe any changes as being induced by the higher demand.

Crucially, because both ReEDS (a capacity expansion model) and PLEXOS (a production cost model) were re-run for each year, the resulting generation mixtures include potential structural responses to changes in load. If only a production cost model was perturbed, the generator fleet between the two mixtures would be the same, and the results would therefore only be short-run values.

Note that in the 2020 Cambium release this approach was approximated by comparing two sequential model years (e.g., the LRMER for 2022 was calculated by comparing the differences between 2020 and 2022). While this approach worked reasonably well, there were often changes between model years that were not a consequence of load growth, which could not be disaggregated. Ultimately, we determined that it was worth the additional computational cost to run each model year twice, rather than try to calculate a LRMER by comparing between modeled years.

\section{Step 2: Allocate Changes in Generation to Regions}

In this step, the changes in generation between the Base and Perturb model runs are allocated to GEA regions, along with the fuel consumption of that generation. This approach is based on the work of Bialek (1996), previously described in Section 5.3, but modified for allocating differences instead of absolute values.

First, the generation mixtures for both the Base and Perturb model solves are aggregated by GEA regions $(g)$ and technology $(t)$, and their difference calculated $\left(\Delta g_{g, t}\right)$. The changes in generation are split into generation increases $\Delta g_{g, t,+}$ and generation decreases $\Delta g_{g, t,-}$ for region $g$ and technology $t$ (in the set of technologies with $n$ technologies), and the sum of all technologies with non-negative generation is calculated as $\Delta g_{g,+}$. The corresponding fuel consumption is also calculated. 


$$
\Delta g_{g,+}=\sum_{t=1}^{n}\left\{\begin{array}{rr}
0, & \Delta g_{g, t}<0 \\
\Delta g_{g, t}, & \Delta g_{g, t} \geq 0
\end{array}\right.
$$

Transmission flows are also aggregated to the interfaces between GEA regions and their differences calculated. $\Delta f_{i n, g}$ indicates the change in flows into GEA region $g$, whereas $\Delta f_{\text {out }, g}$ indicates the change in flows out.

The change in load $\Delta l_{g}$ in region $g$ is then calculated as the sum of increased generation and new imports less new exports.

$$
\Delta l_{g}=\left\{\begin{aligned}
1, & \Delta g_{g,+}+\Delta f_{\text {in, }}-\Delta f_{\text {out }, g}<0 \\
\Delta g_{g,+}+\Delta f_{\text {in, },}-\Delta f_{\text {out }, g}, & \Delta g_{g,+}+\Delta f_{\text {in, }, g}-\Delta f_{\text {out }, g} \geq 0
\end{aligned}\right.
$$

Note that it is possible for the derived load changes $\Delta l_{g}$ to be negative (if a large charging load in the Base run is not present at that time in the Perturb run). The value $l_{g}$ is restricted to being positive (with a lower bound of $1 \mathrm{MWh}$ ). Additional treatment for regions where the $l_{g}$ value would have been negative are explained later when we are handling energy storage generators in the following step.

As with the original form of the power flow algorithm, we then calculate the nodal through-flow $P_{g}$, but using $\Delta l_{g}$ and $\Delta f_{\text {out }, g}$

$$
P_{g}=\Delta l_{g}+\Delta f_{\text {out }, \mathrm{g}}
$$

We then calculate the values for the downstream distribution matrix $\left(\boldsymbol{A}_{d}\right)$, which is a square matrix whose length and width is the number of GEA regions. The $(g, l)$ element of $\boldsymbol{A}_{d}$ is:

$$
\left[\boldsymbol{A}_{d}\right]_{g, l}=\left\{\begin{aligned}
1, & g=l \\
-\left|\Delta f_{g-l}\right| / P_{g}, & l \in \alpha_{g}^{(d)} \\
0, & \text { otherwise }
\end{aligned}\right.
$$

Where $\alpha_{g}^{(d)}$ is the set of nodes that are directly supplied by node $g$ and $\Delta f_{g-l}$ is the difference in the total flow into node $l$ directly from node $g$.

We then take the inverse of $\boldsymbol{A}_{d}$ to obtain $\boldsymbol{A}_{d}^{-1}$. Using each $(g, l)$ element of $\boldsymbol{A}_{d}^{-1}$, we calculate an allocation factor, that gives us the fraction of $\Delta g_{g,+}$ (and therefore the technology-specific $\Delta g_{g, t,+}$, as well as any attributes of $\Delta g_{g, t,+}$ that flow with it proportionally, such as fuel consumed) that can be allocated to GEA region $l$.

$$
\omega_{g-l}=\Delta l_{l} *\left[\boldsymbol{A}_{d}^{-1}\right]_{g, l} / P_{g}
$$

The allocated generation increases are aggregated together by technology and GEA region, and then any generation decreases $\left(\Delta g_{g, t,-}\right)$ from each GEA region are subtracted from that aggregation. For example, if a region decreased its coal generation by $10 \mathrm{MWh}$ but increased the amount of coal generation it was importing by $10 \mathrm{MWh}$, the net change in consumed coal 
generation would be zero. This is expressed in the following equation, where $i$ is the number of GEA regions.

$$
\Delta g_{l, t, n e t}=\left(\sum_{g=1}^{i} \Delta g_{g, t,+} * \omega_{g-l}\right)-\Delta g_{g, t,-}
$$

$\Delta g_{l, t, n e t}$ is therefore the generation mixtures by technology $t$ that is allocated to consuming GEA region $l$. The corresponding fuel differences that follow the generation differences are likewise calculated.

Lastly, any negative values (i.e., technologies whose generation decreased on net) are removed from the $\Delta g_{l, t, n e t}$ generation mixtures (and the corresponding fuel mixtures). Although perhaps counterintuitive, this is necessary when producing hourly LRMER values, due to interhour effects: net generation decreases in particular hours tend to be a consequence of conditions in a different hour, and therefore misleading to report in the hour that saw the decrease. For example, in the Perturb solution for a particular year, more solar may be built to serve midday electricity demand. A shoulder daylight hour may subsequently have a net decrease in a different technology's generation (coal, perhaps) not primarily because of conditions in the shoulder hour, but as a spillover from conditions in the midday hours. Said differently, we would not expect a further reduction in coal generation if there was additional demand in the shoulder hour, and therefore reporting a negative value for coal in the LRMER would be misleading.

Further research into interhour effects may develop methods for allocating the net decreases back to the hours that induced them, which may improve the results.

The method described in this step is for a single hour - it is repeated for each hour in a Cambium dataset.

\section{Step 3: Assign Originating Mixtures for Storage and Other Energy-constrained Generators}

The process in step 2 derives mixtures $\left(\Delta g_{l, t, n e t}\right)$ that include the contribution of energy storage technologies (electric batteries and pumped hydro storage) as well as energy-constrained technologies (dispatchable hydropower and Canadian imports, which are treated as dispatchable hydro in Cambium's simulations). Each of these technology groups requires special treatment.

First, energy storage technologies: Energy storage technologies, such as batteries, do not create electrical energy. In order for an energy storage generator to help meet a marginal increase in demand, it would be necessary for a different generator to supply the original energy. Therefore, in order to determine the emissions that were induced by a change in load in an hour where energy storage was part of the $\Delta g_{l, t, n e t}$ mixture, it is necessary for us to estimate the mixtures from other source generators that enabled the energy storage generator's behavior.

As of the 2021 Cambium release, the approach for energy storage generators was relatively simple: energy storage and energy-constrained generators are removed from the $\Delta g_{l, t, n e t}$ term calculated in step 2, and the result is grouped by receiving GEA region $(l)$ and month, and the 
proportion each technology type within that monthly mixture is calculated. That fractional mixture is then assigned to the generation from any energy storage generator located in the receiving GEA region, associated fuel consumption is inflated by that generator's monthly round-trip efficiency, and then allocated using the allocation factors $\omega_{r-l}$ that were calculated in step 2. For example, if a battery located in AZNMc discharges $10 \mathrm{MWh}$ during a particular timestep, and the non-storage and non-energy-constrained receiving mixture of AZNMc during that month was half natural gas and half photovoltaics, then the discharge of that battery is colored as $5 \mathrm{MWh}$ natural gas and $5 \mathrm{MWh}$ photovoltaics. The fuel consumption associated with that discharge would be the fuel consumption of the natural gas, inflated by the losses within the battery.

Next, for energy-constrained generators: these generators are represented in the Cambium workflow as having monthly energy budgets that are dispatched, respecting certain operational constraints, in order to minimize total system operational costs. Their treatment for the LRMER calculation is similar to energy storage, but with an additional step. Whereas energy storing generators cannot be the originating sources of energy, it is possible for energy-constrained generators to be. For example, an increase in dispatchable hydropower generation for a particular timestep could either come from a change in the dispatch of the same energy budget, or from more investment in hydropower capacity that results in the perturb run having a higher energy budget. If the increase came from more hydropower capacity, the generation should take the characteristics of the hydropower generation itself. If the increase came as a consequence of decreasing generation in a different hour, the mixture of generation that is induced by the otherhour decrease should be assigned to the hydropower generation.

Therefore, for energy-constrained generators, we first sum the monthly generation for each technology type between the Base and Perturb solves, calculate the difference, and reflect any increase in the allocation of that technology's generation $\left(\Delta g_{g, t,+}\right)$. For example, if the monthly generation from hydropower in a particular GEA region increased by $100 \mathrm{MWh}$ between the Base and the Perturb solves, and the summation of all increases from that technology (i.e., $\Delta g_{g, t,+}$ summed for the month, where $t$ corresponds to hydropower) equal $200 \mathrm{MWh}$, then we apply that fraction (0.5, in this example) to the generation and allocate it using the $\omega_{g-l}$ factors from step 2. The remaining component of $\Delta g_{g, t,+}$ must be differently-dispatched energy from the same budget, and is treated the same as energy storage, where it is assigned the monthly mixture from the originating region (but without an efficiency loss, since it is just re-dispatch, not charging and discharging). Conceptually, this is an approximation of the mixture that must have been induced to cover the re-dispatch of any energy-constrained generation.

For both of these technology classifications, it would likely slightly improve the answer if the replacement mixtures were derived based on the charging patterns (for storage) or based on the hours where the re-dispatch was drawn from (for the energy-constrained technologies). This step was not implemented in Cambium at this time because of time constraints.

During step 2, we mentioned that calculated busbar loads used for power flow allocations can be lower in the Perturb run then the Base run, despite the fact that the end-use load is always greater in the Perturb runs. As this only occurs when there was a large charging load in the Base run that was reduced significantly in the Perturb run, we know that the end-use load increase was, in 
effect, met by either charging a storage device in a different hour, or not charging it altogether. In either case, it would have been necessary for different generators to increase their generation during different hours, to enable such behavior. Therefore, we approximate the mixture that serves those hours with the same monthly average mixture that was used for storage and energyconstrained generators explained previously in this section.

\section{Step 4: Calculate the LRMER and Adjust to Respect State Policies}

Steps 2 and 3 produce a received generation mixture $\Delta g_{l, t, n e t}$ for each GEA region that is based on the physical flow of power and assuming perfect mixing through each node. In the presence of state policies, such as clean energy portfolio requirements, it may be necessary to take further action capture the effects of the policy.

To determine if further action is necessary, after completing Step 3, we calculate state-level mixtures by combining the GEA region mixtures, weighted by the how much load from each state is located within each GEA mixture. The emissions intensity of those received generation mixtures is calculated, based on the fuel consumption associated with those mixtures and implementing the fuel-specific emissions rates given in Section 5.2.

Portfolio standards and national carbon policies are handled sequentially in Cambium. We will first describe the treatment of portfolio standards.

States are sorted by whether their allocated mixtures either meet their most stringent portfolio standard, or fail to meet it, based on the fraction of qualified generation that was originally allocated to it. For any states with a shortfall (i.e., whose receiving generation mixtures would not be incompliance with their portfolio standard), the fraction of their generation that would have to be offset in order to be in compliance is calculated. The original emissions intensity for each hour is then decreased by that fraction. Note that this implicitly makes the assumption that all emitting generation during all hours of the year is equally offset by accounting transfers.

The sum of all emissions subtracted in this way is calculated, and then allocated to all states that had an excess of clean generation. The emissions are added based on the fraction of non-emitting generation in each hour (e.g., an hour with 100\% clean generation would be allocated twice as much emissions as an hour with $50 \%$ clean generation).

Note that, in practice, these transfers would likely be more specific - e.g., a wind generator in a particular state may be selling all of its renewable energy credits to a utility in a neighboring state. Both the fractional decreases and subsequent reallocation of emissions in Cambium implicitly assume an averaged treatment - all emitting generation is equally offset in states with a shortfall, and all non-emitting generation in states with an excess is assumed to contribute towards covering those shortfalls.

The treatment for national carbon policies is similar, and explained next.

First, it should be noted that, for the purpose of LRMER calculations, the national carbon policies in the 2021 Cambium release are interpreted as being enforced at the state level for $\mathrm{CO}_{2}$ from direct combustion, with unlimited and unrestricted trading credits allowed between states. This means that, while the in-region generation mixtures of different states may be decarbonizing 
at different rates, the ultimate emissions rate of received generation (including accounting transfers) for each state will be the same (unless there is a state portfolio standard that is more stringent then the national carbon policy).

Given this, states are therefore sorted into whether their receiving mixture is either above or below the national average $\mathrm{CO}_{2}$ rate from direct combustion, less any direct air capture of $\mathrm{CO}_{2}$.

For each state with an emissions intensity above threshold the annual fraction of generation that would have to be covered by a transfer to make it in compliance is then calculated $\left(f_{c o 2, c}\right)$. A second fraction $\left(f_{\text {else }}\right)$ is then calculated, which is $f_{c o 2, c}$ but reduced by the fraction of incremental emissions (between the Perturb and Base runs for the year under consideration) covered by direct air capture. For example, if a state would need to have $10 \%$ of its generation covered to make it in compliance, but $40 \%$ of incremental $\mathrm{CO}_{2}$ emissions from direct combustion is covered by direct air capture, then $f_{\text {else }}$ would be 0.06 . Each hour's emissions intensity for each state with a shortfall is then reduced by the corresponding fraction $-f_{\text {co } 2, c}$ for $\mathrm{CO}_{2}$ from direct combustion, and $f_{\text {else }}$ for all other emission types.

As with the treatment of portfolio standards, emissions are then added to states whose annual emission rate is lower than the policy requires. A calculation ensures that the added emissions would not bring a state out of compliance with its portfolio standards, if it has any.

\section{Step 5: Calculate a Rolling Average LRMER}

For the published Cambium databases, the LRMER values undergo a penultimate step in which a rolling average is calculated for each hourly value, taking the simple average of the emissions rate calculated through step 4 for the year under consideration plus its neighboring solve years (e.g., the hourly values for 2030 are the simple average of that hour's value for 2028, 2030, and 2032). This averaged value, after the adjustment for distribution losses in Step 6, is the value reported in the published Cambium databases.

This averaging is performed because the underlying data comes from system-wide least-cost optimization models, which can sometimes see rapid shifts in their solutions year-to-year. E.g., changing technology costs can result in a region building predominately solar capacity in one year and predominately wind capacity in the following year. While these shifts capture important trends, they can appear to be misleading precise because 1) often the changes happen more rapidly in the models than might be expected in practice and 2) the inputs into the models are generally not accurate enough to predict exactly which year such a shift might happen. Averaging the results in this way is an acknowledgement of one of the limitations of the underlying models, and a practical approach to mitigating the associated problems.

\section{Step 6: Adjust the LRMER for Distribution Losses}

As the LRMER is currently most commonly used for assessing emissions associated with changes in end-use load, the published values are reported as kilograms or grams of emissions per MWh of end-use load. This is achieved by taking the hourly value from step 5 and inflated it based on the marginal distribution loss rate. If a user wishes to apply the LRMER to a change in load or generation at the busbar level, they can unwind the distribution loss impact as described in Section 4.1. 


\section{How To Use the Year-over-year LRMER Data}

Cambium databases give LRMER data biennially through 2050. For some analyses, it may be appropriate to utilize a single year's worth of data, if knowing a consequence of a change in load in that specific year is desired. For most applications, however, it would likely be more appropriate to either average or levelize the year-over-year LRMER data for the lifetime of the intervention they are analyzing. ${ }^{17}$

When performing this average or levelization, note that each reported Cambium year covers the nominal year as well as the preceding year. For example, the values for 2024 also cover 2023. Therefore, if an analysis is being done of an intervention that would be introduced in 2024 and last for 10 years, the average or levelization would draw from the nominal years of 2024 through 2034, where the 2034 data is utilized for the final analysis year of 2033.

Levelization is the process of using a discount rate to give greater weight to near-term years then years further out. Said differently, levelizing with a positive discount rate it is effectively stating that if damages from emissions were to occur, it would be preferable to have them occur later rather than sooner.

The equation for levelizing the LRMER for a particular unit of time $h$ (e.g., an hour, a time-ofday, a month-hour, or a year) is given below, where $n$ is the number of years used for the analysis horizon (often an expected lifetime of the intervention being analyzed) and $d$ is a social discount rate. Because the underlying weather and weekday/weekend patterns are the same across the years of a Cambium database, it is coherent to levelize hourly values. Note that if a social discount rate of $0 \%$ is selected, the equation becomes a simple average, which is potentially valid if the analysis is intended to have no preference for when emissions occur.

$$
L_{R M E R_{h, \text { levelized }}}=\frac{\sum_{t=0}^{n-1}\left(\frac{L R M E R_{h, t}}{(1+d)^{t}}\right)}{\sum_{t=0}^{n-1}\left(\frac{1}{(1+d)^{t}}\right)}
$$

\section{Weather Alignment}

The LRMER data, as with all Cambium data, is created using 2012 weather patterns, which influence electricity demand shapes and renewable energy resource quality. If using the hourly data, it is strongly recommended to ensure that other inputs into an analysis also use 2012 weather (e.g., a building energy model should use 2012 weather inputs), otherwise the misalignment of assumptions could cause inaccuracies.

If it is not feasible or desirable to use 2012 weather patterns for an entire analysis, it may sometimes be preferable to utilize either the month-hour or time-of-day temporal aggregations that are provided in the Cambium data sets. These aggregations retain much of the diurnal and

\footnotetext{
17 This statement implicitly assumes that an analysis is being conduced using a single year to characterize a multiyear intervention, as is common. If an analysis is characterizing a multi-year intervention by explicitly analyzing each year, then it would generally be appropriate to directly use the year-over-year LRMER data without averaging or levelization.
} 
seasonal trends while removing specific short-duration weather-driven patterns that might cause meaningful inaccuracies if misaligned with other weather data.

\section{Treatment of National Decarbonization Scenarios}

The 2021 Cambium data release included two scenarios with national decarbonization trajectories (the Mid-case with 95\% decarbonization by 2050 and Mid-case with $95 \%$ decarbonization by 2035). The representation of these scenarios in ReEDS is described in the 2021 Standard Scenarios report (Wesley Cole et al. 2021). Here we describe how the scenarios were treated during the calculation of the LRMER.

First, it is important to note that although the decarbonization trajectory was expressed as an absolute mass-based constraint in ReEDS (i.e., each year had an upper limit on the annual mass of direct carbon dioxide emissions in metric tons), that constraint was interpreted as a rate-based constraint when the Perturb runs were performed for the LRMER derivation. This was done by calculating the tons/MWh annual average emissions rate from the corresponding year's Base run, and then increasing the carbon dioxide cap in the ReEDS Perturb run for that year. For both the Base and Perturb PLEXOS runs, the shadow price on the annual carbon constraint from ReEDS was applied as an adder to any emitting technologies based on their emission rates.

This interpretation of the decarbonization scenarios results in LRMER values (in both magnitude and temporal patterns) that are closest to what might be seen under a policy such as a carbon tax or support for non-emitting generators. Importantly, the magnitude and pattern of the LRMER could take meaningfully different forms under different policy designs. For example, a policy that capped the total mass of emissions would result in a LRMER of zero - any change in electric demand would not result in a change in emissions (as long as the cap was binding, and only for the type of emission being capped). As a different example, a policy that capped emissions on a rate basis (i.e., the allowed mass of emissions being based on the quantity of electricity sales) would be non-zero, but likely not have a time-varying pattern, as any change in electric demand would effect a change in emissions at the specified rate regardless of the timeof-day. Note that both of these policy approaches would have time-varying policy-driven costs that might be obscured if not conveyed in tandem with the LRMER values.

Secondly, although the decarbonization policies are described as national decarbonization policies, they are interpreted here as state-level policies where every state is following the same rate-based decarbonization trajectory but unlimited and unrestricted unbundled trading of emissions credits are allowed. This manifests as the accounting transfers described in Step 4 of the LRMER methodology described above.

\section{Caveats and Limitations}

The LRMER methodology described here has several know limitations:

- Geographic disaggregation: The method described here takes a pair of nation-wide model runs and disaggregates the resulting data into GEA regions, and then ultimately states. This would likely produce at least slightly different results then some equally defensible alternative approaches (such as perturbing each state's load in its own separate model run, which is not feasible due to the computational costs of performing model 
runs). Further research into the consequences and methodologies around the geographic disaggregation is warranted.

- Interdependency of Hours: We treat each hour as independent, but the equilibrium build-out of the power sector is influenced by the combined shape of increasing demand across hours, and operational constraints of the electric sector means the dispatch in one hour can influence the dispatch in another hour. Ultimately, this means that Cambium's hourly LRMER values (which were derived from model runs that scaled up load in all hours equally) are only estimates of the change in emissions from changes in load that follows different hourly patterns.

- Power Flow Allocation: As discussed in the power flow coloring section (Section 5.3), our power flow allocation method just assumes perfect mixing of power through each node and therefore does not capture relevant restrictions or modifications of the actual allocation one might give to the power flows. For example, restrictions on the amount of generation from coal plants that can be imported into California would not necessarily be respected. Cross-state contracts for electricity bundled with RECs, for renewable portfolio standard compliance, might also not be captured.

- Year-Over-Year Values: For Cambium databases, we calculate these LRMER values for every other year based on a perturbation of load during that year. The intention is that analysts would apply these year-over-year values for the duration of the intervention they are analyzing (e.g., an analysis of an asset with a 10-year lifetime starting in 2020 would incorporate the five values from 2020 through 2028). The accuracy of using year-overyear values to estimate the lifetime impacts of interventions has not been explicitly studied.

- Transmission Losses: Our method does not currently accurately capture the effects of transmission losses, because those losses are represented as a load, which dilutes the actual emission rate induced by an increase in load.

- Unknown elasticity: Our method produces a single LRMER based on model runs that perturbed end-use load by $5 \%$. The sensitivity of LRMER values to different levels of perturbation (e.g., decreases in load or significantly larger increases) has not been rigorously studied.

This is an ongoing area of research, and we expect improvements to these methods to continue for some time.

\subsection{Identifying a Region's Short-run Marginal Generator}

The short-run marginal generator, for a particular location and time, is the generator whose output would increase if there were a marginal increase in demand at that location and time. ${ }^{18}$

\footnotetext{
${ }^{18}$ Note that, in Cambium, we differentiate between the marginal generator and the marginal energy source. The marginal generator is the generator that would provide the power to cover an increase in load, at the moment when the load is increased. If the marginal generator does not have the ability to create energy (e.g., an electric battery), a different generator must ultimately increase its generation at a different time for the battery to be the marginal generator. The marginal energy source refers to that generator. See Section 4.3 for a more information.
} 
For several of the metrics reported in Cambium databases (e.g., the short-run marginal emission rate), it is necessary to identify which generator is the marginal generator. ${ }^{19}$

Unfortunately, the marginal generator is not a native output of the PLEXOS runs that Cambium draws from. It is therefore necessary for us to analyze the PLEXOS results to make reasonable judgements as to which generator was likely the marginal generator for each node during each time-step. In this section, we describe our method for doing so, which follows these five steps:

1. Identify balancing areas (BA) that share a marginal generator (T-regions)

2. Identify T-regions with dropped load

3. Evaluate non-energy-constrained generators

4. Evaluate energy-constrained generators

5. Reevaluate non-energy-constrained generators, with relaxed filters.

Step 1: Identifying Regions That Share a Marginal Generator (T-Regions) in Each Hour We run PLEXOS with inter-BA transmission represented as pipe flow with fixed loss rates. Given this, and knowing that the solution is a least-cost optimization, we assume any set of BAs that are connected by partially utilized transmission lines share a marginal generator during that hour. Working with this assumption, we identify all partially utilized transmission lines during each time-step, and we then identify all groupings of BAs that are connected by those lines. ${ }^{20}$ Because we weren't feeling particularly creative on the day we first did this, we gave these groupings of BAs the uninspired name of "transmission connected regions," using the shorthand T-regions.

The BAs that make up T-regions - and therefore the BAs we assume share a marginal generator-shift every time-step. A single BA can often be its own T-region, although it is also common for them to be large, covering dozens of BAs.

\section{Step 2: Identifying T-Regions with Dropped Load}

After identifying T-regions, we find which ones have dropped load. These T-regions will not have a marginal generator, so we label them as such.

\section{Step 3: Evaluating Non-Energy-Constrained Generators}

Having identified BAs we assume share a marginal generator for a given time-step, we try to estimate which generator in those BAs is the marginal generator. We first identify all the generators that were generating in those BAs at that point in time. We then filter out generators that are:

\footnotetext{
${ }^{19}$ Much of the published research on short-run marginal emission rates takes an empirical approach (Siler-Evans et al. 2012), often deriving marginal emission factors based on the changes in generation mixtures between sequential hours in data from system operators. We take the approach of identifying the marginal generator from our simulations, to maintain consistency with other metrics being reported by Cambium. Though we do maintain consistency, the simulation-based method is highly sensitive to the accuracy and peculiarities of the dispatch model being used.

${ }^{20}$ For our implementation we use the undirected graph capabilities of the python-based networkx package.
} 
- At their minimum generation levels.

- At their maximum generation levels ${ }^{21}$

- Ramping their energy generation as fast as they can, relative to either the previous or the following hour

- Energy-constrained generators, which we evaluate later in step $4 .{ }^{22}$

We assume any generator that passes these filters is more likely to be the marginal generator at that time than the generators that were filtered out. Often, only a single generator passes the filters, which is consistent with a least-cost dispatch of the grid. In that case, we select that single generator as the marginal generator for that T-region.

If multiple generators are curtailing ${ }^{23}$ we select the curtailing generator with the greatest noncurtailed generation during that time-step, and we designate that generator as the marginal generator. If there are multiple generators and none of them is curtailing, we find the one whose short-run marginal cost (SRMC) is closest to the average marginal energy cost across that Tregion, and we designate that generator the marginal generator for that T-region.

\section{Step 4: Evaluating Energy-Constrained Generators}

In many instances (often in around half the T-regions), no generators make it through the filters listed in Step 3. In these T-regions, the marginal generators must be an energy-constrained generator: either an energy-constrained generator that is discharging (in which case it could discharge more to serve a marginal increase in demand) or an energy-constrained generator that is charging (in which case it could charge less to free up power to serve a marginal increase in demand).

For T-regions where no marginal generator was identified in Step 3, we estimate the short-run marginal cost (SRMC) of all the energy-constrained generators that are actively charging or discharging - but not at their maximum rates. Because the energy-constrained generators cannot produce additional power, but rather only shift it, their SRMC is estimated by finding a nonenergy-constrained generator that could have increased its output in a different time-step to allow the energy-constrained generator to have more available energy during the time-step being evaluated. The SRMC of the energy-constrained generator is set by the SRMC of the nonenergy-constrained generator, modified by any relevant transmission and efficiency losses. For a detailed explanation of how this is done, see Section 5.6.

Energy-constrained generators can form "chains" (e.g., a battery can charge from another battery that is ultimately charging from a thermal generator). To capture this potential, we iterate over

\footnotetext{
${ }^{21}$ For variable generators like wind and solar, this is the maximum output that they can generate during that hour, given the weather conditions - not their nameplate capacity. A variable generator would only be below its maximum generator level if it is curtailing.

${ }^{22}$ Technologies such as batteries and pumped hydro storage (which cannot ever create new electricity, only shift it around) are always energy-constrained. Technologies like dispatchable hydropower CSP with thermal energy storage - which have fixed budgets of energy flowing into them - are typically energy-constrained (if, in our PLEXOS dispatch, they dispatched all the energy that was available to them), but also can be classified as nonenergy-constrained (in the more rare occurrences where they did not expend all of their available energy).

${ }^{23}$ This can happen because the solution is degenerate when curtailment is happening.
} 
Step 4 several times to try to identify pathways where energy-constrained generators are chaining with other energy-constrained generators.

Once we have estimated the SRMC of all the energy-constrained generators in each of the Tregions being evaluated in this step, we find the one with the SRMC closest to the average marginal energy cost in each T-region, and we designate that as the marginal generator.

\section{Step 5: Filling in Any Remaining Regions by Relaxing Filters}

Once we have evaluated both energy-constrained and non-energy-constrained generators, and we have identified T-regions with dropped load, we find all the T-regions in which we have not identified a marginal generator. This is always the case for at least a small number of T-regions at this point.

For these T-regions, we repeat Step 3 (evaluating non-energy-constrained generators), but without filtering out generators at their minimum generation levels. If there are multiple such generators, we select the one whose SRMC is closest to the average marginal energy cost in the T-region. In this way, we are selecting a generator that was committed and generating at that time, and which has generation capacity remaining.

For any remaining T-regions that still do not have a designated marginal generator, we again repeat Step 3, but without filtering out any generators for minimum or maximum generation levels or for ramping. Doing so identifies a generator that is committed and generating.

\section{Caveats and Limitations}

In addition to the general caveats discussed in Section 2, our current approach for identifying marginal generators has three significant limitations:

- Because the marginal generator is not a native output of a solution to a production cost model, our method relies on trying to post-process the results and identify which generator would most likely have been the marginal generator at any point in time. Although it is clear what the marginal generator is at some points in time, it is less clear at many other points, particularly when energy-constrained generators are involved. Our method is likely not perfectly accurate in finding the marginal generator.

- Even when the marginal generator for the PLEXOS solution is correctly identified, whether the result matches real-world marginal generator patterns depends on how well the PLEXOS solutions match real unit commitment and dispatch decisions. Because we run PLEXOS as a system-wide least-cost optimization without forecast error, the PLEXOS dispatch is likely deviating from dispatches in practice, potentially in important ways. Often, for example, PLEXOS leverages energy-constrained generators to avoid starting up thermal generators in a way that is potentially too precise and would not be realized in practice. Characterization of the results of this method against real-world marginal generator practices is an ongoing effort.

- Relative to other metrics that we report, the identification of the marginal generator is highly sensitive to changes in demand. Therefore, these marginal generator patterns are likely inappropriate for analyses that assume there are significant quantities of load that is being shifted in reaction to what generator is on the margin; for example, if tens of 
megawatts of electric vehicle charging was timed to try and minimize how much charging was done when coal was on the margin, that would likely be enough to meaningfully change the patterns of which technologies are on the margin at what times.

Altogether, as we have mentioned, we recommend analysts approach these marginal generator patterns with a critical eye, as we work to improve our understanding of the quality and usefulness of these modeled results.

\subsection{Identifying the Energy Source When an Energy-Constrained Generator is on the Short-run Margin}

For some analyses, we are interested in identifying the effects of marginally increasing demand at a particular location and time. For example, the short-run marginal emission rate tells us what the increase in short-run emissions would be if demand were marginally increased. The first step in this process is identifying the marginal generator, as we discussed in Section 5.5.

For most generators that are the marginal generator, we have the information we need. If a natural gas generator is the marginal generator, for example, a marginal increase in demand would induce more generation from that generator, and we can calculate the metrics we are interested in.

For generators that are energy-constrained - meaning they cannot create their own energy (e.g., batteries or pumped hydro storage) or they have a constrained energy budget (e.g., dispatchable hydropower or CSP with thermal energy storage) - the treatment is more complicated. ${ }^{24}$ Because such generators cannot create new energy, any actions by them must induce a different generator (one that can create new energy) to increase its generation at a different point in time. If we wish to know the effects of increasing demand when an energy-constrained generator is on the margin, we must therefore also identify the non-energy-constrained generator that would be induced to increase its generation as a result of the increase in demand.

In Cambium, we use the terms marginal generator and marginal energy source to describe these two generators. In this section, we describe how we try to identify the marginal energy source when the marginal generator is an energy-constrained generator.

Consider, for example, trying to determine the short-run emissions impact of increasing demand when an electric battery is on the margin. Because the electric battery cannot create new energy, but can only shift energy, we know that our increased demand from the battery must result in a different generator - one capable of creating energy - increasing its generation in a different hour, to enable the electric battery to be a marginal generator during the hour we are increasing demand. If, by demanding more energy from the battery, a coal plant would increase its

\footnotetext{
${ }^{24}$ Technologies such as batteries and pumped hydro storage (which can never create new electricity, but only shift it) are always energy-constrained. Technologies like dispatchable hydropower CSP with thermal energy storage, which have fixed budgets of energy flowing into them, are typically energy-constrained (if, in our PLEXOS dispatch, they dispatched all the energy that was available to them), but they also can be classified as non-energyconstrained (in the more rare occurrences where they have not expended all their available energy). Therefore, whether a generator is energy-constrained is not an immutable characteristic of the generator; it also depends on how it was dispatched.
} 
generation in a different hour, and that would clearly lead to a different emissions impact than if a natural gas plant increased its generation.

This is one example of a general situation: If an energy-constrained generator is on the margin, we must find out which source-energy generator would increase its generation, at a different point in time, to enable the energy-constrained generator to increase generation. The characteristics of the source-energy generator, modified by relevant transmission and efficiency factors, define the implications of increasing our demand during the hour when the energyconstrained generator is on the margin.

For Cambium, we developed a method for identifying the source-energy generator that would most likely increase its generation, if an energy-constrained generator is the marginal generator. Our method is specifically designed to interpret the results from a production cost model: postprocessing a given pattern of unit commitment and dispatch to identify the marginal sourceenergy generator for every energy-constrained generator. Although many of the concepts here likely transfer to similar situations in real-world dispatch, we discuss only the interpretation of simulated dispatches in this section.

Our method for identifying the source energy generator for an energy-constrained marginal generator is:

1. Identify the span of time the energy-constrained generator could have obtained more energy: its "opportunity window"

2. Reduce the span of the window if it extends beyond what is reasonable for the scheduling and forecasting assumptions of the run under consideration (e.g., restrict the window to $+/-24$ hours from the time-step being analyzed)

3. Remove all time-steps where the energy-constrained generator is already charging fully

4. Remove all time-steps when no generator is available that could increase its own generation, to either charge the energy-constrained generator or cover its reduced discharge

5. From the remaining time-steps, calculate efficiency and transmission adjustments, to determine the energy-constrained generator's SRMC if it drew from that time-step

6. Select the time-step (and associated generator) with the lowest resulting SRMC

7. Calculate derivative values, such as marginal emission rates.

Here we explain our method for this with a toy example: an electric battery that is charging and discharging over a 20-hour period. The battery's charging and discharging patterns, and its stateof-charge, are shown in Figure 4. The battery has a maximum charge and discharge rate of $1 \mathrm{MW}$ and a maximum energy storage level of $2 \mathrm{MWh}$. The battery has a round-trip efficiency of $80 \% .^{25}$

\footnotetext{
${ }^{25}$ For the sake of simplicity in this toy example, we apply all the losses during charging, and we treat the charge and discharge limits as limits to the rate of change of the battery's energy level. Increasing the stored energy level by 1 MWh requires $1.25 \mathrm{MWh}$ of consumed energy, for example, and is shown as a 1-MW rate of charging in the figures.
} 
For this example, we evaluate the battery's behavior assuming it was identified as the marginal generator during the $11^{\text {th }}$ hour, as indicated with the shaded area in Figure 4 (page 51). Because the battery itself cannot create energy, we want to identify the source-energy generator that would have increased its generation in a different time-step, in order for the battery to have the energy required to be the marginal generator during the $11^{\text {th }}$ hour. Doing so allows us to calculate the implications of a marginal increase in demand during the $11^{\text {th }}$ hour, such as the short-run marginal emission rate.

For the battery to marginally increase its output during the $11^{\text {th }}$ hour, one of two things must happen: the battery must either enter the $11^{\text {th }}$ hour with a marginal amount more energy or exit the $11^{\text {th }}$ hour with a marginal amount less energy. These actions would then necessitate the battery either charging more or discharging less during a different hour. For the method we are discussing here, we assume this action could have happened either before or after the $11^{\text {th }}$ hour; in other words, we assume the increased demand (relative to the original system dispatch) during the $11^{\text {th }}$ hour was anticipated and system operators could have planned accordingly. If we wanted to analyze the implications of an unexpected increase in demand, this method would have to be modified, but we do not explore that scenario here.

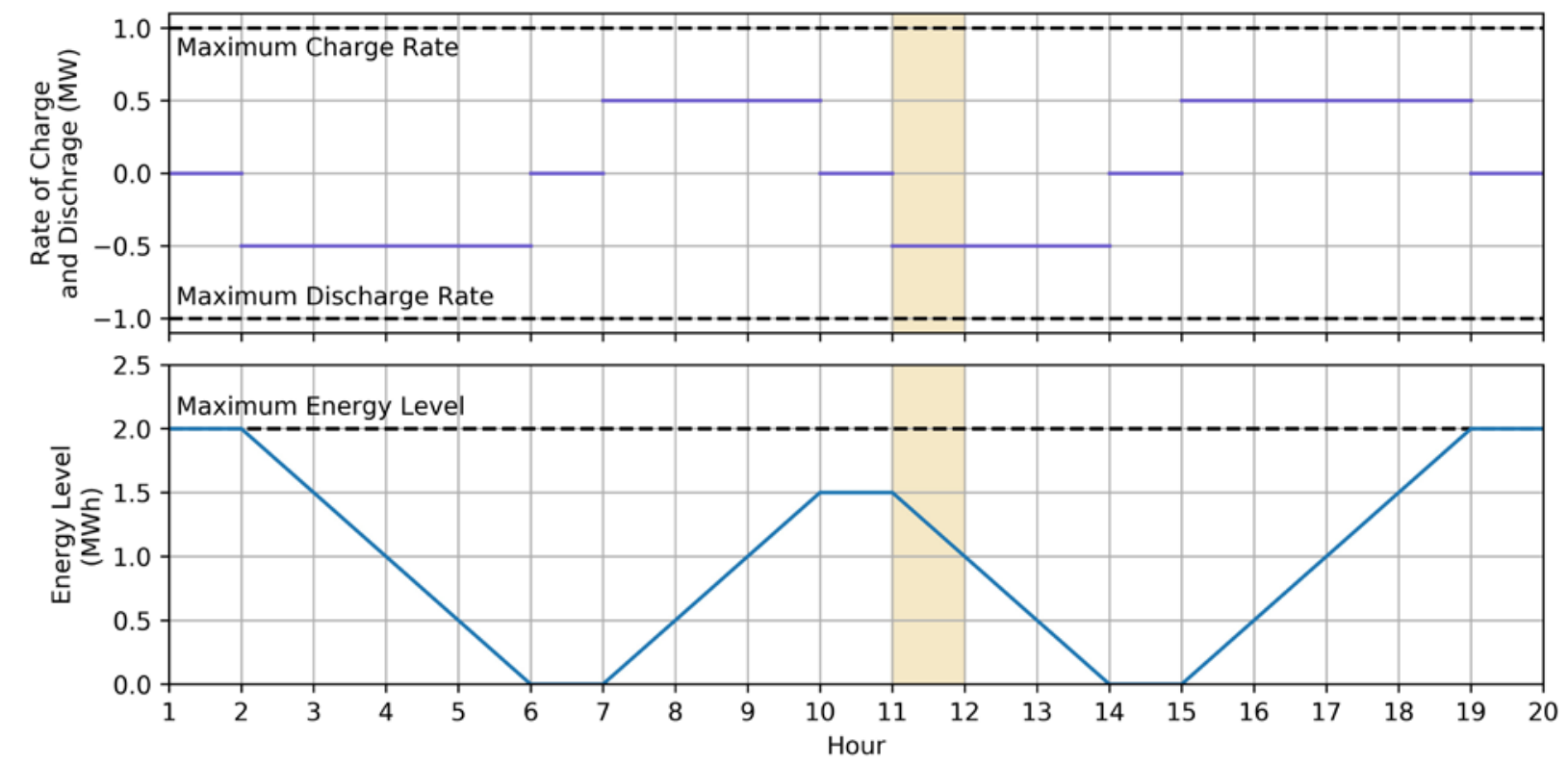

Figure 4. Charge and discharge patterns of an electrical battery

Looking before the $11^{\text {th }}$ hour, we see that the battery could have obtained a marginal increase of energy at any point after the end of the $1^{\text {st }}$ hour. Before the end of the $1^{\text {st }}$ hour, however, it could not have obtained more energy and held it until the $10^{\text {th }}$ hour, because the battery was already full during the $1^{\text {st }}$ hour. A similar approach could be taken looking after the $11^{\text {th }}$ hour: the battery could exit the $11^{\text {th }}$ hour with an energy deficit and make it up at any point before the 
beginning of the $14^{\text {th }}$ hour. However, once the $14^{\text {th }}$ hour is reached, the battery becomes depleted, and it therefore could not hold the deficit beyond that point. ${ }^{26}$

We illustrate these bounds in Figure 5. In the top panel of the figure, the $11^{\text {th }}$ hour shows a marginal discharge, because that is the hour in which the battery is assumed to be on the margin. Starting at the beginning of the second hour and until the end of the $13^{\text {th }}$, the shaded area shows the span in which the battery would have been able to increase its stored energy, to enable the increased discharge during the $11^{\text {th }}$ hour.

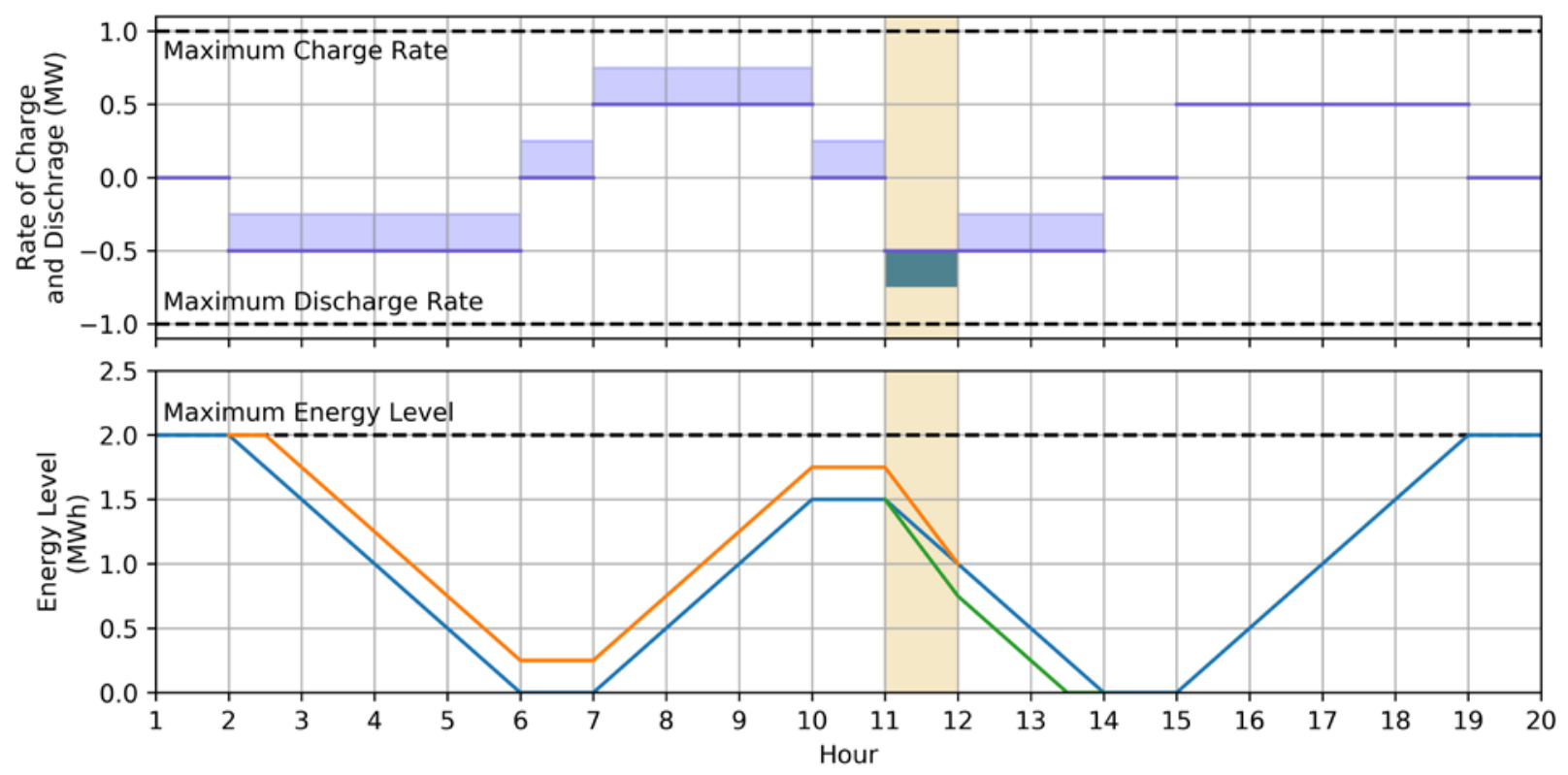

Figure 5. Example of an "opportunity window" for an electric battery

At first thought, it may seem like we are looking only for opportunities for the battery to charge (i.e., obtain more energy that it could then discharge during the $11^{\text {th }}$ hour). However, this is not the case, because the increased energy does not always need to pass through the battery. For example, during the $2^{\text {nd }}$ through the $5^{\text {th }}$ hours and during the $12^{\text {th }}$ through the $13^{\text {th }}$ hours, the battery could simply have discharged less, thus reserving more energy for the $11^{\text {th }}$ hour. For this to happen, a different generator would still have to increase its generation - but importantly for our purposes, there is no round-trip efficiency penalty for the scenarios where the battery discharges less, because the energy is not actually passing through the battery.

In the lower panel of Figure 5, we can visually see the general rule: the battery's range of opportunity goes back in time as far as the most recent time that the battery was completely

\footnotetext{
${ }^{26}$ The assessment of these bounds illustrates a fundamental assumption of our approach: we make only marginal adjustments to the original dispatch of the battery. Clearly, the battery could be entirely redispatched differently to extend these bounds beyond the $1^{\text {st }}$ and $14^{\text {th }}$ hours; however, we assume that, if it were not cost-optimal to dispatch the battery in that manner initially, it would also not be cost-optimal to redispatch it in that manner for a marginal increase.
} 
full, and as far forward in time as the next time that the battery is completely empty. ${ }^{27}$ This establishes the bounds of an "opportunity window"-Step 1 in our list of steps given above (page 49) - which is the span of time in which the battery could either charge more or discharge less. In theory, this window could extend indefinitely. For Cambium databases, however, we restrict the windows to $+/-24$ hours from the hour in which the battery is the marginal generator, to reflect practical limits to dispatch scheduling (Step 2).

Having identified the opportunity window, we then filter out the hours during which the battery could not have actually drawn more energy (Steps 3 and 4).

First, we remove the hours where the battery was already charging at its maximum rate. If the battery were already charging as much as it could have, it clearly could not charge more.

Next, we remove the hours where we have not yet identified a marginal generator that could have increased its generation to either to charge the battery or cover the battery's reduced discharge. For a detailed discussion of the process by which we identify marginal generators, see Section 5.5. ${ }^{28}$

After applying those two filters, we end up with a set of hours where the battery is technically capable of charging and there is a generator that can either charge the battery or cover its reduced contribution. To identify which hour, and therefore which generator, would be called on, we calculate the short-run marginal cost (SRMC) of drawing from each hour.

When calculating the SRMC, four possible situations can occur, and each has different implications for applying an adjustment for the effects of efficiency. The four situations, shown in Table 3, are defined by what the energy-constrained generator is doing in (1) the time-step in which it is on the margin (the "anchor time-step") and (2) the time-step in which it would induce an increase in another generator (the "point time-step").

Table 3. Efficiency Adjustments

\begin{tabular}{|l|l|l|l|}
\hline $\begin{array}{l}\text { Anchor } \\
\text { Time-Step } \\
\text { Behavior }\end{array}$ & $\begin{array}{l}\text { Point } \\
\text { Time-Step } \\
\text { Behavior }\end{array}$ & Description & $\begin{array}{l}\text { Efficiency } \\
\text { Adjustment }\end{array}$ \\
\hline Charging & Charging & $\begin{array}{l}\text { Energy-constrained generator reduces its charging } \\
\text { during the anchor time-step and increases its charging } \\
\text { during the point time-step. }\end{array}$ & 1.0 \\
\hline Charging & Discharging & $\begin{array}{l}\text { Energy-constrained generator reduces its charging } \\
\text { during the anchor time-step and reduces its } \\
\text { discharging during the point time-step. }\end{array}$ & RTE \\
\hline
\end{tabular}

\footnotetext{
27 This is only for the situation where the battery is discharging during the hour that it is on the margin (i.e., we are considering the right-hand marginal). When the battery is charging (i.e., the left-hand marginal), the bounds are inverted: the prior bound is the most recent time the battery was empty, and the following bound is the next time the battery is full. We therefore have an interesting situation where the right-hand and left-hand marginals can be different. All Cambium values are currently generated for right-hand marginals.

${ }^{28}$ Typically, an hour will be missing a marginal generator if the marginal generator in that hour is itself an energyconstrained generator - for this reason, we must iterate through the steps we are describing here, to find the situations where energy-constrained generators chain off of each other.
} 


\begin{tabular}{|l|l|l|l|}
\hline $\begin{array}{l}\text { Anchor } \\
\text { Time-Step } \\
\text { Behavior }\end{array}$ & $\begin{array}{l}\text { Point } \\
\text { Time-Step } \\
\text { Behavior }\end{array}$ & Description & $\begin{array}{l}\text { Efficiency } \\
\text { Adjustment }\end{array}$ \\
\hline Discharging & Charging & $\begin{array}{l}\text { Energy-constrained generator increases its discharge } \\
\text { during the anchor time-step and increases its charging } \\
\text { during the point time-step. }\end{array}$ & $1 /$ RTE \\
\hline Discharging & Discharging & $\begin{array}{l}\text { Energy-constrained generator increases its discharge } \\
\text { during the anchor time-step and reduces its discharge } \\
\text { during the point time-step. }\end{array}$ & 1.0 \\
\hline
\end{tabular}

RTE is the round-trip efficiency of the energy-constrained generator.

To better understand the contents of Table 3, and to show how the efficiency adjustment is applied (Step 5), we return to our toy example. We assume the only hours that had available generators were the $8^{\text {th }}$ hour and the $12^{\text {th }}$ hour. Because the battery is discharging during the anchor time-step, these hours correspond to the discharging-charging and dischargingdischarging situations respectively. To put some numbers on our example, we assume the battery was called on to discharge $0.25 \mathrm{MWh}$ during the $11^{\text {th }}$ hour, that the SRMC of the marginal generator in the $8^{\text {th }}$ hour was $\$ 10 / \mathrm{MWh}$, and the SRMC of the generator in the $12^{\text {th }}$ hour was $\$ 11 / \mathrm{MWh}$. As mentioned before, the round-trip efficiency of the battery is assumed to be $80 \%$.

If the battery increased its stored energy during the $8^{\text {th }}$ hour, it would have to increase its rate of charging. Therefore, the marginal generator in that hour would have to generate $0.3125 \mathrm{MWh}$ more, for a cost of $\$ 3.125$. Because of losses in the battery, the delivered $0.25 \mathrm{MWh}$ would have an effective SRMC of $\$ 12.5 / \mathrm{MWh}$, which is the SRMC of the marginal generator in the point time-step multiplied by the efficiency adjustment of 1/RTE. ${ }^{29}$

Looking to the $12^{\text {th }}$ hour, we see that because the battery was already discharging, it could increase its stored energy by simply discharging less, not charging more. Therefore, the 0.25 MWh of energy could be provided to the $11^{\text {th }}$ hour at a cost of $\$ 2.75 / \mathrm{MWh}$. This is an effective cost of $\$ 11 / \mathrm{MWh}$, which is the SRMC of the marginal generator in the point time-step multiplied by the efficiency adjustment of 1 ; in other words, there was no efficiency penalty, because the additional energy did not pass through the battery.

Of the two hours being considered, the costs are lower if the battery draws from the $12^{\text {th }}$ hour, and therefore we assume it would do so (Step 6). Note that the SRMC of the marginal generator in the $12^{\text {th }}$ hour was greater than the SRMC of the marginal generator in the $8^{\text {th }}$ hour, but because the energy from the $8^{\text {th }}$ hour would have had to take an efficiency penalty, the $12^{\text {th }}$ hour was the lower-cost solution.

If the marginal generator in the hour that was selected is a source-energy generator, we have the information we want: the characteristics of the source-energy generator will allow us to calculate the impacts of a marginal increase in demand during the $11^{\text {th }}$ hour (after applying the same transmission and efficiency adjustments that we previously used for the SRMCs).

\footnotetext{
${ }^{29}$ If transmission losses would occur as a result of the energy-constrained generator drawing from this hour, the SRMC of the marginal generator in that hour should also be modified by the transmission losses. For this example, we assume there are no transmission losses.
} 
If, however, the marginal generator is another energy-constrained generator, we have a chain, and we must follow the chain until we ultimately reach a source-energy generator. When deriving values for Cambium databases, we iterate over this step several times, to identify these chains.

\subsection{Calculating Time-Varying Distribution Loss Rates}

Both ReEDS and PLEXOS balance load and generation at the busbar level (i.e., before distributing electricity to end users). However, Cambium databases include end-use values, so to get end-use metrics from busbar metrics, we need time-varying distribution loss rates.

Our method for calculating both average and marginal hourly distribution loss rates draws primarily from Borenstein and Bushnell (2019). As in their work, we assume $25 \%$ of annual distribution losses are fixed losses that do not vary with load (e.g., losses in transformers), and $75 \%$ are resistive losses that scale with the square of the flow on a line.

We assumed that the annual average distribution loss rate is $3.6 \%$ for each BA. This was derived by taking the national average Grid Gross Loss from eGRID data for 2018 (EPA 2020) (which includes all forms of losses), performing a ReEDS model run for 2018 and calculating a loss rate from that run for non-distribution losses, and subtracting those from the eGRID Grid Gross Loss rate.

We start by calculating the total annual fixed $\left(L_{f, a}\right)$ and variable $\left(L_{v, a}\right)$ losses for each BA as a function of the annual busbar load consumed for end uses $\left(Q_{b, a}\right)$, the aforementioned no-load loss fraction $(\pi)$ and annual loss rate $\left(r_{a}\right)$.

$$
\begin{gathered}
L_{f, a}=Q_{b, a} * r_{a} * \pi \\
L_{v, a}=Q_{b, a} * r_{a} *(1-\pi)
\end{gathered}
$$

We then calculate an annual variable loss factor $f_{v, a}$ :

$$
f_{v, a}=L_{v, a} / Q_{b, a}^{2}
$$

We then calculate each BA's hourly variable losses $\left(L_{v, h}\right)$, using the annual variable loss factor $\left(f_{v, a}\right)$ and the hourly busbar load consumed for end uses $\left(Q_{b, h}\right)$ :

$$
L_{v, h}=f_{v, a} * Q_{b, h}^{2}
$$

The total hourly losses $\left(L_{t, h}\right)$ are then the sum of the hourly variable losses and one hour's worth of the fixed no-load losses:

$$
L_{t, h}=L_{v, h}+L_{f, a} / 8760
$$

We can then calculate each hour's average distribution loss rate $\left(\alpha_{h}\right)$ :

$$
\alpha_{h}=L_{t, h} / Q_{b, h}
$$


and each hour's marginal distribution loss rate $\left(\mu_{h}\right)$ as the derivative of the square of the hour's busbar load times the annual variable loss factor:

$$
\mu_{h}=Q_{b, h} * 2 * f_{v, a}
$$

\subsection{Calculating Hourly Marginal Capacity Costs}

The marginal capacity costs in Cambium are estimates of the costs of acquiring sufficient firm capacity to meet a system's planning reserve margin if there is a marginal increase in peak demand. The annual marginal cost of firm capacity is determined by our ReEDS model, which is then allocated to the highest net-load hours to produce an hourly marginal capacity cost pattern. We first explain how ReEDS determines the annual marginal cost of firm capacity, and we then explain how we allocate that value to specific hours.

\section{Calculating an Annual Marginal Cost of Firm Capacity with ReEDS}

ReEDS has a constraint that requires sufficient firm capacity to be procured in each balancing area (BA) to exceed a year's peak demand by a planning reserve margin (e.g., if the peak busbar demand in a BA is $100 \mathrm{MW}$ and the planning reserve margin is 0.15 , ReEDS will require 115 MW of firm capacity). ${ }^{30}$

The shadow price off of this constraint is the \$/MW-year marginal cost for obtaining additional firm capacity. ReEDS will find the least-cost option through three possible decision variables within the model:

- New Generation Capacity: Referred to as net cost of new entry (net CONE), the shadow price of the capacity constraint may be set by the annualized revenue needed to recover the costs of the generator that can provide firm capacity at the lowest cost, minus any revenue that generator could obtain by providing other services (e.g., energy or operating reserves). This is often a natural gas combustion turbine plant, although in certain regions it can also be variable resources like wind and solar, if their generation aligns well with peak demand. ${ }^{31}$

- New Transmission Capacity: If a neighboring BA has excess generation capacity, the shadow price of the capacity constraint may be set by the annualized cost of building additional transmission capacity, minus the revenue that the line would obtain from transmitting energy or operating reserve products.

\footnotetext{
${ }^{30}$ Planning reserve margins are heuristics for the amount of capacity required to maintain a desired level of reliability in the electric system. Probabilistic resource assessments and the associated metrics, like loss-of-load probabilities, can give a more accurate assessment of the reliability of an electric grid. Cambium relies on planning reserve margins, however, because of shortcomings in the integration of these more sophisticated methods into our capacity expansion models, particularly in the presence of large amounts of variable generation and storage generators.

${ }^{31}$ ReEDS assesses the ability of variable generators (wind and solar) to provide firm capacity through a net load duration curve approach. Doing so tends to result in variable generators being able to provide firm capacity in the near term, which eventually goes to zero as net load peaks shift away from times of peak variable generation. See (Ho et al. 2021) and the forthcoming documentation of the 2021 version of ReEDS for a more detailed discussion of this.
} 
- Delayed Retirement: ReEDS will choose to retire generation capacity if the capacity generator is not providing sufficient value to the system to cover its fixed costs (amplified by a multiplier to represent the "stickiness" of retirement). When this is happening, the shadow price of the capacity constraint can be set by the revenue that would have been required to keep that capacity online, minus the revenue it would have received for any other services.

Because of the prevalence of retiring generators, and the ability of wind and solar to contribute firm capacity, Cambium results in the 2020s often show capacity shadow prices that are substantially lower than what they would be if the shadow price were only being set by the net CONE of a natural gas combustion turbine.

If the capacity constraint in ReEDS is not binding, the shadow price on the constraint will be zero.

\section{Allocating the Annual Shadow Price to Individual Hours}

Having obtained an estimate of the annual marginal cost of additional firm capacity (i.e., the shadow price on the capacity constraint from ReEDS), we want to allocate that value to individual hours. Our method follows these steps:

1. Obtain each BA's shadow price $\left(\rho_{B A}\right)$ off of the annual capacity constraint in ReEDS. ${ }^{32}$

2. Multiply the annual shadow price by $(1+$ planning reserve margin $)$, to obtain the marginal cost of procuring the firm capacity that would be required by an increase in peak busbar load $\left(\delta_{B A}\right):^{33}$

$$
\delta_{B A}=\rho_{B A} *\left(1+p r m_{B A}\right)
$$

3. Calculate the hourly net load $\left(\eta_{\text {raz,h }}\right)$ for the 18 reliability assessment zones (RAZ) shown in Figure 1 (page 10). The net load in Cambium is given by net_load_busbar and is the busbar_demand_for_enduse less generation from nondispatchable wind and solar generators. ${ }^{34}$

4. Determine a threshold MW value ( $\left.\eta_{\text {raz,threshold }}\right)$ for each RAZ that is either the net load during the $101^{\text {st }}$ greatest net-load hour $\left(\eta_{\text {raz,41 }}\right)$ or $95 \%$ of the RAZ's annual peak net load $\left(\eta_{\text {raz }, 1}\right)$, whichever is lower:

\footnotetext{
${ }^{32}$ ReEDS is not allowed to endogenously retire generators in the first nonhistorical year (i.e., only announced retirements are allowed), because imperfections in our representation sometimes produce unrealistically large retirements in the near term. For this reason, the capacity constraint in the first nonhistorical year is often zero, which we do not consider realistic. Therefore, if the shadow price is zero in the first nonhistorical year, we replace it with the shadow price of the second nonhistorical year.

${ }^{33}$ For example, if the planning reserve margin is $15 \%, 1 \mathrm{MW}$ more of peak busbar demand will require $1.15 \mathrm{MW}$ more firm capacity. If the shadow price for firm capacity was $\$ 10 / \mathrm{MW}$-year, the capacity cost per MW of additional peak load would be $\$ 11.50 / \mathrm{MW}$-year.

${ }^{34}$ Load from storage generators charging is not included in the net load, with the idea being that that load is flexible and in most instances the charging could be reduced (without impacting reliability) if there were a capacity shortage. However, it is possible that in certain futures there could be situations where storage would need to charge during certain periods of time for reliability reasons (e.g., charging during the day after providing required firm capacity during a morning peak, in anticipation of being needed during an evening peak). We do not capture that possibility.
} 


$$
\eta_{\text {raz,threshold }}=\operatorname{MIN}\left(\eta_{\text {raz,101 }}, \eta_{\text {raz,1 }} * 0.95\right)
$$

5. Calculate the total amount of each RAZ's net load that exceeds its threshold value $\left(\mathrm{N}_{r a z}\right)$ :

$$
\mathrm{N}_{\text {raz }}=\sum_{h=1}^{8760} \operatorname{MAX}\left(\eta_{\text {raz,h }}-\eta_{\text {raz,threshold }}, 0\right)
$$

6. Calculate a weight for each hour $\left(w_{r a z, h}\right)$ whose net load exceeds the threshold value, defined as the amount that hour's net load exceeds the threshold value divided by the total amount of load exceeding the threshold in that RAZ in that year; the weights will sum to 1 .

$$
w_{\text {raz }, h}=\frac{M A X\left(\eta_{\text {raz }, h}-\eta_{\text {raz,threshold }}, 0\right)}{\mathrm{N}_{\text {raz }}}
$$

7. Allocate each BA's annual marginal capacity cost $\left(\delta_{B A}\right)$ from Step 2 using the hourly weights of the RAZ that that BA is in:

$$
c_{b a, h}=w_{r a z, h} * \delta_{B A}
$$

\section{Caveats and Limitations}

Our method of calculating marginal capacity costs has an important limitation and two important caveats.

First, our method relies on heuristics. The use of a planning reserve margin, and the subsequent allocation of the annual capacity cost based on a net-load threshold, are heuristics. They are meant to approximately capture the costs induced by increased demand during high-net load hours, but they do not represent the most sophisticated techniques for resource adequacy assessment.

The use of the $101^{\text {st }}$-hour/95\%-peak threshold, in particular, is only an approximation, although it is similar to the top-hour counts used by other models. The 2020 version of ReEDS uses the top 10 net-load hours in each of 4 seasons for assessing the capacity credit of variable resources. Hale, Stoll, and Mai (2016) used the top 100 net-load hours for estimating the capacity value of flexible resource in the Resource Planning Model. In the publicly available Avoided Cost Calculator (Energy+Environmental Economics 2016), which was developed for use in California, the default values for 2020 has 334 hours with nonzero weights for generation capacity costs, although $80 \%$ of the weight was in the top 40 hours and $99 \%$ in the top 90 hours. ${ }^{35}$

We selected this approach because it has three attractive features:

- The hours with the highest net loads have the greatest marginal capacity costs.

\footnotetext{
${ }^{35}$ The default generation capacity value allocation factors in the Avoided Cost Calculator were based on loss-ofload-probability calculations within the Renewable Energy Capacity Planning, or RECAP, model developed by Energy + Environmental Economics.
} 
- The marginal capacity costs phase out, instead of cutting out sharply at a threshold (which would occur if costs were allocated evenly to a number of top hours).

- The sum across a year's hourly capacity costs will equal the $\$ / \mathrm{MW}$-year shadow price, amplified by the PRM.

A more technically sophisticated approach could involve the derivation of hourly probabilistic loss metrics (e.g., loss of load probability). These probabilistic metrics could be used to assign weights to individual hours, or to directly calculate a marginal cost of capacity by using the rate of change of the loss metrics as a function of increased load and a cost of lost load. Currently, however, we do not have a method for calculating hourly probabilistic loss metrics that can be deployed coherently with our ReEDS model. Given that the ReEDS model makes capacity investment decisions based on a combination of a planning reserve margin and net load duration curve techniques, more-sophisticated assessments of the reliability of the systems that ReEDS builds could produce nonsensical results - for example, consistently showing negligible loss of load probabilities (if ReEDS tends to over-build the electric system), and therefore showing negligible capacity costs. The use of heuristics to allocate the ReEDS-derived shadow price is a tractable solution to a complex problem.

The first significant caveat for our method of calculating marginal capacity costs is that Cambium capacity costs can be lower than conceptually similar values used in practice, such as Net CONE derived assuming a NGCT. The ReEDS capacity shadow price can often be meaningfully lower than the annualized cost of a natural gas combustion turbine (NGCT), which is sometimes taken as a benchmark value for additional firm capacity in practice. These low values are generally driven by the fact that the pool the model can draw from when calculating the incremental cost of firm capacity includes 1) otherwise-retiring generators, 2) batteries, and 3) variable generators, commiserate with their ability to provide generation during the highest net load hours.

If a marginal capacity cost derived from such an inclusive pool of resources is not suitable for a given analysis (e.g., if the expectation is that the marginal capacity cost is derived from a Net CONE value of a NGCT), then the marginal costs provided in Cambium may not be suitable. If a different annual marginal cost of firm capacity is known or available, it is possible to use the hourly marginal capacity costs in Cambium to allocate that different annual value. This could enable an analyst to use their own estimate of the annual cost of firm capacity while respecting the temporal patterns of the Cambium dataset.

As the second caveat, as with all marginal costs in Cambium databases, we do not provide elasticities for these marginal capacity costs. Large interventions (e.g., widespread electrification of transportation) could change load patterns sufficiently to change these marginal capacity costs: the annual capacity cost, the hourly pattern, or both. If an analysis includes a large intervention, we encourage analysts to consider directly calculating changes in peak net load using the net_load_busbar values in Cambium, instead of relying on these marginal price-taking values. 


\subsection{Calculating Marginal Portfolio Costs}

Marginal portfolio costs are the costs associated with staying in compliance with renewable portfolio standards (RSP) and clean energy standards (CES), when end-use demand is increased. Treating this in post-processing is necessary for Cambium because RPS and CES are represented in our ReEDS runs but not our PLEXOS runs, which means the marginal energy costs do not have these costs embedded in them (i.e., the marginal unit of energy may not be in compliance with a state's RPS or CES policy, necessitating remedial action to stay in compliance). In this section, we discuss how we calculate the cost of that remedial action, when necessary.

Depending on the scenario, Cambium databases can include state RPS (including technologyspecific carveouts), national RPS, and CES policies. They are all handled the same way, however, so we just generically refer to policies in this section.

\section{Calculating a Marginal Portfolio Cost}

Each policy in Cambium databases is represented in ReEDS as a constraint. The shadow price on that constraint is the dollar cost of obtaining one more credit for the policy; for example, a $\$ 10 /$ credit shadow price on a RPS constraint is conceptually equivalent to a price of $\$ 10$ per 1 MWh of renewable energy credits (REC); however, it is different in important ways, as we explain at the end of this section. ${ }^{36}$ If the policy is not binding in given state and year, the shadow price would be zero, and therefore the marginal cost would also be zero.

For documentation of how the various policies are represented in ReEDS, see (Ho et al. 2021).

Using the shadow price for each policy, we calculate the cost of staying in compliance with each of the policies as end-use demand is increased. The marginal cost can change from hour to hour, depending on whether the marginal generator at that point in time can contribute to the policy (a generator needs to be an eligible technology and either be in a location that within the region covered by the policy or be able to trade credits with the region covered by the policy).

If the marginal generator is unable to contribute to the policy (because it is either not an eligible technology or it is not in a location that can trade credits with the region covered by the policy), the marginal cost of policy $n\left(C_{n}\right)$ in $\$ / \mathrm{MWh}$ of end-use demand is given by:

$$
C_{n}=f_{n} * p_{n}
$$

where $f_{n}$ is the fraction of end-use demand that must be covered by generation from an eligible technology, and $p_{n}$ is the annual shadow price for policy $n$.

We emphasize that, when calculating $f_{n}$, we calculate the average fraction for the region covered by the policy. That can result in $f_{n}$ values that deviate from the nominal top-line numbers used to describe a policy, as some load within a region is often excluded from the policy. Many states, for example, exempt utilities below a certain size from their RPS. This would result in a $f_{n}$ that is lower than the nominal RPS goal.

\footnotetext{
${ }^{36}$ We use the term "credit" to refer to the mechanism by which policy compliance is tracked, although it should be noted that different policies use various terms and have various tracking mechanisms in practice.
} 
The equation given above is straightforward: if a state has a policy where, say, $30 \%$ of end-use load must be covered by a credit, and the shadow price on credits is $\$ 10 / \mathrm{MWh}$, a $1-\mathrm{MWh}$ increase in end-use demand when a noneligible generator is on the margin means 0.3 credits must be obtained for a marginal cost of $\$ 3 / \mathrm{MWh}$ of end-use demand.

Notably, if the marginal generator can contribute to the policy (i.e., it is both an eligible technology and in a region that can trade with the region covered by the policy), the marginal cost can be negative (i.e., there is actually a marginal benefit to increasing consumption):

$$
C_{n}=-\left(\frac{1}{1-\mu_{h}}-f_{n}\right) * p_{n}
$$

where $\mu_{h}$ is the marginal distribution loss rate at that point in time, as explained in Section 5.7.

Conceptually, the reason the cost can be negative is because the additional consumption can create more credits than are required by the policy to cover that additional consumption. Because the credits have value, the excess credits count as a benefit.

Consider a situation where an eligible technology is on the margin (e.g., an in-region solar generator is currently curtailing), the marginal distribution loss rate is $5 \%$, the policy covers $30 \%$ of end-use demand, and the shadow price is $\$ 10 / \mathrm{MWh}$. In this case, an increase in end-use demand of $1 \mathrm{MWh}$ increases generation from the solar plant by $1.053 \mathrm{MWh}$ (amplified slightly because of the distribution losses). However, only 0.3 MWh of credits are needed to cover the additional load, so $0.753 \mathrm{MWh}$ of credits remain and they are valued at $\$ 10$ per credit. Therefore, there is a marginal benefit of $\$ 7.53 / \mathrm{MWh}$ of end-use demand.

For busbar marginal costs, we modify the end-use marginal costs by the marginal distribution loss rate.

\section{Caveats and Limitations}

Our representations of marginal portfolio costs have two important limitations:

- Incomplete Policy Representations: The shadow prices used to calculate marginal portfolio costs are driven by the representations of the policies in ReEDS, which can be incomplete. Though significant effort is put into correctly categorizing technology eligibility, fractions of load covered, and trading restrictions, there are still missing components (e.g., inter-year REC banking and technology-specific multipliers).

- Shadow Prices are Long-Run Values: Because the annual shadow prices on each policy come from ReEDS, which solves for the long-run equilibrium position, the shadow prices themselves are long-run values. In other words, they incorporate the option of building new capacity to generate credits. Where credits are traded in practice, their prices would potentially be better described as a short-run prices, although the ability of banking RECs better years makes the distinction less clear. Altogether, we recommend the policy shadow prices not be used directly as forecasts of future prices of these credits, as the markets for the credits likely deviate in significant ways from our modeled representations. 


\subsection{Operating Reserve Requirements and Limitations}

Cambium represents three operating reserve products, which are simplified representation of the reserves held to ensure supply-side flexibility is sufficient to address fluctuations in the balance of supply and demand. In order of fastest to slowest response time, the three types of reserves are:

- Regulating reserves are reserves held to provide rapid response for restoring system frequency. They may be deployed after an event and are also used to address normal random short-term fluctuations in the balance of supply and demand.

- Spinning reserves are held to supply power if there are failures in generators or transmission lines.

- Flexibility reserves are an emerging and evolving reserve product that is used to address relatively "slow" variations in net load, such as those caused by variability in net load from wind and solar generators. They are also known as load-following or ramping reserves.

The amount of each reserve product that is required in each hour is shown in Table 4.

Table 4. Operating Reserve Requirements

\begin{tabular}{|c|c|c|c|c|}
\hline $\begin{array}{l}\text { Reserve } \\
\text { Product }\end{array}$ & $\begin{array}{l}\text { Load Requirement } \\
(\% \text { of load) }\end{array}$ & $\begin{array}{l}\text { Wind Requirement } \\
\text { (\% of generation) })^{\mathbf{b}}\end{array}$ & $\begin{array}{l}\text { PV Requirement } \\
\text { (\% of capacity) })^{\mathrm{b}}\end{array}$ & $\begin{array}{l}\text { Time Requirement } \\
\text { to Ramp (minutes) }\end{array}$ \\
\hline Regulation & $1 \%$ & $0.5 \%^{c}$ & $0.3 \%^{c}$ & 5 \\
\hline Spinning & $3 \%$ & - & - & 10 \\
\hline Flexibility & - & $10 \%$ & $4 \%$ & 60 \\
\hline
\end{tabular}

a See Lew et al. (2013), Section 5.3.4

${ }^{b}$ Reserve requirements for wind and PV are derived from the outcomes of Lew et al. (2013). The flexibility requirement for wind is estimated as the ratio of the change in the reserve requirement to the change in wind generation from the Lew et al. High Wind scenario; the requirement for PV was similarly estimated using the Lew et al. High Solar scenario.

${ }^{c}$ The estimated regulation requirements $(0.5 \%$ wind generation and $0.3 \% \mathrm{PV}$ capacity) are based on incremental increases in regulation reserves across all scenarios in Lew et al. (2013).

Flexibility and regulation reserve products are influenced by PV capacity, but only when the PV capacity is generating. Capacity is used instead of generation because these reserves are especially important around sunset and sunrise, when PV generation is lower.

In the PLEXOS runs that Cambium draws from, the quantity of operating reserves is determined for 18 reliability assessment zones (RAZ), shown in (Figure 1, page 10). Any eligible generator within a RAZ can contribute to the reserves required for the RAZ: there are no transmission capacity requirements. This is a simplification. It would be more realistic to have the reserve products defined for each BA and require bilateral trading within a RAZ. For the reserve product quantities in Cambium databases, we report the amount of reserve product induced by the load and generation within each BA, although it should be noted that the PLEXOS runs balance the operating reserves at the RAZ level. 
Unless otherwise specified in a particular scenario's description, nuclear, wind, PV, and CSP without storage cannot provide operating reserves. All other generators can provide reserves, limited by their availability capacity (their online capacity minus any capacity being used for energy generation) and their ramp rates. Table 5 (page 62) shows the ramp rates used for different technologies in Cambium's PLEXOS runs, and the resulting amount of capacity that each generator can dedicate toward each reserve product. For example, natural gas CTs (NGCT) can ramp $8 \%$ of their capacity per minute, and the regulation reserve product requires a 5 -minute ramp, therefore NGCTs can dedicate $40 \%$ of their capacity to regulation reserves.

Energy storage technologies can provide reserves, as long as they have at least one hour's worth of stored energy. Generators are allowed to provide both flexibility and spinning reserves with the same capacity.

Table 5 actually overstates the capacity available for reserves for most technologies, because minimum generation constraints force generators to dedicate a fraction of their capacity to energy generation if they are online. For example, because NGCTs have a minimum generation level of $55 \%$, they can actually only ever dedicate $45 \%$ of their capacity to flexibility and spinning reserves.

Table 5. Technology Flexibility Parameters

\begin{tabular}{|c|c|c|c|c|}
\hline & \multirow[b]{2}{*}{$\begin{array}{l}\text { Assumed } \\
\text { maximum ramp } \\
\text { rate }(\% / \mathrm{min})\end{array}$} & \multicolumn{3}{|c|}{ Maximum Capacity Available for Reserves ${ }^{a}$} \\
\hline & & $\begin{array}{l}\text { Flexibility } \\
\text { (60- min. ramp } \\
\text { requirement) }\end{array}$ & $\begin{array}{c}\text { Spinning } \\
\text { (10-min. ramp } \\
\text { requirement) }\end{array}$ & $\begin{array}{l}\text { Regulation } \\
\text { (5-min, ramp } \\
\text { requirement) }\end{array}$ \\
\hline Natural Gas CT & 8 & 100 & 80 & 40 \\
\hline Natural Gas CC & 5 & 100 & 50 & 25 \\
\hline Coal & 4 & 100 & 40 & 20 \\
\hline Geothermal & 4 & 100 & 40 & 20 \\
\hline CSP with Storage & 10 & 100 & 100 & 50 \\
\hline Biopower & 4 & 100 & 40 & 20 \\
\hline Landfill gas & 4 & 100 & 40 & 20 \\
\hline Oil-gas-steam & 4 & 100 & 40 & 20 \\
\hline Hydro & 100 & 100 & 100 & 100 \\
\hline Storage & 100 & 100 & 100 & 100 \\
\hline
\end{tabular}

a $(\%$ of online capacity $)=$ Ramp Rate $(\% / m i n){ }^{*}$ Ramp Requirement $(\min )$

\section{Caveats and Limitations}

Our representation of operating reserves has several important caveats and limitations:

- These shadow prices are poor estimates of market prices: Whereas other Cambium metrics are can be suitable as estimates of equivalent market products, the shadow prices on operating reserve constraints deviate significantly from market prices for operating 
reserves in practice. This is primarily because the PLEXOS runs that Cambium draws from represent the commitment of generators as an integer decision (i.e., each generator's capacity is committed as a block). As a result, most hours and regions tend to have at least some online capacity that is not already dedicated to energy generation and reserve provision. When combined with the absence of direct operating costs, this tends to result in the shadow price on the operating reserve constraints being zero. While a technically correct description of how the model is viewing the relevant constraints (and therefore made available for specific research questions), the values are not good estimates of market prices for similar reserves, which tend to be non-zero in practice.

- Simplified Representations: These are stylized, simple representations of reserve products that are meant to capture the need to hold capacity in reserve for reliable operation of the grid. Actual markets may have different products, or they have similarly named products with different definitions.

- Lack of Direct Operating Costs: We do not assign an operating cost to generators for providing these reserves, which means the given shadow prices do not reflect any direct costs that would be incurred by a marginal increase in reserve provision.

- Incomplete Representation of Services: Not all operating reserves are represented. Frequency-response reserves, which operate on a much faster timescale than our PLEXOS runs, are not represented. Other reliability services, such as black-start and voltage support, are also not captured by these products.

- Reserve Requirements for Some Futures are Poorly Understood: Some of our scenarios are significantly different from the current grid (e.g., large amounts of variable generators and storage). The types and quantities of reserves needed to sustain reliable grid operation in these future scenarios is an ongoing area of research, and the quantities represented here may be too much or too little.

\section{Marginal operating reserve costs}

In the preceding release of Cambium data (the 2020 release), estimates of operating reserve costs induced by a marginal change in end-use demand were provided (op_res_cost_busbar and op_res_cost_enduse). These metrics have been discontinued, primarily due to the limitation discussed in the first bullet of the preceding Caveats and Limitations section.

\subsection{Creation of Generation and Emission Assessment (GEA) Regions}

Cambium's GEA regions are 20 regions covering the contiguous United States. They are based off of the US EPA's eGRID regions (https://www.epa.gov/egrid), but are not identical to them due to the geographic structure of the models in the Cambium workflow (i.e., the GEA regions are groupings of the ReEDS balancing areas (BAs), whose borders do not necessarily line up with the borders of eGRID regions, which are based on utility service territories). The GEA regions are shown in Figure 6.

Users should note that the geographic differences between GEA regions and eGRID regions can lead to meaningful differences in metrics such as average emission rates. GEA regions should not be interpreted as direct equivalents of eGRID regions, but rather close approximations of 
them. The GEA region names follow the eGRID region they are approximating, but with an additional "c" (for "Cambium") to make their non-equivalence more clear.

Table 6 gives the mapping between GEA regions and ReEDS BAs.

The method by which GEA regions were created out of groupings of the 134 ReEDS BAs was ${ }^{37}$ :

1. Use Geographic Information System (GIS) techniques to determine the eGRID region with the greatest geographic overlap with each BA, and the fraction of that region's overlap.

2. Use eGRID plant data (EPA 2021) to determine the eGRID region with the greatest net generation associated with each BA, and the fraction of that BA's net generation from that eGRID region.

3. Where step 1 and 2 associated a BA with the same eGRID region, that BA was assigned to that region. Where the steps associated with different eGRID regions, the eGRID region from the step with the greatest fraction was selected. For example, if a BA had $58 \%$ of its generation from SRTV but $73 \%$ of its area in SRSO, that BA would be associated with SRSO.

4. Enforce a requirement for contiguous areas for each of the groupings of BAs. This involved re-assigning p74 and p119 from RFCW to MROE and RFCE, respectively.

\footnotetext{
${ }^{37}$ We thank Leo Rainer from Lawrence Berkley National Laboratory for his collaboration in developing this
} methodology. 


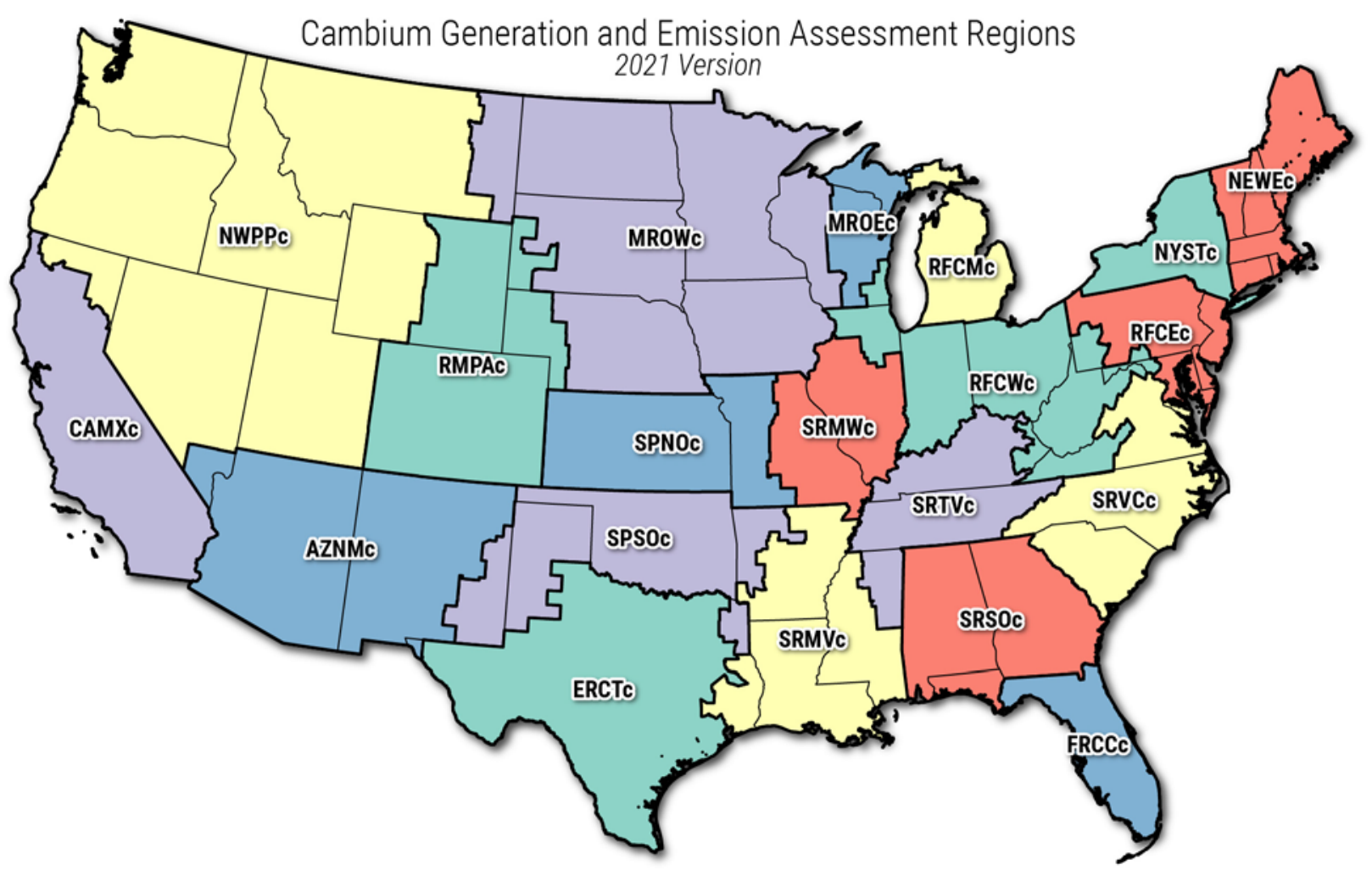

Figure 6. Cambium's Generation and Emission Assessment (GEA) Regions (repeat of Figure 2) 
Table 6: Mapping between GEA regions and ReEDS balancing areas

\begin{tabular}{|c|c|c|c|c|c|c|c|}
\hline $\begin{array}{c}\text { GEA } \\
\text { Region }\end{array}$ & $\begin{array}{c}\text { ReEDS } \\
\text { BA }\end{array}$ & $\begin{array}{c}\text { GEA } \\
\text { Region }\end{array}$ & $\begin{array}{c}\text { ReEDS } \\
\text { BA }\end{array}$ & $\begin{array}{c}\text { GEA } \\
\text { Region }\end{array}$ & $\begin{array}{c}\text { ReEDS } \\
\text { BA }\end{array}$ & $\begin{array}{c}\text { GEA } \\
\text { Region }\end{array}$ & $\begin{array}{c}\text { ReEDS } \\
\text { BA }\end{array}$ \\
\hline AZNMc & p28 & MROWc & $\mathrm{p} 46$ & RFCEc & p125 & SPSOc & p51 \\
\hline AZNMc & $\mathrm{p} 13$ & MROWc & p35 & RFCEC & p124 & SPSOc & p57 \\
\hline AZNMc & p31 & MROWc & p77 & RFCEC & p119 & SPSOc & $\mathrm{p} 47$ \\
\hline AZNMc & p29 & MROWc & $\mathrm{p} 42$ & RFCMc & p103 & SPSOc & p56 \\
\hline AZNMc & $\mathrm{p} 27$ & NEWEC & p132 & RFCMc & p104 & SPSOc & $\mathrm{p} 49$ \\
\hline AZNMc & p59 & NEWEC & p131 & RFCWc & $\mathrm{p} 80$ & SRMVc & p58 \\
\hline AZNMc & p30 & NEWEC & p130 & RFCWc & p112 & SRMVc & p85 \\
\hline CAMXC & p9 & NEWEC & p134 & RFCWc & p107 & SRMVc & p66 \\
\hline CAMXC & $\mathrm{p} 10$ & NEWEC & p133 & RFCWc & p116 & SRMVc & $\mathrm{p} 87$ \\
\hline CAMXC & $\mathrm{p} 11$ & NEWEC & p129 & RFCWc & p115 & SRMVc & p86 \\
\hline ERCTC & p63 & NWPPC & p5 & RFCWc & p105 & SRMWc & p72 \\
\hline ERCTC & p65 & NWPPc & p2 & RFCWc & p111 & SRMWC & p81 \\
\hline ERCTC & p67 & NWPPC & $\mathrm{p} 4$ & RFCWc & p79 & SRMWC & p83 \\
\hline ERCTC & p64 & NWPPc & $\mathrm{p} 25$ & RFCWc & $\mathrm{p} 117$ & SRMWC & p84 \\
\hline ERCTC & p60 & NWPPc & $\mathrm{p} 1$ & RFCWc & p114 & SRMWC & p82 \\
\hline ERCTC & p62 & NWPPC & p21 & RFCWC & p118 & SRMWC & p71 \\
\hline ERCTC & p61 & NWPPc & p20 & RFCWc & p106 & SRMWC & p73 \\
\hline FRCCC & $\mathrm{p} 101$ & NWPPc & $\mathrm{p} 15$ & RFCWc & $\mathrm{p} 110$ & SRSOc & p94 \\
\hline $\mathrm{FRCCC}$ & p102 & NWPPc & $\mathrm{p} 12$ & RFCWC & $\mathrm{p} 121$ & SRSOc & p90 \\
\hline MROEC & p75 & NWPPC & p3 & RFCWc & p113 & SRSOc & p89 \\
\hline MROEC & p76 & NWPPc & p17 & RFCWc & p120 & SRSOc & p91 \\
\hline MROEC & p78 & NWPPc & p6 & RMPAC & p33 & SRTVc & p92 \\
\hline MROEc & p74 & NWPPc & $\mathrm{p} 16$ & RMPAc & p34 & SRTVc & p109 \\
\hline MROWc & $\mathrm{p} 43$ & NWPPC & p18 & RMPAC & p24 & SRTVc & p88 \\
\hline MROWc & p70 & NWPPc & $\mathrm{p} 26$ & RMPAC & $\mathrm{p} 23$ & SRTVc & p108 \\
\hline MROWc & p36 & NWPPC & p14 & RMPAC & p39 & SRTVc & p93 \\
\hline MROWc & $\mathrm{p} 45$ & NWPPc & p7 & RMPAC & p32 & SRVCC & p99 \\
\hline MROWc & $\mathrm{p} 40$ & NWPPC & p8 & RMPAC & p22 & SRVCC & p97 \\
\hline MROWc & $\mathrm{p} 41$ & NWPPc & $\mathrm{p} 19$ & SPNOC & p53 & SRVCC & p98 \\
\hline MROWc & p38 & NYSTC & p127 & SPNOC & p54 & SRVCC & p95 \\
\hline MROWc & p37 & NYSTC & p128 & SPNOC & p55 & SRVCC & p96 \\
\hline MROWc & p68 & RFCEC & p122 & SPNOC & p52 & SRVCc & p100 \\
\hline MROWc & $\mathrm{p} 44$ & RFCEC & p126 & SPSOc & p50 & & \\
\hline MROWc & p69 & RFCEC & $\mathrm{p} 123$ & SPSOc & $\mathrm{p} 48$ & & \\
\hline
\end{tabular}




\section{References}

A. D. Hawkes. 2010. "Estimating Marginal CO2 Emissions Rates for National Electricity Systems." Energy Policy 38 (10): 5977-87.

- 2014. "Long-Run Marginal CO2 Emissions Factors in National Electricity Systems." Applied Energy 125: 197-205.

Bloom, Aaron, Aaron Townsend, David Palchak, Joshua Novacheck, Jack King, Clayton Barrows, Eduardo Ibanez, et al. 2016. "Eastern Renewable Generation Integration Study.” NREL/TP-6A20-64472. National Renewable Energy Lab. (NREL), Golden, CO (United States). https://doi.org/10.2172/1318192.

Cole, W., B. Frew, T. Mai, Y. Sun, J. Bistline, and G. Blanford. 2017. "Variable Renewable Energy in Long-Term Planning Models: A Multi-Model Perspective.” NREL/TP-6A2070528. EERE, NREL, EIA, EPA ... https:/www.osti.gov/scitech/biblio/1416124variable-renewable-energy-long-term-planning-models-multi-model-perspective.

Cole, Wesley, J Vincent Carag, Maxwell Brown, Patrick Brown, Stuart Cohen, Kelly Eurek, Will Frazier, et al. 2021. "2021 Standard Scenarios Report: A U.S. Electricity Sector Outlook." NREL/TP-6A40-80641. NREL. https://www.nrel.gov/docs/fy22osti/80641.pdf.

Cole, Wesley, Nathaniel Gates, Trieu Mai, Daniel Greer, and Paritosh Das. 2019. "2019 Standard Scenarios Report: A U.S. Electricity Sector Outlook.” NREL/TP-6A20-74110. Golden, CO: National Renewable Energy Laboratory. https://doi.org/10.2172/1481848.

Cole, Wesley, Daniel Greer, Jonathan Ho, and Robert Margolis. 2020. "Considerations for Maintaining Resource Adequacy of Electricity Systems with High Penetrations of PV and Storage." Applied Energy 279 (December).

Energy+Environmental Economics. 2016. "Avoided Cost Calculator User Manual." Energy+Environmental Economics.

_. 2020. "Time Dependent Valuation of Energy for Developing Building Efficiency Standards."

Energy Exemplar. 2019. PLEXOS Integrated Energy Model. Energy Exemplar. https://energyexemplar.com/solutions/plexos/.

EPA. 2020. "EGRID 2018 Gross Grid Loss Estimates.” Washington, D.C.: EPA. https://www.epa.gov/egrid/download-data.

—. 2021. "EGRID2019 Data File." United States Environmental Protection Agency. https://www.epa.gov/egrid/download-data.

Frew, Bethany, Wesley Cole, Paul Denholm, Will Frazier, Nina Vincent, and Robert Margolis. 2019. "Sunny with a Chance of Curtailment: Operating the US Grid with Very High Levels of Solar Photovoltaics.” IScience 21 (November): 436447. https://doi.org/10.1016/ j.isci.2019.10.017.

Hale, Elaine, Brady Stoll, and Trieu Mai. 2016. "Capturing the Impact of Storage and Other Flexible Technologies on Electric System Planning.” Renewable Energy, 91.

Ho, Jonathan, Jonathon Becker, Maxwell Brown, Patrick Brown, Ilya (ORCID:0000000284917814) Chernyakhovskiy, Stuart Cohen, Wesley (ORCID:000000029194065X) Cole, et al. 2021. "Regional Energy Deployment System (ReEDS) Model Documentation: Version 2020." NREL/TP-6A20-78195. Golden, CO: National Renewable Energy Laboratory. https://doi.org/10.2172/1788425. 
James Littlefield, Selina Roman-White, Dan Augustine, Ambica Pegallapati, George G. Zaimes, Srijana Rai, Gregory Cooney, and Timothy J. Skone. 2019. "Life Cycle Analysis of Natural Gas Extraction and Power Generation.” National Energy Technology Laboratory.

Janusz Bialek. 1996. "Tracing the Flow of Electricity." IEE Proceedings - Generation, Transmission, and Distribution 143 (4): 313-20.

Lew, D., G. Brinkman, E. Ibanez, B. M. Hodge, M. Hummon, A. Florita, and M. Heaney. 2013. "The Western Wind and Solar Integration Study Phase 2." NREL/TP-5500-55588. National Renewable Energy Lab. (NREL), Golden, CO (United States). https://doi.org/10.2172/1095399.

Marc Carreras-Sospedra, Michael MacKinnon, Donald Dabdub, and Robert Williams. 2015. "Assessment of the Emissions and Energy Impacts of Biomass and Biogas Use in California." Agreement \#11-307. California Air Resources Board.

National Renewable Energy Laboratory. 2021. "U.S. Life Cycle Inventory Database." NREL. https://www.lcacommons.gov/nrel/search.

NERC. 2010. “2010 Long-Term Reliability Assessment.” North American Electric Reliability Corporation. https://www.nerc.com/files/2010_tra_v2-.pdf. . 2020. "Glossary of Terms Used in NERC Reliability Standards." North American Electric Reliability Corporation. https://www.nerc.com/files/glossary_of_terms.pdf.

NREL. 2021. “2021 Annual Technology Baseline.” Golden, CO: National Renewable Energy Laboratory. https://atb.nrel.gov/.

Seel, Joachim, and Andrew Mills. 2021. "Integrating Cambium Marginal Costs into Electric Sector Decisions: Opportunities to Integrate Cambium Marginal Cost Data into Berkeley Lab Analysis and Technical Assistance.” https://doi.org/10.2172/1828856.

Severin Borenstein, and James Bushnell. 2019. "Do Two Electricity Pricing Wrongs Make a Right? Cost Recovery, Externalities, and Efficiency.” Working Paper Energy Institute WP 294R. Energy Institute at HAAS: Energy Institute at HAAS.

Sigrin, Benjamin, Michael Gleason, Robert Preus, Ian Baring-Gould, and Robert Margolis. 2016. "The Distributed Generation Market Demand Model (DGen): Documentation." NREL/TP-6A20-65231. Golden, CO: National Renewable Energy Laboratory. http://www.nrel.gov/docs/fy16osti/65231.pdf.

Siler-Evans, Kyle, Inês Lima Azevedo, and M. Granger Morgan. 2012. "Marginal Emissions Factors for the U.S. Electricity System." Environmental Science \& Technology 46 (9): 4742-48. https://doi.org/10.1021/es300145v.

Thind, Maninder P. S., Elizabeth J. Wilson, Inês L. Azevedo, and Julian D. Marshall. 2017. "Marginal Emissions Factors for Electricity Generation in the Midcontinent ISO." Environmental Science \& Technology 51 (24): 14445-52. https://doi.org/10.1021/acs.est.7b03047.

Timothy Skone, James Littlefield, Joe Marriott, Greg Cooney, Matt Jamieson, Jeremie Hakian, and Greg Schivley. 2014. "Life Cycle Analysis of Natural Gas Extraction and Power Generation.” DOE/NETL-2014/1646.

United States Environmental Protection Agency. 2016. "Greenhouse Gas Inventory Guidance: Direct Emissions from Stationary Combustion Sources." United States Environmental Protection Agency. https://www.epa.gov/sites/default/files/201603/documents/stationaryemissions_3_2016.pdf. 